University of Louisville

ThinkIR: The University of Louisville's Institutional Repository

Electronic Theses and Dissertations

$12-2019$

\title{
Charting a course through confusion: mapping pathological cranial lesions in an Archaic population from Kentucky.
}

Austin Warren

University of Louisville

Follow this and additional works at: https://ir.library.louisville.edu/etd

Part of the Archaeological Anthropology Commons

\section{Recommended Citation}

Warren, Austin, "Charting a course through confusion: mapping pathological cranial lesions in an Archaic population from Kentucky." (2019). Electronic Theses and Dissertations. Paper 3400.

https://doi.org/10.18297/etd/3400

This Master's Thesis is brought to you for free and open access by ThinkIR: The University of Louisville's Institutional Repository. It has been accepted for inclusion in Electronic Theses and Dissertations by an authorized administrator of ThinkIR: The University of Louisville's Institutional Repository. This title appears here courtesy of the author, who has retained all other copyrights. For more information, please contact thinkir@louisville.edu. 


\title{
CHARTING A COURSE THROUGH CONFUSION: MAPPING PATHOLOGICAL CRANIAL LESIONS IN AN ARCHAIC POPULATION FROM KENTUCKY
}

\author{
By \\ Austin Warren \\ B.A., Western Kentucky University, 2012
}

\begin{abstract}
A Thesis
Submitted to the Faculty of the

College of Arts and Sciences of the University of Louisville In Partial Fulfillment of the Requirements

for the Degree of
\end{abstract}

Master of Arts in Anthropology

Department of Anthropology

University of Louisville

Louisville, Kentucky

December 2019 

CHARTING A COURSE THROUGH CONFUSION: MAPPING PATHOLOGICAL CRANIAL LESIONS IN AN ARCHAIC POPULATION FROM KENTUCKY

$$
\text { By }
$$

Austin Warren

B.A., Western Kentucky University, 2012

A Thesis Approved on

November 22, 2019

by the following Thesis Committee:

Fabian Crespo, $\mathrm{PhD}$

Thesis Director

Thomas Jennings, $\mathrm{PhD}$

Nicole Roth, $\mathrm{PhD}$ 


\section{ACKNOWLEDGEMENTS}

I would like to thank my advisor, Dr. Fabian Crespo, for his patience and guidance in this research process, and for his gentle nudges to keep me on the path to completion. I would also like to thank my mentor, Philip DiBlasi, whose critical yet nurturing tutelage has substantially helped mold me in both scholarship and stewardship of my community. Dr. Sharon DeWitte deserves a hearty commendation for teaching me several of the analytical methodologies used in this study. I must also thank my wife, Kristin, for tolerating me through this never-ending project; we were not yet engaged when this research began (I love her, she is a saint). Most importantly, thanks to our daughter, Estelle, who has so nobly fulfilled her duty as the most wonderful distraction any father would be eternally proud of; Estelle, a world of opportunity is yours. I hope you accept no limitations, cherish your opportunities, and that you always strive to surpass your father. 


\title{
ABSTRACT \\ CHARTING A COURSE THROUGH CONFUSION: MAPPING PATHOLOGICAL CRANIAL LESIONS IN AN ARCHAIC POPULATION FROM KENTUCKY
}

\author{
Austin Warren
}

November 22, 2019

Osteological observations interpreted as evidence for anemia (porotic hyperostosis and cribra orbitalia) have been used to interpret health and diet of past populations. These observations have contributed significantly to arguments that a deterioration of human health over time can be attributed to the adoption of agricultural subsistence practices and increased settlement aggregation. This study utilized a sample $(n=110)$ from the Ward site (15Mcl11), a pre-agricultural, fisher-hunter-gatherer cemetery site dated to the Archaic Period in Kentucky, a part of the Shell Midden Archaic cultural complex. The impact of porotic alteration on differential mortality was assessed using Kaplan-Meier survival analysis. The Ward sample exhibited high incidence of porotic alteration $(n=90)$. Survival curves illustrated reduced survival for children exhibiting cribra orbitalia, but limited measureable impact of porotic hyperostosis on adult mortality. These results suggest that the selective pressure imposed by porotic hyperostosis might be inextricable from that of other variables influencing mortality. 


\section{TABLE OF CONTENTS}

\section{PAGE}

ACKNOWLEDGEMENTS

ABSTRACT

LIST OF TABLES

iv

LIST OF FIGURES

INTRODUCTION 1

History of Anemia in Archaeology 1

Etiology of Porotic Hyperostosis and Cribra Orbitalia 4

Alternatives to Iron Deficiency $\quad 8$

$\begin{array}{ll}\text { Timing and Impacts of Pathologies } & 14\end{array}$

$\begin{array}{ll}\text { Old Answers and a New Question } & 17\end{array}$

$\begin{array}{ll}\text { BACKGROUND } & 20\end{array}$

$\begin{array}{ll}\text { Climate and the Rise of Agriculture } & 21\end{array}$

History of Excavations $\quad 23$

Previous Skeletal Analyses $\quad 26$

Shell Use in the Shell Midden Archaic $\quad 29$

Diet and Nutrition $\quad 35$

RESEARCH OBJECTIVES AND HYPOTHESIS 38

Assumed Health Patterns: A Prediction $\quad 39$

Observed Health Patterns: Differential Mortality $\quad 40$

MATERIALS AND METHODS 42

Site Background $\quad 42$

Skeletal Assemblage $\quad 46$

Osteological Analytical Methodologies $\quad 48$

$\begin{array}{lr}\text { Pathological Analysis } & 50\end{array}$

$\begin{array}{ll}\text { Statistical Analysis } & 53\end{array}$

RESULTS

$\begin{array}{ll}\text { Sample Demographic Makeup } & 54\end{array}$ 
$\begin{array}{lr}\text { Porotic Expression } & 55\end{array}$

$\begin{array}{lr}\text { Porotic Distribution } & 58\end{array}$

$\begin{array}{ll}\text { Kaplan-Meier Survival Curves } & 61\end{array}$

$\begin{array}{ll}\text { DISCUSSION } & 65\end{array}$

Concerns and Conclusions about Diet and Porotic Hyperostosis 69

$\begin{array}{ll}\text { Porotic Distribution Patterns and Differential Mortality } & 76\end{array}$

$\begin{array}{lr}\text { CONCLUSIONS } & 89\end{array}$

$\begin{array}{ll}\text { REFERENCES } & 92\end{array}$

$\begin{array}{ll}\text { APPENDIX } & 102\end{array}$

$\begin{array}{ll}\text { CURRICULUM VITAE } & 103\end{array}$ 


\section{LIST OF TABLES}

TABLE

1. Known Etiologies of Porotic Hyperostosis and Cribra Orbitalia

2. Age and Sex Distribution in the Ward Assemblage

3. Porotic Expression Frequencies at Ward

4. Distribution Pattern Frequencies at Ward
PAGE

13

54

56

61 


\section{LIST OF FIGURES}

FIGURES

PAGE

1. Stuart-Macadam's porotic lesion "types" 3

2. Bilateral trabecular outgrowth in the orbital roofs 3

3. "Filariform (L3) hookworm larva in a wet mount"

4. Diphyllobothrium latum, fish tapeworm, "Scolex of D. Latum" 10

5. Eastern Woodlands Cultural Region 20

6. Map of the Green River Drainage West of Mammoth Cave 24

$\begin{array}{ll}\text { 7. Ward site excavation plan } & 47\end{array}$

8. Scattered fine porosity $\quad 51$

9. Hypertrophic expression of trabecular bone 52

10. Representation of Ward sample age distribution 55

11. Bilateral orbital porosity in UKMA 12-93 57

12. Representation of observed pattern of porotic lesions: isolated orbital porosity

13. Representation of observed pattern of porotic lesions: sagittal concentration 59

14. Representation of observed pattern of porotic lesions: lambdoidal concentration

15. Representation of observed pattern of porotic lesions: full expression

16. Kaplan-Meier survival curve for the entire Ward sample

17. Kaplan-Meier survival curves pertaining to the five observed patterns of cranial porosity 
18. Kaplan-Meier survival curves simplifying observed patterns of cranial porosity into vault or orbital lesions

19. Kaplan-Meier survival curves testing the comparability of combined pathologies to either porotic hyperostosis or cribra orbitalia

20. Kaplan-Meier survival curves based on estimated sex

21. Kaplan-Meier survival curves based on observed patterns of porotic distribution from males

22. Kaplan-Meier survival curves based on observed patterns of porotic distribution from females

23. Original published plan view map of the Ward site's (15Mc111) WPA excavation

24. Cranium exhibiting lateral distribution limit at the temporal line 75

25. UKMA 12-421 showing cut marks on superior portion of frontal 79

26. UKMA 12-44 exhibiting unilateral cribra orbitalia 84 


\section{CHAPTER 1: INTRODUCTION}

Studies of anemia in the past have been used to make or support large scale conclusions concerning the dietary consequences of subsistence strategies, identifying famine, intensity of parasitic infection, and child-rearing practices in past populations. The conclusions of such studies are often based on the identification and proliferation of two cranial pathologies throughout past populations: porotic hyperostosis and cribra orbitalia. While many challenges have arisen in recent years to contest the specific etiology of both pathologies, questioning anemia itself as the culprit, little effort has been made to attempt a measurement of their real impacts on mortality.

\section{History of Anemia in Archaeology}

Stuart-Macadam (1992:39) defines porotic hyperostosis as a condition impacting the outer tables of the frontal, parietals, and occipital, which is identified by "small holes of varying size and distribution that penetrate the outer compact bone of the skull." The name was coined by Angel (1966:760), who defined it as "an overgrowth of the spongy marrow space of the skull." An earlier name was given to the pathology by Aleš Hrdlička (1914), who observed it in archaeological specimens from Peru. The terminology he used was osteoporosis symmetrica, which was a simple descriptive labeling of the porous nature of the outer table of the cranium in afflicted individuals. The names cribra cranii and hyperostosis spongiosa have also been used to describe this same pathology in the past (El-Najjar et al. 1976:477). Cribra orbitalia has been identified as a 
skeletal pathology for longer. The terminology was coined by Welcker (1885), when he described the recurring phenomenon of exposure of the mesh-like structure of spongy bone in the orbital roofs of skulls from the Yemeni island of Socotra. He reported observing this pathology in 48 percent of his specimens from the island, where by comparison he had observed three percent in an undisclosed German sample (Welcker 1885:93-94).

Aside from Hrdlička original ascription of symmetry to the distribution of porotic lesions on the cranial surface, little attention has been paid to the distribution of porosity in discussion of the pathology. Stuart-Macadam commented that, "Although there is no quantitative information on distribution, it [has] long been recognized that vault lesions occur bilaterally and symmetrically" (1989:188). In one of her dissertation samples, Stuart-Macadam observed that parietal lesions were both symmetrical and equally severe in a majority of cases, at about a $92 \%$ rate (ibid.). Similar to porotic vault lesions, orbital lesions are also typically expected to manifest bilaterally. Both orbital and vault lesions are often expected to co-occur; Stuart-Macadam (ibid.) reported $88 \%$ of skulls with vault lesions from her Poundbury Camp assemblage also exhibited orbital lesions. An additional example of analytical scrutiny of porous distribution would be Ortner's works (for example, Ortner and Ericksen 1997; Ortner et al. 1999; Ortner et al. 2001), which suggested that porotic lesions observed on the greater wing of the sphenoid are evidence of an alternative metabolic disorder. 
Instead of porotic distribution, attention in studies is typically given to intensity, as can be observed from arbitrary classification schema employed in past analyses (StuartMacadam 1985; Steckel et al. 2002a). When treated as a variable, intensity usually refers to the observable size of individual porosities and the density of perforations through any given portion of the cranial surface. For example, Stuart-Macadam $(1985,1987,1989)$ employed multiple scoring criteria for intensity of porotic lesions throughout her several publications on the subject. The following is derived from her 1989 paper and used to define observed porosity in both orbital and vault lesions: "type 1) scattered fine foramina, type 2) large and small isolated foramina, type 3) foramina that have linked into a trabecular structure, and type 4) outgrowth in trabecular form from the outer table surface" (Figures 1 and 2, Stuart-Macadam 1989:187-188).

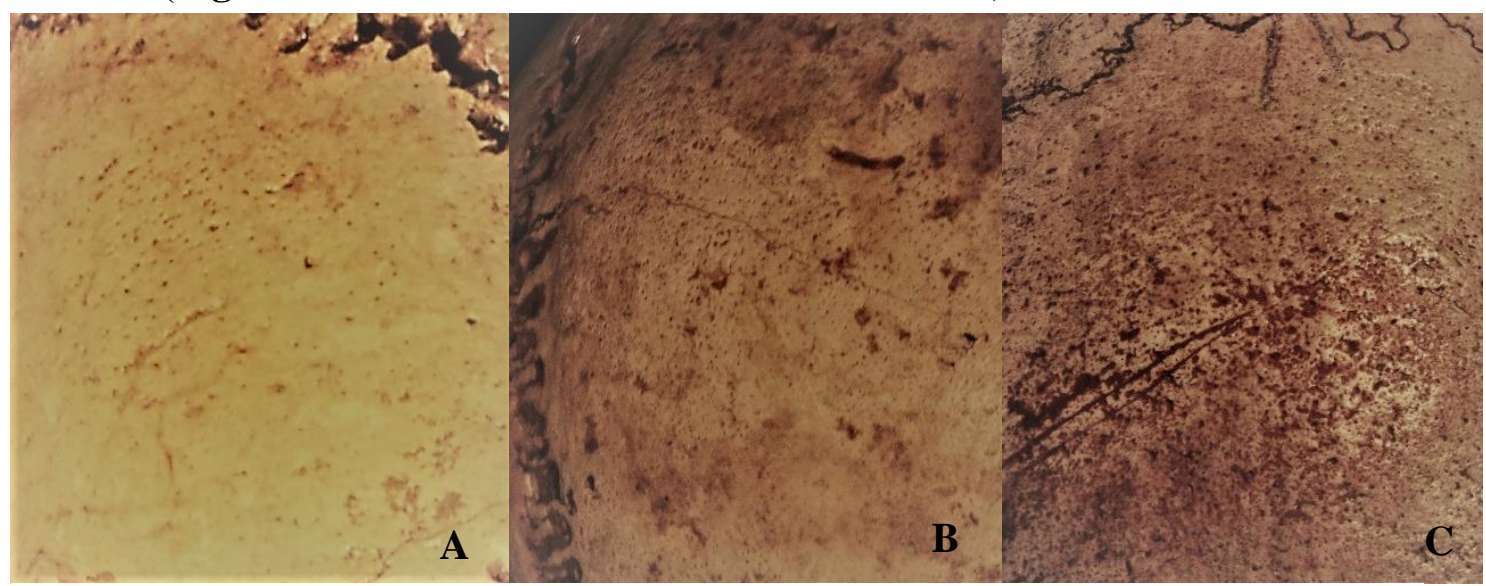

Figure 1 Stuart-Macadam's porotic lesion “types:” A. Type 1, scattered, fine patterning of foramina on a right parietal from UKMA 12-384; B. Type 2, isolated foramina on a left parietal from UKMA12-271; C. Type 3, trabeculation of foramina on a frontal from UKMA 12-421. Photos from the author.

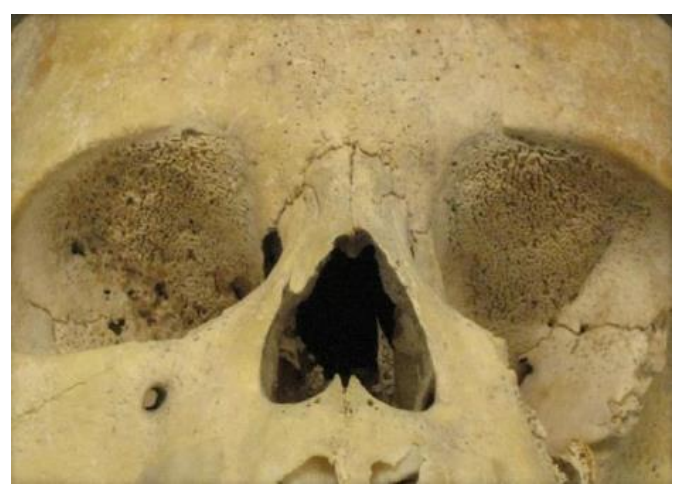

Figure 2 Bilateral trabecular outgrowth in the orbital roofs (from Morgan 2014:132) 


\section{Etiology of Porotic Hyperostosis and Cribra Orbitalia}

The sieve-like lesions identified as porotic hyperostosis and cribra orbitalia are generally thought to both be caused by the same hematological process. This process is marrow hyperplasia (or marrow hypertophy), a condition that "is indicative of abnormal demand for increased hematopoietic marrow" (Ortner et al. 2001:343), which is to say, excessive red blood cell (RBC) production. When this overproduction is intense enough, it results in an increase in physical size of the RBC production centers. According to Huss-Ashmore and colleagues (1982:414), "as the marrow spaces expand, the outer layer of bone becomes very thin, often exposing the trabecular bone of the diploe." The expansion in trabecular bone (marrow containing space) puts pressure on the outer table and eventually expands through it (Ponec and Resnick 1984). The resultant exposure of trabecular bone on the outer surface provides the hallmark porous appearance of porotic hyperostosis and cribra orbitalia.

The stimulus which is thought to trigger marrow hyperplasia is still rigorously debated. Over several decades researchers have asserted that causation for porotic hyperostosis and cribra orbitalia is anemia, and specifically acquired iron-deficiency anemia in most populations (for example, Angel 1966; El-Najjar et al. 1976; Goodman and Armelagos 1989; Holland and O'Brien 1997; Oxenham and Cavill 2010; Mcllvaine 2015). Stuart-Macadam (1992:40) defines iron-deficiency anemia as a "reduction below normal levels of hemoglobin and hematocrit (packed red cell volume) in blood." Because of iron's importance in the formation of hemoglobin, and hemoglobin's subsequent importance in oxygen transportation in the body, anemia causes hypoxia, or oxygen deprivation in tissues. Hypoxia in turn stimulates augmented production, as much as 
doubling normal production, of red blood cells (RBCs) in bone marrow in an effort to compensate for the deficiency (Mushrif 2000).

Anthropologists have traditionally favored dietary iron-deficiency anemia as the causative agent behind these porous cranial lesions, and even utilized the pathology as a marker of nutritional stress in past research (for example, Steckel et al. 2002a, 2002b; Barrett and Armelagos 2013; Larsen 2015b, 2000; Larsen et al. 2001). This emphasis has led to the association of porotic hyperostosis with agricultural development in the Neolithic (Barret and Armelagos 2013), as well as the "maize dependency hypothesis," championed by El-Najjar et al. (1976). These theories are constructed around the presence of phytates in cereal grains and other plant resources, which act as ironinhibitors, blocking absorption of dietary iron in the intestine (Larsen 2015a, 2000; HussAshmore et al. 1982; Lallo et al. 1977; El-Najjar et al. 1976). The assumption is that when populations all over the world shifted primarily to agriculture-based subsistence practices, the bodily intake of dietary iron was mitigated by phytate consumption and therefore an accompanying rise in frequency of porotic hyperostosis should be expected.

Some authors, however, have disputed the notion that intake of dietary iron is actually responsible for causing iron-deficiency anemia (Rothschild 2012; Walker et al. 2009; Stuart-Macadam 2006, 1992; Palkovich 1987; Kent 1986). Iron supply in the human body is a nearly closed system, with a $90 \%$ recycle rate from hemolysis (breakdown of red blood cells, Stuart-Macadam 1992, 2006). Typical RBCs have a lifespan of approximately 120 days before they are engulfed and destroyed by phagocytes in the liver or spleen. Hemolysis will free up a vast majority of the iron required for RBC production. According to Cavill (2002:400), "in normal circumstances daily red cell 
production is balanced by an equal red cell destruction." Given the efficiency of the body's iron-recycling system, there is little room for dietary input in the creation of iron deficiency. Most absorption of dietary iron occurs in the large intestine, but the mechanism by which that absorption of iron is regulated is unknown (Stuart-Macadam 2006). Rather than a deficit of dietary iron intake, iron would have to be lost from the system through other means. Bothwell and colleagues (1989) suggest augmented demand for iron in growth and development, and iron expenditure in childbirth as major contributors to iron-deficiency. Ortner and colleagues have suggested this loss can occur through direct loss of blood in severe menstrual bleeding, bleeding in the GI tract, or even traumatic injury as causative of iron-deficiency (Ortner et al. 2001).

An alternate explanation for the iron loss thought to be causative of anemia can be credited to the body's defenses against pathogenic invasion in the form of iron withholding. Stuart-Macadam outlines this mechanism as follows:

"when faced with chronic infections and inflammatory conditions the body's natural response is to station iron-binding proteins at sites of entry for pathogens, decrease intestinal absorption of iron from the diet, prevent the release of iron into the blood from storage sites, and bind available serum iron onto proteins that transport and store iron" (Stuart-Macadam 2006:130).

All of these mechanisms serve to inhibit the growth and reproduction of microorganisms, which do not keep their own stores of iron, and therefore require and acquire it from their hosts. These pathogens have several methods of acquiring iron from hosts. They typically manufacture siderophores, which are iron-binding proteins that extract iron from transferrin in the blood supply, or bind directly with the transferrin and other iron carrying molecules. Some pathogens also break down RBCs directly (Weinberg and Miklossy 2008). In this manner, Stuart-Macadam $(1992,2006)$ describes iron-deficiency 
anemia not as a disease per se, but as a symptom of, and an immune response to, parasitic infection (Holland and O’Brien 1997).

Iron serves numerous roles in the metabolic systems of innumerable species: it is heavily utilized in human physiology. Its principle role is the part it plays in oxygen transport as a component of the oxygen-binding protein, hemoglobin (Cavill 2002). For pathogens, iron is typically a requisite ingredient in DNA replication and RNA transcription. Healthy iron concentration in humans can vary between three and six grams, of which half occurs in hemoglobin. Hematopoiesis (production of RBCs) uses $30-40 \mathrm{mg}$ of this iron on a daily basis, and iron atoms will not typically go unutilized in the bloodstream for more than 90 minutes at a time (Cavill 2002). Most of the rest is stored via the mononuclear phagocyte system in places like the liver, spleen and bone marrow. Circulating iron is typically bound to proteins, like transferrin, and the remainder is unbound serum iron (Cavill 2002; Stuart-Macadam 2006).

Parasitism as an etiological factor behind porotic hyperostosis has been assumed and utilized in numerous studies in recent decades (Blom et al. 2005; Sullivan 2005; Rothschild 2000; Holland and O’Brien 1997; Kent 1986). As stated previously, parasites require iron for their own metabolic processes. Depending on the species, the primary means of acquiring iron from a human host is through direct consumption of red blood

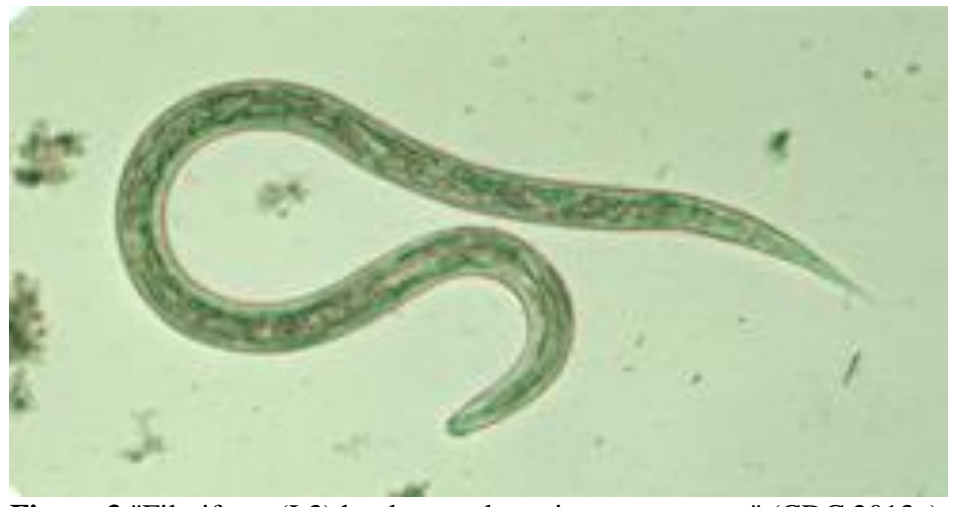

Figure 3 "Filariform (L3) hookworm larva in a wet mount," (CDC 2013a). 
cells. This especially is the case with hookworm (Necator americanus, Figure 3), which consumes blood directly from the mucosal capillary in the large intestine (Aufderheide and Rodriguez-Martin 1998:239). In such cases, the requirement of replacing blood lost directly to parasitic consumption, coupled with the hypoxic conditions triggered by irondeficiency combine to exacerbate hematopoiesis. The Centers for Disease Control and Prevention (CDC, 2013a) estimates between 576 and 740 million people suffer from hookworm infection worldwide, and classify the parasitic worms as soil-transmitted helminths.

\section{Alternatives to Iron Deficiency}

The case for a link between parasitism and porotic hyperostosis has an early precedent. The initial association of porotic cranial lesions with iron-deficiency was assumed from the skeletal marker's known association with clinically identified cases of hemolytic anemia, most notably sickle cell anemia and thalassemia. The mechanism by which the hemolytic anemias are thought to generate marrow hypertrophy is similar to that of iron-deficiency anemia. In the case of sickle cell anemia, a point mutation in the gene coding for hemoglobin synthesis that, in individuals homozygous for the trait, produces misshaped, elongated RBCs. These sickle-shaped RBCs can cause blocked capillaries and directly reduce blood flow, but they also are subject to premature hemolysis (Aufderheide and Rodriguez-Martin 1998:348). Heterozygous individuals are conferred a degree of immunity to parasitic infections of malaria, as the mutated hemoglobin in affected RBCs prevent malarial (specifically falciparal) merozoites from attaching and destroying those cells (ibid.:232). Thalassemia is similar in that it is a 
genetic mutation resulting in abnormal hemoglobin, though the degree to which it confers immunity to malaria is not as well known (ibid.).

The hemolytic anemias are known and associated regularly with cases of porotic hyperostosis in the Old World (Rothschild 2000; Angel 1966). The premature destruction of the malformed RBCs produced by these genetic conditions is the factor that triggers marrow hyperplasia that produces the evident pathology. It is largely assumed that "congenital anemia probably did not occur in the New World until after contact with the malaria-adapted populations of the Old World" (Blom et al. 2005:153). This assumption also rests on a belief that there was a paucity of malaria in the pre-contact New World, as claimed originally by Angel (1966:153), but echoed later by many of his readers: "falciparum malaria spread over the anopheline belts of the Old World in coincidence with porotic hyperostosis, but did not penetrate the New World." Porotic hyperostosis, however, is prevalent in the remains of pre-historic populations in the New World. It is this contradiction that led many authors to assign iron-deficiency anemia as a primary causative factor in porotic hyperostosis.

Iron deficiency anemia as the etiology responsible for marrow hypertrophy in porotic hyperostosis and cribra orbitalia was widely considered paleopathological dogma throughout the latter half of the $20^{\text {th }}$ century. Since then, however, alternative etiologies have been presented by numerous researchers. Chief among these is megaloblastic anemia resulting from vitamin B12 and folic acid deficiency (Rothschild 2000, 2012; Walker et al. 2009). Megaloblastic anemia operates in a similar manner to the hemolytic anemias in that it affects the DNA synthesis of RBCs during production in hematopoietic marrow, resulting in malformed RBCs that grow continuously without dividing. This 
process, known simply as irregular erythropoiesis, leads to enlarged RBCs which are relatively inefficient at transporting oxygen and purged from circulation prematurely (Walker et al. 2009), again resulting in augmented production and expansion of hematopoietic marrow.

It is specifically folic acid deficiency that triggers irregular erythropoiesis, given the role it maintains in the DNA synthesis of immature RBCs. Vitamin B12 deficiency contributes to irregular erythropoiesis indirectly through its role in folic acid recycling within the body. Folic acid deficiency as a result of its absence in the diet can result in megaloblastic anemia in its own right, but a co-deficiency of vitamin B12 and folic acid is the more common cause. Vitamin B12 deficiency is routinely associated with diets absent of or scarce in animal protein (Walker et al. 2009), but is also subject to loss via

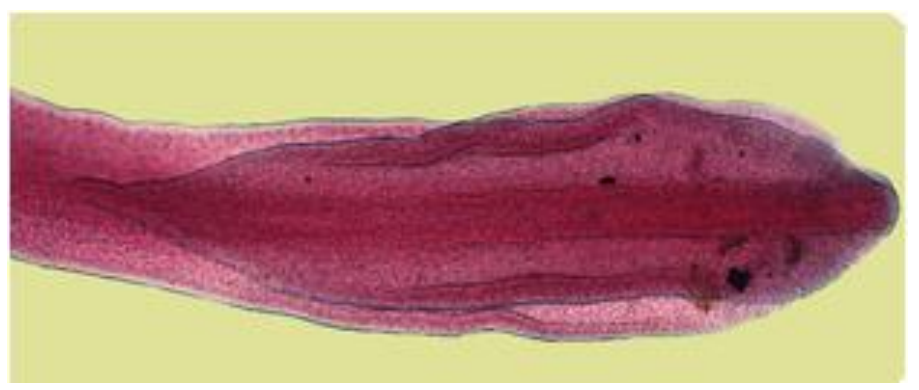

Figure 4 Diphyllobothrium latum, fish tapeworm, "Scolex of D. Latum" (CDC 2013b).

parasitic infection. Rothschild (2000) identifies the fish tapeworm, Diphyllobothrium spp., as a prodigious consumer of vitamin B12 from human hosts (Figure 4).

Walker and colleagues (2009) vehemently deny that iron-deficiency anemia plays any role in the formation of porotic hyperostosis, arguing that iron-deficiency shuts down erythropoiesis as opposed to exciting it. In reaction to their conclusion, some authors have responded with a defense of the traditional paleopathological interpretation (McIlvaine 2012; Oxenham and Cavill 2010). According to McIlvaine (2012), iron- 
deficiency is met with one of two responses: shutting down erythropoiesis, as suggested by Walker and colleagues (2009); or, continuing erythropoiesis while producing iron deficient hemoglobin in RBCs. Oxenham and Cavill (2010) argue that the two pathologies are not exclusive, and instead advocate for the incorporation of both megaloblastic and iron-deficiency anemias in the ever-growing suite of etiologies that contribute to differential diagnosis of porotic hyperostosis and cribra orbitalia. Vitamin B12 is, after all, abundantly available in animal resources, and its deficiency in the diet is frequently conflated with that of iron (Walker et al. 2009; Steyn et al. 2016). In short, the two anemias are highly likely to co-occur, so differentiating which may have impacted the skeletal tissue of any given individual is difficult, if not impossible.

Some researchers have suggested additional etiologies, which do not involve anemia, be added to the suite of differential diagnoses for porotic hyperostosis and cribra orbitalia. Principal among these are the impacts of scurvy. Scurvy is identified as a chronic deficiency of vitamin C, typically as a result of diet (Zuckerman et al. 2014:28). Ortner and Ericksen (1997) outline vitamin C's metabolic role in human tissue formation:

One of the factors in the pathogenesis of scurvy is the importance of vitamin $\mathrm{C}$ in the formation of connective tissues, including collagen and cement material, particularly the cement substance that binds the endothelial layer in blood vessels. A defect in this cement material causes increased susceptibility to haemorrhage that results from even normal movement or muscle activity such as chewing or eye motion, but is more evident with trauma [Ortner and Ericksen 1997:213].

The presumption is that subperiosteal bleeding is responsible for at least some of the cranial vault and orbital lesions normally attributed to anemia. This argument is especially compelling in the case of cribra orbitalia, where vascular ruptures in the orbit can cause hemorrhaging along the orbital roof. The porosity that is observed on skeletal 
tissues is the result of blood pooling beneath the periosteum, which may separate the periosteum from the underlying bone. The separated periosteum is dissolved, and growth of the underlying bone is stimulated in order to repair the damage (Ortner and Ericksen 1997; Ortner et al. 1999; Ortner et al. 2001).

It is possible to have similarly damaging inflammation without scurvy, in the orbits or otherwise. Ortner and colleagues (1999) define inflammation on the basis of increased vascularity "and the presence of inflammatory cells associated with the removal of extravasated blood" (Ortner et al. 1999:323). In scorbutic and non-scorbutic cases of inflammatory porous skeletal lesions, the porosity observed in skeletal tissue is caused by the formation of new blood vessels to remove the blood pooled along the bone surface. Since these blood vessels penetrate the surface of the bone cortex, their presentation can be easily confounded with that of porotic lesions normally associated with the anemias.

Ortner and colleagues $(1997,2001)$ argue that scorbutic lesions of the vault can be differentiated from marrow hypertrophy primarily on the basis of their location on the cranium: specifically when they are located on the exterior surface of the greater wing of the sphenoid. Porosity in this location is attributed to scorbutic weakening of the vasculature of the temporalis muscle where it articulates with the sphenoid. These vessels are ruptured as a result of simple mastication, and the resulting hemorrhaging causes the perforation of the sphenoid's surface by new blood vessels. The assumption that scurvy causes this particular porous lesion, as opposed to normal inflammation, is based on the relative protection of the sphenoid by the temporalis muscle (Ortner and Ericksen 1997). Scorbutic lesions and inflammation on other portions of the skull can only be 
differentiated from marrow hypertrophy when the porosity is associated with thickening of the trabecular bone (Zuckerman et al. 2014).

Still other possible etiologies exist for porotic hyperostosis and cribra orbitalia. Steyn and colleagues (2016) contend that cribra orbitalia may be mimicked by traumatic injury, and rickets (vitamin D deficiency). Peckmann (2003) has even suggested a link between smallpox infections and marrow hypertrophy. Ortner (2003:89) goes so far as to suggest that cribrous lesions can be caused by "inflammation of the frontal, maxillary and ethmoidal sinuses, inflammation of the lacrimal gland, and meningeal reactions." Schultz (2001:131) also cited inflammation as a source of alternative etiologies of porotic hyperostosis, warning about the similarities of anemic hypertrophy to the appearance of osteomyelitis, periostitis, osteitis, hemorrhagic processes associated with inflammation or generalized trauma, and in some rare cases, tumors. For Schultz (2001), differential diagnosis is most accurately performed microscopically. A plethora of even less common scenarios have been utilized to explain the formation of porous cranial lesions, the known and most widely accepted prominent causes of porotic hyperostosis and cribra orbitalia are listed in Table 1.

\section{Table 1 Known Etiologies of Porotic Hyperostosis and Cribra Orbitalia}

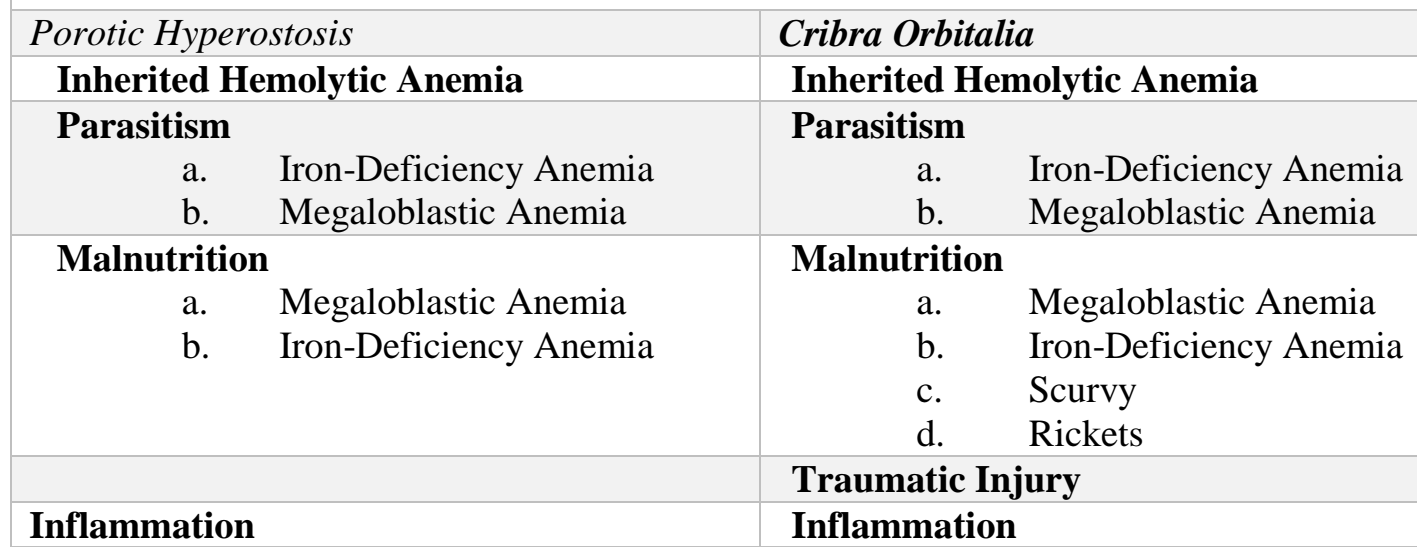




\section{Timing and Impacts of Pathologies}

The pathologies that can cause porotic hyperostosis and cribra orbitalia may impact living individuals at any point in their lives. The window in which those pathologies can leave skeletal manifestations is likely more limited. Stuart-Macadam (1985) solidified a hypothesis that porotic hyperostosis and cribra orbitalia is primarily the result of skeletal modifications occurring in early childhood. This means that for adults, the assumption of peri- or close premortem association of the pathology is likely invalid. In the spirit of Wood's (1992) osteological paradox, she claims, "that porotic hyperostosis does not always reflect a current anemia," and that skeletal manifestations of the pathology can be attributed to "an anemia acquired during early childhood, that is, the result of growth period bone changes that have not undergone complete remodeling" (Stuart-Macadam 1985:392). El-Najjar and colleagues (1976) similarly observed porosity to occur more frequently in children than in adults or even subadults. Yet, porotic hyperostosis and cribra orbitalia can still be observed in adult remains. This suggests that porosity is not ever completely remodeled in growth. In this way, porotic alteration of bone can be utilized in a manner similar to linear enamel hypoplasia; as indicative of nutritional deficiency during early growth and development.

Stuart-Macadam (1985) also contends that marrow hyperplasia in the bones of young children, which are already filled with red marrow, results in pressure on the surrounding compact bone and eventual expansion through it. In adults, such marrow spaces are occupied primarily by yellow marrow, which allows for red marrow expansion to occur without fully occupying the cavity. This process allows adults to compensate for tissue hypoxia through RBC production without leaving evidence of marrow 
hypertrophy. Clinical data cited by Stuart-Macadam (1985) also suggests that porotic hyperostosis and cribra orbitalia occur early in childhood. In the case of cribra orbitalia, particularly in individuals with sickle cell anemia, orbital roof thickening primarily occurs before the age of five. Palkovich (1987) suggests an even earlier attribution for the formation of hypertrophic lesions, arguing that skeletal manifestations would be actively forming between 2 and 6 months, with anemic stress climaxing at two to three years. This proposition aligns with the understanding of age-related consumption of iron resources due to requirements for growth and development. According to Bothwell and colleagues (1989), an infant requires a daily intake of iron between 0.3 and one mg, depending on birthweight. In their second year, most children will consume $80 \mathrm{mg}$ of iron for growth equating to a weight gain of approximately $2.5 \mathrm{~kg}$ (Bothwell et al. 1989:358).

Walker and colleagues (2009) agree that cranial trabecular tissue is largely devoid of hematopoietic marrow by approximately the age of five, at which time the primary locus of RBC production shifts to the marrow cavities of the long bones and eventually to the axial skeleton where it remains throughout adulthood. Stuart-Macadam summarizes the process as such: "at birth the marrow cavities of the entire skeleton are completely filled with hematopoietic... marrow," which is gradually replaced by fatty yellow marrow (Stuart-Macadam 1985:393). Yellow marrow begins to form at about 4 years, and noticeable patches are visible in long bone diaphysis by 12-14 years.

"Marrow involution begins in the extremities and proceeds axially so that after the age of 20 red marrow is limited to vertebrae, sternum, ribs, clavicles, scapulae, bones of the skull and pelvis and to some extent the proximal ends of the femora and humerii" [Stuart-Macadam 1985:393394]. 
For the non-hypertrophy etiologies of porotic hyperostosis and cribra orbitalia, timing of lesion appearance is a little different. In the case of inflammation and traumatic injury, the stimulus that causes vascularization of the bone is typically external, and is not impacted by the marrow content of the nearby trabecular bone. The incidence of scurvy is not affected by age-related skeletal changes, however the extent of scorbutic modification of skeletal tissue can be. It has been suggested that, while adults are not immune, subadults are more likely to encounter the negative effects of Vitamin C deficiency, as they require a potent nutrient supply in order to support growth. Subadults have an elevated risk for forming orbital porosity from subperiosteal hemorrhage, given the tenuous attachment of the periosteum in the orbital roofs, which grows more durable with age (Zuckerman et al. 2014).

All of these pathological etiologies have a substantially larger impact on the livelihoods of those impacted by them than the relatively minor visible traces left on their skeletons might suggest. In adults, iron deficiency typically presents symptoms of chronic fatigue, shortness of breath, tachycardia and malaise (Aufderheide and Rodriguez-Martin 1998:346). Megaloblastic anemia due to B12/folate deficiency can damage the myelin sheaths of nerves, resulting in: "irritability, abnormal reflexes, various psychiatric disorders, and reduced alertness progressing to coma" (Walker et al. 2009:114). Presentation of any such symptoms in adults with megaloblastic anemia, however, is very rare, given the ability of the liver to store large quantities of vitamin B12 (Walker et al. 2009). The primary symptom of scurvy is hemorrhage, which presents everywhere, is generally painful, and leads to reduced physical activity (Ortner and 
Ericksen 1997). Outcomes for adults with these pathologic conditions are generally less than grave: the more severe impacts occur in infants and developing children.

From the outset, the etiologies that are thought to cause porotic hyperostosis and cribra orbitalia are more dangerous for children. Megaloblastic anemias are routinely a result of nursing and weaning practices, where weaning foods are typically non-animal resources. Mothers experiencing B12 deficiency during pregnancy birth infants that have a greater vulnerability to infection (Walker et al. 2009). Blom and colleagues (2005) suggest a link between maternal iron deficiency anemia and elevated frequencies of infant mortality and miscarriage. Those same authors also link iron deficiency to diminished cognitive functions in afflicted children, describing them as: "less alert, active, responsive, and goal directed; they have shorter attention spans and speak less" (Blom et al. 2005:153). The hereditary hemolytic anemias are even more serious, particularly in the case of homozygous sickle cell anemia; children with this diagnosis rarely survive to puberty (Aufderheide and Rodriguez-Martin 1998:232).

\section{Old Answers and a New Question}

The impacts of the etiologies which cause porotic hyperostosis and cribra orbitalia on past peoples has not been the primary concern of archaeologists and researchers in the decades since the skeletal pathologies' initial identifications. Rather, the utility of the pathologies as a measurement device of culture's impact on biology has traditionally occupied academic attention. Such treatments typically applied a known or assumed characteristic of the pathologies to past populations in which they were identified. For example, El-Najjar and colleagues (1976) ascribed to the theory that dietary iron- 
deficiency was responsible for creating vault and orbital lesions observed on crania from pre-contact agriculturalists in the American Southwest. Their study identified different frequencies of porotic lesions observed between individuals from canyon bottom and sage plain sites, and the authors attributed that disparity to subsistence practices. Specifically, canyon bottom dwellers utilized a primarily maize-dependent diet, where sage plain inhabitants maintained a more diversified diet largely consisting of animal resources. El-Najjar and his coauthors (1976) identified a higher rate of porotic hyperostosis among canyon dwellers, which they argued was the result of their dependence on maize agriculture.

The association of agriculture and porotic hyperostosis is not a novel one in archaeological research. Some of those researchers even assume a direct connection between porotic lesions and the implementation of agriculture itself. Larsen (2000, 2015a), for example, argues that the frequency of appearance of porotic hyperostosis, as a stand in for iron-deficiency anemia, increases dramatically on a worldwide scale with the transition of populations from foraging to farming (Larsen 2000:102). The argument is that as societies transition from hunter-gatherer subsistence strategies, which are largely supported by iron-rich animal resources, to a dependence on less nutritious, plant-based agricultural products, people suffer negative health consequences. It is a thesis that was first championed by El-Najjar and colleagues (1976), and carried on by authors like Cohen (1989) and Larsen (2000, 2015a; Larsen et al. 2001), creeping into large scale projects which continue to today (for example, Steckel and Rose 2002).

Not all researchers were taken with the maize-dependency hypothesis. Susan Kent, for example, argued that sedentism, not diet, was responsible for observed 
increases in porotic hyperostosis through time (Kent 1986). Her idea was that increased reliance on agriculture as a subsistence strategy led to populations becoming less mobile. Using Ancestral Puebloan (she uses the term Anasazi) skeletal assemblages, she hypothesizes that rather than poor diet initiating iron-deficiency, parasitic infection was the culprit. The assumption is that as Ancestral Puebloan groups aggregated into more permanent, and densely populated, settlements, sanitary conditions deteriorated. Kent argues that this lack of sanitation is accompanied by a "cycle of chronic viral, bacterial and parasitic infections," leading to diarrheal illness and parasitic blood loss creating iron deficiency and subsequently porotic hyperostosis and cribra orbitalia (Kent 1986:623). Some authors, like Holland and O'Brien (1997), were critical of a non-dietary explanation for the prevalence of cribra orbitalia and porotic hyperostosis in agricultural societies. Others, like Rothschild (2000, 2012), were more receptive to the ascription of parasitism as the causative agent behind porotic hyperostosis. Still others were ambivalent to the necessity of choosing sides between the proposed causative stimuli (Cohen 1989; Walker et al. 2009; Oxenham and Cavill 2010). Among most of these theories and the theorists behind them, there is agreement that evidence suggests a clear progression in human health over time; as civilizations become more complex, whether measured by way of settlement or subsistence pattern, the people become less healthy. Health, in all of the referenced studies, is measured by porotic hyperostosis and cribra orbitalia. So when an example of non-aggregated populations of hunter-gatherers in the purportedly malaria-free pre-contact New World arises, what do porotic hyperostosis and cribra orbitalia have to say about their health? Such an example can be found in the Archaic Period populations of the Eastern Woodlands in North America. 


\section{CHAPTER 2: BACKGROUND}

The Eastern Woodlands is a cultural region delineated primarily by a generalized mixed deciduous arboreal ecology (Figure 5), bounded on the East and West by the Atlantic Ocean and the Mississippi River, respectively. Due to the large nature of this region and the variation inherent, the present study has confined its focus to Kentucky. Kentucky, geographically, serves as a sort of hub of the Eastern Woodlands. That is not to argue that Kentucky is fully representative culturally of the whole region (such a claim would require an immense and intensive academic debate). Kentucky is, however, the locus of the earliest known independent plant domestication in the region; Cucurbita pepo subspecies ovifera was domesticated by Archaic Period hunter gatherers in Red

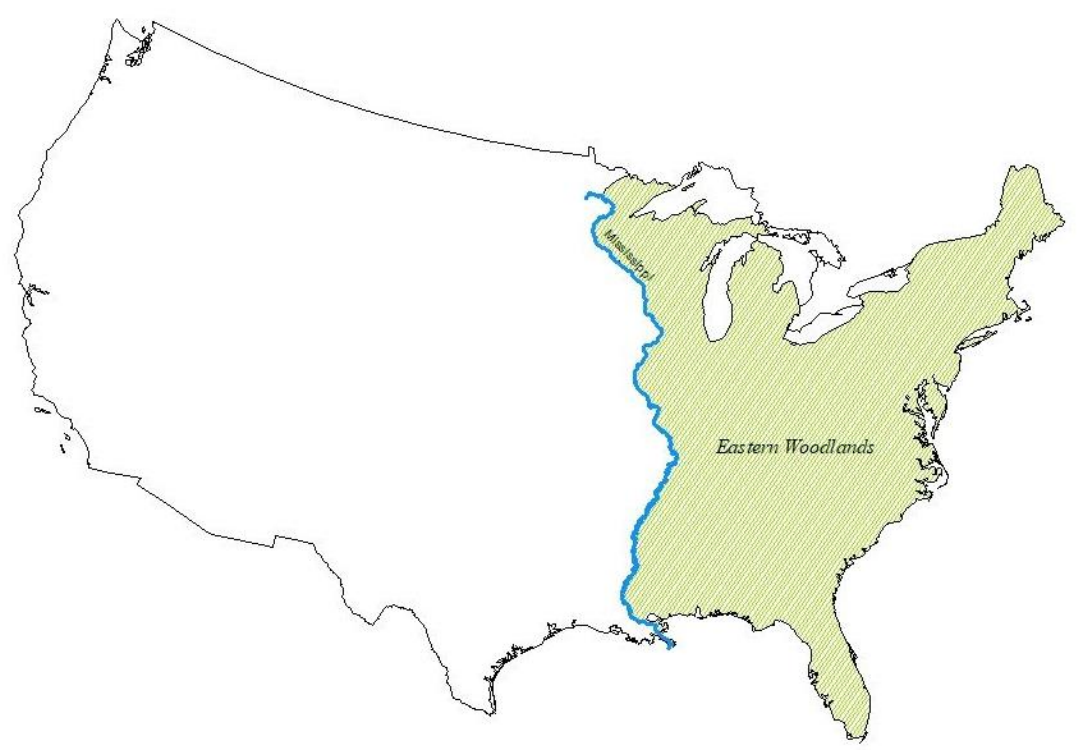

Figure 5 Easter Woodlands Cultural Area 
River Gorge, an area which shows evidence for human occupation in Kentucky as early as 13,500 years BP (Delcourt et al. 1998).

While plant domestication may have occurred early in the Archaic Period of Kentucky Prehistory, its adoption as a subsistence strategy did not occur until significantly later in the state. The Archaic Period in Kentucky is typically delineated as occurring between 12,000 and 3,000 years $\mathrm{BP}$, and is culturally associated with seasonally mobile non-agrarian populations (Jefferies 2008; Webb 1946). In terms of subsistence, Archaic populations were predominantly hunter gatherers, relying on the exploitation of wild plant and animal resources (Jefferies 2008). At Indian Knoll, for instance, one of the largest Archaic sites excavated in the state, the faunal assemblage consisted of a total of 25,756 bones. Of that total, $89.99 \%(n=23,177)$ were identified as belonging to Odocoileus virginianus (white-tailed deer), (Pedde and Prufer 2001: 72). O. virginianus was exploited heavily throughout the Archaic Period. The Late Archaic (5,000 to 3,000 years BP) is characterized in the state of Kentucky by an exploitation of riverine resources, most notably freshwater mussel shell (Family: Unionidae, various spp.) and the accumulation of that shell into large midden deposits regularly referred to as shell mounds or shell midden (Pedde and Prufer 2001; Webb 1946). For this reason, the terminal Archaic is routinely referred to as the Shell Midden Archaic (SMA).

\section{Climate and the Rise of Agriculture}

The SMA terminates rather abruptly at approximately $3000 \mathrm{BP}$, which is surprising given the extent and intensity of many of the classic sites that represent the period. One likely scenario for the disappearance of the Archaic cultural groups in the Archaeological Record is provided by Kidder (2006). Kidder points to an instance of 
rapid climate change, a result of solar forcing (augmented average absorption of solar energy) compounded with other factors, which resulted in a prolonged period of cooler climate and increased rainfall, particularly in the Eastern Woodlands (2006). This shift resulted in an influx in the frequency and intensity of flooding events throughout the major river drainages. These flooding events caused major disruptions in the productivity and accessibility of riverine resources throughout much of the region, rendering pelecypod collection or mass capture fishing techniques ineffectual (Kidder 2006). Schmidt (2001) attributes a substantially greater role for riverine fish resources in Late Archaic subsistence strategies than is presented by the faunal data from the Indian Knoll assemblage mentioned previously. The pervasive lack of fish remains in the Indian Knoll faunal assemblage is unique in the SMA cultural tradition, and is likely a result of either preservation or (more likely) excavation and collection bias (Pedde and Prufer 2001): the site was initially excavated in the 1930's, along with numerous others, at standards significantly below those common in modern practice.

Kidder focuses on the Mississippi valley, but the resulting model is readily applied to its tributaries such as the Ohio and Green Rivers in Kentucky. This cooling period is shown to be reflected in the "sharp decline or hiatus in archaeologically visible occupations in the alluvial portions of the Mississippi River basin ca. 3000-2600 BP" (Kidder 2006: 216). This trend is mirrored in Kentucky sites, where the SMA largely disappears by 3000 BP (Jefferies 2008). As a result of the collapse of riverine resources and the concurrent, necessary abandonment of alluvial occupation zones, the prehistoric population of Kentucky (and much of the Eastern Woodlands) suffered significant collapse (Fiedel 2001). These diminished populations adapted new strategies for coping 
with subsistence instability. These new strategies, arriving in the adoption of intensified agriculture and ceramic food storage, define the Woodland Period of Kentucky Prehistory (3000-1100 BP, Applegate 2008).

\section{History of Excavations}

The presumed locus of the Shell Midden Archaic has traditionally been considered the Green River in central Kentucky (Figure 6), home to the largest shell

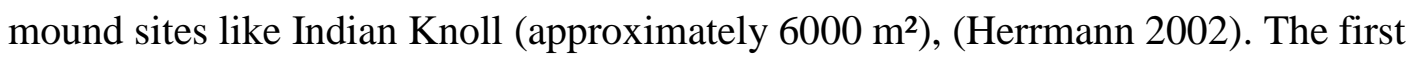
explorations of the Green River shell middens were undertaken by C. B. Moore in the fall and winter of 1915 and 1916, who was working for the Academy of Natural Sciences in Philadelphia (Webb 1946; Haskins and Herrmann 1996). This work was more akin to a treasure hunt than a scientific exploration, where the principal investigator staged his explorations from his steam powered paddleboat, The Gopher, and forays rarely ventured far beyond the shore. As an example of the level of precision executed in Moore's excavation at Indian Knoll, an eight man team worked a grand total of 179 hours to excavate 298 burials. Of those opened burials, only 66 of the best cranial specimens were kept, the rest were reburied at the site (Haskins and Herrmann 1996:108). These specimens were sent to and remain curated at what would become the National Museum of Natural History at the Smithsonian Institution. During this time, the chief preoccupation in skeletal biology was racial affinity, which was assessed for Moore's collection by Aleš Hrdlička (Haskins and Herrmann 1996). 


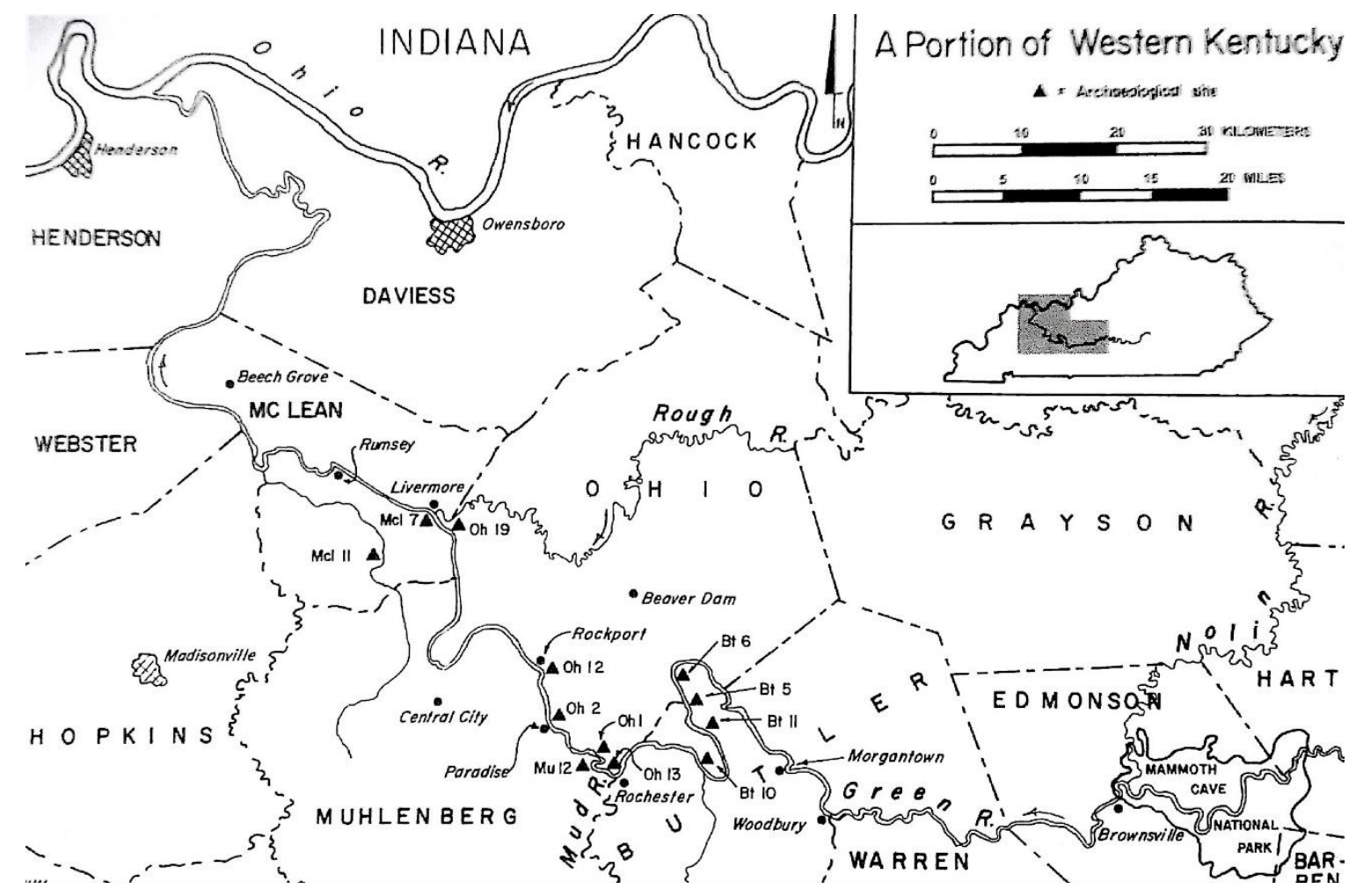

Figure 6 Map of the Green River Drainage West of Mammoth Cave, showing the larger shell mound sites in the region, reproduced here from Watson and Marquardt (2005:14).

The second wave of shell midden excavations occurred under the direction of

William S. Webb and the patronage of the Works Progress Administration (WPA) in the 1930's and 1940's (Lyon 1996; Webb 1946; Pedde and Prufer 2001). The WPA archaeology program intentionally engaged in the most labor-intensive excavation projects it could identify in the rural areas hardest hit by the Great Depression, offering a much needed form of unemployment alleviation in Western Kentucky (Neumann et al. 2010). The monumental volume of these projects, some recovering the remains of as many as 880 individuals (Indian Knoll, Webb 1946), excavating in total a minimum of 2,991 burials (Haskins and Herrmann 1996), has guaranteed their significance in perpetuity as intellectual fodder for numerous master's theses and doctoral dissertations (Crothers 2011). The importance of WPA projects in archaeological research is not a recent phenomenon. In 1938, almost every paper given at the Society for American 
Archaeology meeting was a product of a WPA project (Lyon 1996: 67). In the early years of Kentucky WPA projects, previously known prehistoric sites were chosen based on local unemployment and therefore, availability of labor. Leading up to 1939, available local labor decreased generally as more and more unemployed men were recruited into or volunteered for the war effort (Lyon 1996), In some cases, the shortfall in labor led to the termination of large, long-term projects, Indian Knoll among them (Webb 1946).

In 1971, William Marquardt and William Fischer began fieldwork for a long-term multidisciplinary investigation that would later become the Shell Midden Archaeological Project (SMAP), (Watson and Marquardt 2005). The scope of research contained in the literature produced from the SMAP project substantially outweighs (literally and figuratively) the publications derived from the initial WPA excavations. Occurring over multiple decades, the SMAP project included excavations at Carlston Annis (15Bt5), DeWees Mound (15Bt6), and smaller excavations of rockshelters in the area (Watson and Marquardt 2005). Excavations at Carlston Annis contributed a great deal to Crothers' (2005) interpretation of faunal exploitation at the shell midden sites, where a paucity of such data as a consequence of curatorial decisions had previously made reinterpretation impossible. Much of the analysis undertaken by the SMAP project relied on reinvestigation of or, in numerous cases, initial analysis of WPA assemblages.

Much of the continued utilization in archaeological research of these sites is owed to prohibitive restrictions on contemporary excavation presented by modern cultural resource laws, chief of which is the Native American Graves Protection and Repatriation Act (NAGPRA), ratified in 1990 (Neumann et al. 2010). NAGPRA prohibits the excavation of Native American interments by any individual, including archaeologists, 
without first demonstrating significant scientific value, descendant community approval, or the perception of imminent threat to that cultural resource. The law delivers significant legal protections for sites and resources that are vulnerable to damage or destruction by looting activities or semi-scientific exploration, but it also effectively proclaimed a moratorium on academic excavation of human remains within the boundaries of the modern United States. Any human remains that are excavated, under the auspices of the law, can be repatriated to any group or tribe that demonstrates cultural affiliation, which can significantly impact or completely curtail their availability for scientific study (Neumann et al. 2010). While there is no current precedent for repatriating Archaic remains or artifacts in Kentucky, additional excavation is precluded by the cost and timeconsuming nature of extensive, modern archaeological investigation. The scale of the WPA excavations may never be repeated due largely to these considerations. As such, it is highly unlikely that additional skeletal materials will be systematically recovered from any of the Green River shell middens, a fact which provides the impetus behind the WPA collections' continued use and enduring influence in Archaic research in the region, including in the present study.

\section{Previous Skeletal Analyses}

Initial bioarchaeological research utilizing the WPA shell midden assemblages was conducted by Charles Snow, who directed physical anthropology at the University of Kentucky for much of his career. Apart from a few monographs on specific skeletal series, like his report on Indian Knoll (Snow 1948), in-depth analysis was reserved for burials that contained grave goods or individuals that exhibited unique pathologies (such 
as the eloquently named flint-in-the-face man, Snow 1948:523). Snow conducted significant metric analyses on many of the human remains from WPA sites, in particular Indian Knoll, largely with the purpose of "establishing predefined racial types within the series" (Haskins and Herrmann 1996:113).

This early interest in racial typology was succeeded by more recent assessments of biodistance between skeletal series (Herrmann 2002; Haskins and Herrmann 1996). Herrmann's (2002) dissertation on biodistance between SMA skeletal series concluded that a degree of biological relationship was maintained between the groups that occupied the Green River drainage, principally via a local mate exchange network. This network, according to Herrmann's model, did not appear to extend far outside of the Green River to shell midden sites in the nearby Tennessee River drainage (2002).

Paleodemographic explorations of three of the Shell Midden Archaic sites (Indian Knoll, Carlston Annis [15Bt5], and Read [15Bt10]) have demonstrated that each of the sites exhibit a Type II survivorship curve (Haskins and Herrmann 1996), which is to say that the occupants of those sites were perceived to face constant selective pressure throughout the full term of their lives. This selective pressure was apparently highest in the beginning of life among previously studied sites, where $20 \%$ of infants died before reaching one year in age at Indian Knoll, Carlston Annis, and Chiggerville (15Oh1; Powell 1996).

Among the SMA sites, Indian Knoll has been subject to the most research involving health and mortality; Cassidy (1973) and Kelley (1980) both utilized the site in attempting to measure patterns of changing health over time. Cassidy (1973) Identified high frequency of juvenile mortality at Indian Knoll, reporting that $44.6 \%$ of the 
population was deceased by the age of 17 , and the majority of those individuals dying by the age of 4. Kelley (1980) also identified high infant mortality in another sample of the same skeletal assemblage, reporting a life expectancy for Indian Knoll inhabitants of 19 years. Morbidity was also very prevalent in both assessments of the Indian Knoll assemblage. Cassidy (1973) identified linear enamel hypoplasia in $93.8 \%$ of juveniles, $90.4 \%$ and $86.0 \%$ of males and females respectively. Kelley (1980) identified evidence of rickets (vitamin D deficiency) in 7 cases $(n=345)$. With such strong evidence of malnutrition at Indian Knoll, Cassidy (1973) identified porotic cranial lesions in 31.7\% $(\mathrm{n}=90)$ of her sample $(\mathrm{n}=284)$. However, she declined to ascribe anemia to the porotic lesions observed, citing the gracile characteristics of the specific porosity she observed (Cassidy 1973). Kelley (1980) did identify porotic cranial lesions as porotic hyperostosis and cribra orbitalia in $3.8 \%$ of his Indian Knoll sample ( $\mathrm{n}=345)$.

Snow (1948) identified extremely high incidence of abscesses in a large subsample $(n=475)$ of sexually-identifiable specimens from the Indian Knoll (15Oh2) SMA skeletal assemblage. He identified the incidence of abscesses in males from that subsample to be an extremely high value of $68.94 \%(\mathrm{n}=182$ of 264$)$, and $54.98 \%(\mathrm{n}=$ 116 of 211) in identified-females within that representative subset. While Snow's methodology for assessing sexual characteristics is likely a source for demographic error, the identification of abscesses is a straightforward affair. Abscesses are formed by a loss of periodontal bone due to bacterial infection, which can be the result of trauma, heavy macrowear, or most frequently caries (Aufderheide and Rodriguez-Martin 1998). Larsen (2000:41) succinctly describes caries as "a disease process characterized by the progressive destruction of teeth by acids produced by bacterial fermentation of 
carbohydrates, especially sugar.” Both caries and abscesses are easily identified in osteological specimens, as the pathologies produce distinctively bound voids in teeth and bones, respectively.

Beyond caries and abscesses, Snow identified a cranial pathology prevalent among a large grouping of Early Woodland skeletal remains which he described as osteoporosis symmetrica (an older name for porotic hyperostosis): "the curious pinhole-like appearance of the outer surfaces of the brain case, the parietal and occipital bones in particular, is interpreted as evidence of osteoporosis symmetrica" (Webb and Snow 1974:274). He noted porosity on the outer surface of the cranial vault, but also mentioned, without going into detail, observing porous lesions on the "bases of the great wings of the sphenoid" (Snow 1948:498). Snow also found cribra orbitalia in subadult specimens (Webb and Snow 1974). Even as early as the 1940's, he postulated that the occurrence of these porotic alterations were "evidence of some kind of dietary deficiency" (Snow 1948:498). Specific statistics for the incidence of these pathologies, however, are not available from the original researchers. The first detailed accounts of these pathological bone alterations were reported by Cassidy (1976) and Kelley (1980), discussed previously.

\section{Shell Use in the Shell Midden Archaic}

The hallmark of the shell mound sites in the Archaic Period is the ubiquitous presence of fresh-water bivalve mussel shell (Unionidae) that comprises a bulk of the midden deposits from these sites. An early off-hand remark that occurs in Funkhouser and Webb (1928) suggested a high proportion of the shells excavated from these sites 
during the WPA era were recovered as closed pairs, with no sediment inside, implying that they were disposed of whole. This comment led to generations of researchers in the Green River Archaic to question the nature of and purpose for mussel exploitation. The questions that arose from Funkhouser and Webb's (1928) implication centered on whether or not the unionids were harvested for consumption.

Claassen (1996) as well as Morey and Crothers (1998) have addressed the issue of bivalve pairing, or the phenomena noted by Funkhouser and Webb (1928) of recovering mussel shells that had apparently never been opened. Morey and Crothers (1998) argued that one possibility for the frequency of finding closed valve pairs has to do with the strategy which was employed for their consumption: basically, the shellfish probably weren't cooked. The shells were pried open, some meat was extracted, and then the organism was discarded, allowing for it to close with the contraction of any residual tissue. Claassen (1996:134) observed that the likelihood of encountering closed pairs was increased with proximity to the water's edge. This suggests that the closed pairs of shells recovered archaeologically were selectively discarded. For Claassen, the level and fact of subsistence exploitation of fresh-water unionids remains an unanswered question.

The Green River watershed is home to the most diverse collection of fresh-water mollusks in the world (Claassen 2010). A few of the unionid species identified for the region are thought to be extinct, having only ever been seen in archaeological assemblages (Morey et al. 2002). Some of these extinctions might have been a result of historic modifications to the river channel. It has been suggested that the unionid species of the drainage are reasonably resistant to harvest pressure: fresh water mussel shell from the area has been harvested in historic times for numerous industries. These industries 
have scaled from cottage-level souvenir creation for visitors to Mammoth Cave and other nearby tourist attractions, to supplying the button industry, all the way up to international export operations supporting the Japanese cultured pearl industry after World War II (Claassen 2010). In 1959 and 1960, 3.5 million tons (3.2 billion kg) of freshwater mussel shell were exported to Japan from the nearby Tennessee River valley alone (Claassen 2010:53). There are numerous methods used to harvest mussel shells, but among the least efficient is hand collection, which Claassen (2010) suggests leaves 80 to 90 percent of a mussel bed population intact. When coupled with a fast population recovery rate, the inefficiency of hand capture suggests that Shell Midden Archaic populations would not likely have been exhausting their shellfish resources even if depending heavily on them for subsistence.

The modern Green River does not adequately reflect the contemporary habitat that its Archaic occupants would have recognized. Discharge volume, current velocity, sediment quality, and even water depth have all changed significantly as a result of historic impoundment activity that served the purpose of enhancing the river's navigability. The impoundments began in the $19^{\text {th }}$ century, with the construction of six locks and dams starting as far downstream as near the Green's confluence with the Ohio River. The first four locks and dams were operational by 1842, and Lock \& Dam 6 was completed in 1904 (Morey and Crothers 1998). Lock \& Dam 6 has failed recently and as of March 2017 is being demolished without plans for replacement. Lock \& Dam 5 is similarly slated for demolition. Additionally, dredging activities, most notably by the US Army Corps of Engineers, have served to deepen and widen the river channel for navigation purposes throughout the $20^{\text {th }}$ century (Morey and Crothers 1998). A typical 
target for dredging activity were the large, shallow shoals which served as rich habitats for freshwater mussels and ideal harvesting grounds for their terrestrial predators: most notably, humans.

Despite the significant alterations to the modern channel of the Green river, research has been conducted by Morey and colleagues (Morey and Crothers 1998; Morey et al. 2002) to reconstruct the prehistoric river environment using malacological data and pre-impoundment survey maps. The pre-impoundment map data indicated that "historically noted shallow areas were present in the general vicinity of the principal midden sites" (Morey et al. 2002:528). Even in the present day, heavily modified environment of the Green River, these shallow areas still produce substantive mussel populations (Morey and Crothers 1998). In identifying the species and subspecies present in the mussel shell assemblages at several shell midden sites, most notably Indian Knoll, Morey and colleagues (2002) were able to estimate the specific environment from which the various species comprising the assemblage were harvested. In the case of Indian Knoll, the mussel taxa suggested that the shell was harvested from "a swiftly flowing, shallow to moderately deep setting of the main river channel" (Morey et al. 2002: 548). Moderately deep in this case suggests somewhere between one and two meters.

The larger Green River was not the sole host of classic shell midden sites, nor was it the sole victim of historic waterway improvement practices. The Ward site (15Mcl11), located along Cypress Creek in nearby McClean County, is representative of non-Green River sites in both regards. A straight, 900 meter long drainage canal, built some time before the original WPA excavation, bypasses the bend of the creek where the site existed (Webb and Haag 1940). There is no record of impoundment projects occurring on 
the Cypress Creek waterway, historic or otherwise. However, Cypress Creek does deposit into the Green River (by way of the Pond River) upstream from Lock \& Dam 1 in Spottsville, Kentucky. As a result, it is not advisable to interpret prehistoric waterway activities based on the likely deeper, modern river channel. A series of five maximum stream flow and height measurements recorded by the USGS between 1979 and 1993 indicate that Cypress Creek is capable of reaching depths as deep as $4.3 \mathrm{~m}$ and attaining discharge as high as 2,100 cubic feet per second (USGS 2017). Considering that discharges as low as 30 cubic feet per second (cfs) are navigable by lightweight modern watercraft, depending on the size of the waterway, Cypress Creek was probably similarly navigable during occupation of the Ward site. As a maximum discharge level, $2100 \mathrm{cfs}$ is pretty low, which suggests that Cypress Creek is a normally shallow stream. The five maximum discharge volumes and stream depth measurements mentioned previously are the only quantitative data available for the entirety of Cypress Creek, and substantially less research has been devoted to assessing its suitability for particular mussel species.

The Ward site represents a point of contention in the ascription of a common subsistence strategy to the SMA cultural group. Principally, the relationship between the site's skeletal interments and its shell midden is not as clear as Indian Knoll, where the two deposits were comingled. Claassen (2010:48) has conjectured that Ward's location on what she describes as a bluff would preclude its function as a village site which was meant to exploit riverine resources from Cypress Creek below. The original WPA excavation block lies on the southwest facing slope of a bluff overlooking the creek, encompassing the peak at approximately 470 feet AMSL and continuing down the slope to 446 feet AMSL (Hermann 2002). The creek, by contrast flows just below 380 feet 
AMSL (USGS 7.5 Minute Quadrangle, O20). Far from being an arduous trek to the water's edge, however, the bluff's peak is an approximate 150 meter walk from the contemporary water's edge. There is little information available regarding the specific conditions in which mussel shell resources would have existed at the time of the Ward site's occupation. However, Ward is known to have included a significant portion of mussel shells in the site's midden, in contrast to the contemporaneous Kirkland site (15Mcl2) further downstream, which was reported to be a shell-free Archaic mortuary site (Webb and Haag 1940).

It should be clarified that some authors have stated unambiguously that shell was a significant component of the Ward site's midden, with deer and shellfish dominating the faunal assemblage as reported from the initial WPA investigation (Pedde and Prufer 2001), while a great many others have unequivocally labelled it as a shell-free or low shell site (Marquardt and Watson 2005; Herrmann 2002; Hensley 1991; Claassen 2010). Claassen argues that the location of the Ward site indicates that mollusk harvesting was an ancillary concern to Ward's inhabitants (2010), an idea which others have denounced explicitly (Morey et al. 2002; Morey and Crothers 1998). It has been noted that the site was not entirely shell free in later re-excavations, but that unlike many of the other shell middens in the region, the majority of shell debris was deposited at the base of the bluff instead of directly on the burial field. Morey and colleagues (2002), reported that many of the mussel species that were recovered from test excavations at Indian Knoll (15Oh2) would have been preferentially found in water depths of a meter or less, conditions which are likely to mirror Archaic Period water levels of Cypress Creek. 


\section{Diet and Nutrition}

Nutritional information on fresh-water bivalves is not readily available, since they are largely disregarded as edible resources today. A few rare analyses have been done, however, to determine what quality of subsistence resource mussels provided in the past by analyzing living samples. Nutritional analysis of two species of fresh water shellfish (Megoalonaias gigantea and Amblema costata) revealed that they are comprised of roughly 8 to $9 \%$ protein by weight, and have a caloric value relative to weight of roughly $60 \%$ of the calorie and protein rich white-tail deer (Parmalee and Klippel 1974:431). Parmalee and Klippel (1974) contend that this fact goes so far as to suggest that the shellfish represent a supplemental subsistence supply instead of primary resource. Assuming a modest diet of 2000 calories per day, those authors estimate that a village the size of Indian Knoll, supposing approximately 100 inhabitants, would require between 228,00 and 270,000 individual mussels per month if they were being exploited as the sole dietary resource (Parmalee and Klippel 1974:433).

Vertebrate fauna were likely the most vital component of the Archaic subsistence strategy. SMAP investigations at Carlston Annis yielded an exhaustive list of the fauna exploited and their relative importance in the site's subsistence strategy, as reported by Crothers (2005:313): “in decreasing order of NISP [number of identified specimens], white-tailed deer, freshwater drum [Aplodinotus grunniens], tree squirrels [Sciurus sp.], box turtle [Terrapene carolina], catfish [Ictaluridae], musk turtle [Sternotherus odoratus], rabbit [Sylvilagus sp.], raccoon [Procyon lotor], wild turkey [Meleagris gallopavo], and softshell turtle [Apalone sp.] are the most numerous food species 
represented." All of these faunal resources represent sources of dietary iron, as well as vitamin B12, both of whose deficiencies are routinely compounded (Steyn et al. 2016).

The prevalence of dental abscesses, in the case of Archaic Period hunter gatherers known principally to rely on deer and riverine meat resources, represents the diversified subsistence strategy employed by the shell midden inhabitants. Nuts, in particular acorn (Quercus sp.), and hickory (Carya sp.) were identified in flotation samples from Carlston Annis, with evidence for acorn's contribution to the diet increasing over time (Crawford 2005:203-204). Marquardt and Watson (2005) have suggested that these two nut species played the largest role in the overall SMA diet outside of deer meat. Also identified among the plant food remains from Carlston Annis were the seeds of fleshy fruits such as blackberry (Rubus sp.), grape (Vitis sp.), honey locust (Gleditsia tracanthos L.), and persimmon (Diosporos virginiana L.; ibid:182). Harvesting of these wild plant species was also likely a significant contribution to the diet of shell midden populations, providing the carbohydrates that help to explain the high rates of caries and abscesses (observed by Snow 1948) not typically associated with hunter gatherers. Crawford (2005) recognized that many of these exploited plant species thrive best in disturbed soil and managed forests, suggesting that the shell middens served as early proving grounds for horticultural subsistence practices in the eastern woodlands.

One of the subsistence methods not included in this suite of resources is domesticated plant materials, which were long thought to be part of the Shell Midden Archaic adaptive strategy. Patty Jo Watson's research into the human utilization of Salts Cave offered tantalizing evidence that Archaic occupants of the Green River Region were utilizing domesticated plant resources, particularly Cucurbita pepo variety ovifera 
identified from paleofeces by Richard Yarnell (Watson and Yarnell 1969). Crawford (2005:204) lists the domesticates left behind by the horticulturalists at Salts Cave as amaranth (amaranthus sp.), maygrass (Phalaris caroliniana), ragweed (Ambrosia sp.), blueberry (Vaccinium sp.), sumac (Rhus sp.), pokeweed (Phytolacca americana), gourd (Cucurbita pepo), and sumpweed (Iva апnиa var. macrocarpa). The popular idea was that the flood plain occupations of the Shell Midden Archaic offered fertile territory for early populations to experiment with wild plant cultigens (Marquardt and Watson 2005). This speculation even led some researchers to refer to the Green River shell midden populations as horticulturalists. However, the SMAP project was unable to detect any such residue in the midden of Carlston Annis, and the directors of the project concluded that the ascription of horticulturalism in the Green River Archaic was likely wishful thinking (ibid.). The Archaic assemblages in the shell midden sites, predating the Early Woodland Salt's Cave occupation, were devoid of evidence of these early domesticates (Crawford 2005). 


\section{CHAPTER 3: RESEARCH OBJECTIVES AND HYPOTHESIS}

The primary objective of this study was to assess porotic hyperostosis and cribra orbitalia in a context outside of the traditional model for health deterioration in the transition to agriculture: namely, the Shell Midden Archaic (SMA). Pursuit of this primary objective allowed this study to additionally address other lines of inquiry, including:

1. assessing the frequency and severity of porotic hyperostosis and cribra orbitalia in a population where they have not been extensively studied previously

2. examining the influence on differential mortality on porotic hyperostosis and cribra orbitalia in the SMA

3. and, re-evaluating the possible etiology or etiologies of porotic hyperostosis and cribra orbitalia in the specific dietary context of the SMA

Such objectives feed the dual purposes of contributing specific research about an understudied population representing a distinct cultural group and time period in American prehistory, while also enabling that population's participation in larger scale examinations of the history of human health.

It is generally assumed that the transition to agriculture had deleterious effects on human health (for in-depth discussion of these patterns, see Larsen 2000; Cohen 1989; Kent 1986; El-Najjar et al. 1976), typically focusing on nutrient disruption due to reliance on monoculture subsistence activities. This pattern was argued for based on skeletal 
evidence observed from maize-dependent populations of late-prehistoric and colonial North America and the populations that preceded them in the same areas. Chief among the lines of skeletal evidence employed by this model are porotic hyperostosis and cribra orbitalia, which in many classic archaeological texts is conflated with iron deficiency anemia (Stuart Macadam 1985, 1987, 1992; El-Najjar et al. 1976; Kent 1986; Cohen 1989; Larsen 2000). Rather than the traditional model of diminished health as a result of the adoption of agriculture and settlement aggregation, the Late Archaic in Kentucky likely represents a unique case. Using porotic hyperostosis and cribra orbitalia as indicators of dietary health as has been done in other cases will show that the health of the non-agricultural, non-aggregated SMA populations was already suppressed.

\section{Assumed Health Patterns: a Prediction}

Where the SMA populations diverge from the traditional model of health decline after agricultural transition is likely a result of the conflation of porotic lesions with dietary iron deficiency anemia. The problems with this assumption have been discussed by numerous authors in recent decades (see Chapter 1), but can be summarized in the argument that dietary iron deficiency in not the sole cause of marrow hyperplasia (StuartMacadam 1992; Walker et al. 2009; Rothschild 2000; Oxenham and Cavill 2010; Schultz 2001). This study was not meant to question Cohen (1989) and Larsen's (2000) entire models, rather as a re-evaluation of one of the tools employed by those models: porotic hyperostosis and cribra orbitalia as indicators of health.

It was predicted at the beginning of this study that analysis of porotic hyperostosis and cribra orbitalia in SMA populations would reveal a higher frequency of the 
pathologies than would be anticipated by the agricultural transition model. After all, Charles Snow (Webb and Snow 1974) had already identified porotic hyperostosis and cribra orbitalia in the SMA populations, though his original analyses are severely dated. Given the robust and heavily diversified subsistence strategy employed by Archaic hunter-gatherers inhabiting shell midden sites, malnutrition would not represent a significant stimulus for the etiological stimulation of marrow hyperplasia. Iron and vitamin B12 are readily available in both the terrestrial and riverine animal resources that constituted the bulk of the Archaic subsistence strategy, ruling out both dietary iron deficiency and dietary megaloblastic anemias as etiological stimuli for osteological pathology. Parasitic infection is a more likely candidate to explain any observed instances of porotic hyperostosis and cribra orbitalia among shell midden populations, which similarly does not concur with models of health and settlement aggregation (Kent 1986; Cohen 1989).

\section{Observed Health Patterns: Differential Mortality}

This study also assessed the influence of porotic hyperostosis and cribra orbitalia on differential mortality in the SMA. When viewed through the prism of Wood's (1992) Osteological paradox, porotic cranial lesions represent an adaptive response to negative environmental stimuli. Whether the stimulus is dietary deficiency of iron or Vitamin B12, or blood loss and iron-withholding due to pathogenic or parasitic infection, the body responds by augmenting production of RBCs. From this perspective, the intensity of the adaptive response might correlate with the extent of porotic distribution on afflicted crania. A lack of the pathologies would indicate either a failure to initiate a totally 
ineffective response and rapid mortality or the absence of stimulus. To the opposite extreme, substantial expression of porotic hyperostosis and cribra orbitalia would suggest extreme stimulus, and will likely be associated with premature mortality. Moderate pathological expression is expected to correlate to enhanced survivorship compared to the alternative adaptive responses. 


\section{CHAPTER 4: MATERIALS AND METHODS}

\section{Site Background}

To explore these questions, the analysis at hand will utilize a large skeletal collection derived from a Late Archaic village site in Western Kentucky. This site was excavated at the direction of William Webb under the auspices of the Works Progress Administration (Pedde and Prufer 2001). Webb's excavations were massive undertakings that contributed similarly scaled archaeological assemblages providing substrate for decades of analysis. While these sites were documented well beyond contemporary standards, "this does not obviate the fact that by modern standards they are defective" (Pedde and Prufer 2001:60). The contextual inadequacies of the WPA assemblages, fortunately, can be somewhat overcome by the overwhelming sample sizes that they yield.

The specific Archaic site utilized in this project is Ward (15Mcl11), a large, Middle Archaic shell midden and village site (6700-4500 cal BP, Herrmann 2002:55) located in the alluvial flood plains of the Green River drainage and part of the same complex of SMA sites as Indian Knoll (15Oh2, Pedde and Prufer 2001; Webb 1946; Webb and Haag 1940). John B. Elliot, a geologist at the University of Kentucky in Lexington, led field work on the site beginning 22 February, 1938 and concluding excavations on 20 September of the same year. While eight months may not seem like a lengthy amount time to excavate a large site, federal relief archaeology projects could sometimes be conducted by crews of 60 men (Lyon 1966). In that amount of time, Elliot 
reported clearing 16,200 $\mathrm{ft}^{2}\left(1,505 \mathrm{~m}^{2}\right)$ of the site from surface "to hard pan" (Webb and Haag 1940:71).

Ward was described as a village and cemetery site in the original site report (Webb and Haag 1940), and further evaluations have only reiterated and developed that description (Pedde and Prufer 2001). The excavated site, generally, consists of a thick cultural midden with intrusive burials. Stratigraphy in the midden was not clearly recognized by the original excavators, suggesting a continuous occupation of the site (Webb and Haag 1940; Pedde and Prufer 2001). Recovered from within the dark, brown, clay loam of the midden were faunal remains, fire debris, shell, 433 burials, and 61 nongrave features. These features included fire hearths, caches of mussel shell, caches of mortars, pestles, and hammerstones, and debitage pits (Webb and Haag 1940). Aside from the burials, the midden reflects the predominantly domestic and economic functions of the site as an occupational locale.

Material culture collected from the Ward Site consists largely of the durable remains of subsistence, such as approximately 580 stone projectile points, and an unreported number of bone or antler projectile points (Pedde and Prufer 2001; Webb and Haag 1940). The lithic assemblage of Ward is very much in keeping with other SMA sites, consisting mostly of stemmed and side notched points. Ward's occupants are thought to have primarily hunted using atlatl, evidence of which was recovered directly from several burials at the site (Webb and Haag 1940; Marquardt and Watson 2005). Additionally, the site yields significant evidence of hide production in the form of heavily worn hafted endscrapers $(n=586)$ and thumbnail scrapers $(n=119$, Pedde and Prufer 2001). Also recovered were a large number of flaked stone drills $(\mathrm{n}=201)$ which were 
likely used in hide and ornament production, as evidence by shell and bone beads which were identified as personal ornamentation among burials at the site. Also of apparent importance was food processing in the form of ground stone pestles $(n=216)$, most frequently associated with crushing and grinding hickory and acorn both at Ward and throughout the SMA sites in the region (Pedde and Prufer 2001; Marquardt and Watson 2005).

Burials at the Ward site are directly inserted into the domestic space. Pedde and Prufer (2001) surmised that "burials intrude upon the living spaces... the relationship between the dead and the living was a close one and that there is no segregation of living spaces from burial spaces" (Pedde and Prufer 2001:74). Webb and Haag (1940) argued that there was no general pattern to the distribution of inhumations. They observed that there were no surface markers to indicate the locations of graves, and that later burials would frequently overlap and intrude into previous burials. In some cases older burials were completely removed, and the skeletal remains would either be mixed in with the backfill of the grave feature or on occasion piled in with the new burial.

Most burials in the Ward assemblage were interred in the fully flexed $(n=188)$ or partially flexed $(n=49)$ position in shallow, round pits which were typically just large enough to deposit the human remains. The original WPA excavation also recovered 26 individuals buried in the extended position. The original excavators did not classify the burial context of the 90 individual infant burials (Webb and Haag 1940). These graves most typically involved isolated individuals, but some pits contained multiple individuals, including two separate graves of groups of five individuals who were identified to have perished by violent means. In the Ward sample, one of these graves included three 
separate individuals with weaponry embedded in the skeletal remains (Webb and Haag 1940). Evidence of this type of violence was prevalent in the Ward site (Mensforth 2001), but also more broadly throughout the SMA sites (Mensforth 2005; Marquardt and Watson 2005).

The Ward skeletal sample was originally briefly described by Webb and Haag (1940). In that publication the authors promised forthcoming paleopathological and paleodemographic analysis on the sample in question. That analysis, however, was never published. The first real demographic analysis of the assemblage was conducted by Meindl and colleagues (2001). Those authors identified a high juvenile mortality rate, with only $61 \%$ of individuals surviving to age 15 . From there Meindl and colleagues (2001) identified differential survival between males and females, with females living five-years on average more than males from the age of 15 . Overall, those authors estimated an average life expectancy for Ward site inhabitants at being somewhere in the mid-twenties (Meindl et al. 2001). Similar demographic profiles have been observed among other SMA populations, such as Indian Knoll (15Oh2, Cassidy 1973) and Carlston Annis (15Bt5, Mensforth 2005).

The Green River basin, which is the home to Ward and associated SMA populations such as Carlston Annis (15Bt5, Watson and Marquardt 2005) and Indian Knoll (15Oh2, Webb 1946), was home to large scale shell midden occupations that utilized fresh-water mussel shell and other riverine resources for subsistence exploitation. The Ohio River basin experienced remarkably similar occupation strategies employed by contemporaneous hunter gatherers in the region, such as the Clarksville (12Cl1) and Hornung (15Jf60) Shell Mounds in the Falls of the Ohio River region near Jefferson 
County, Kentucky (Janzen 2008); there is geographic overlap of these site types throughout the region.

In addition to exploitation of freshwater mussel resources, sites in the Shell Midden Archaic are known for their heavy reliance on O. virginianus. Similarly, Webb and Haag (1940) report that $60 \%$ of the surface collected faunal remains retrieved from Ward were attributed to the same species. Unfortunately, in both cases, unless worked into artifacts, all recovered faunal remains were destroyed at some point by curators of the shell midden collections at the University of Kentucky and sold as fertilizer, preventing any sort of harvest pressure analysis (for example, Wolverton 2008) that might substantiate the presumed importance of $O$. virginianus in the Archaic diet.

\section{Skeletal Assemblage}

The assemblage from the original WPA excavation, dated February to September 1938 (Meindl et al. 2001), is curated at the William S. Webb Museum on the campus of the University of Kentucky, in Lexington. The assemblage is made available for academic research by the Office of State Archaeology, under the direction of State Archaeologist Dr. George Crothers. The museum curates the skeletal remains of 434 individuals (433 according to Meindl et al. 2001; Webb and Haag 1940) disinterred from 15Mcl11 by the WPA's excavation. The remains from Ward were reported in excellent condition of preservation, which permits rigorous analysis.

This study does not utilize the entire assemblage, but a representative 25 percent sample. This sample was not a random sample: selection of individuals for analysis was based on three criteria. First, in order to avoid overrepresentation of any specific portion 
of the site (Figure 7), one individual of every four sequentially labeled individuals was chosen for analysis. Second, of each set of four sequential individuals, one would be chosen on the basis of preservation. Particularly, the author was concerned with cranial preservation in all individuals, so as to facilitate the identification and description of cranial pathologies. Additionally, adult specimens that retained portions of or complete innominates were selected preferentially to enable demographic assessment of the remains. Third, with those primary considerations treated, individuals were chosen to prescribe to the demographic distribution identified in Meindl and colleagues' (2001) paleodemographic analysis of the assemblage. For instance, the assemblage was found to consist of 30.8\% children below the estimated age of five (Meindl et al. 2001: 93), so this study's sample attempts to approximate that $30.8 \%(\mathrm{n}=33$ ) makeup of juveniles identified to be under the age of 5. In this way the tested sample approaches a demographically representative assembly of both age group and estimated sex. However, considerations of preservation precluded both of these criteria.

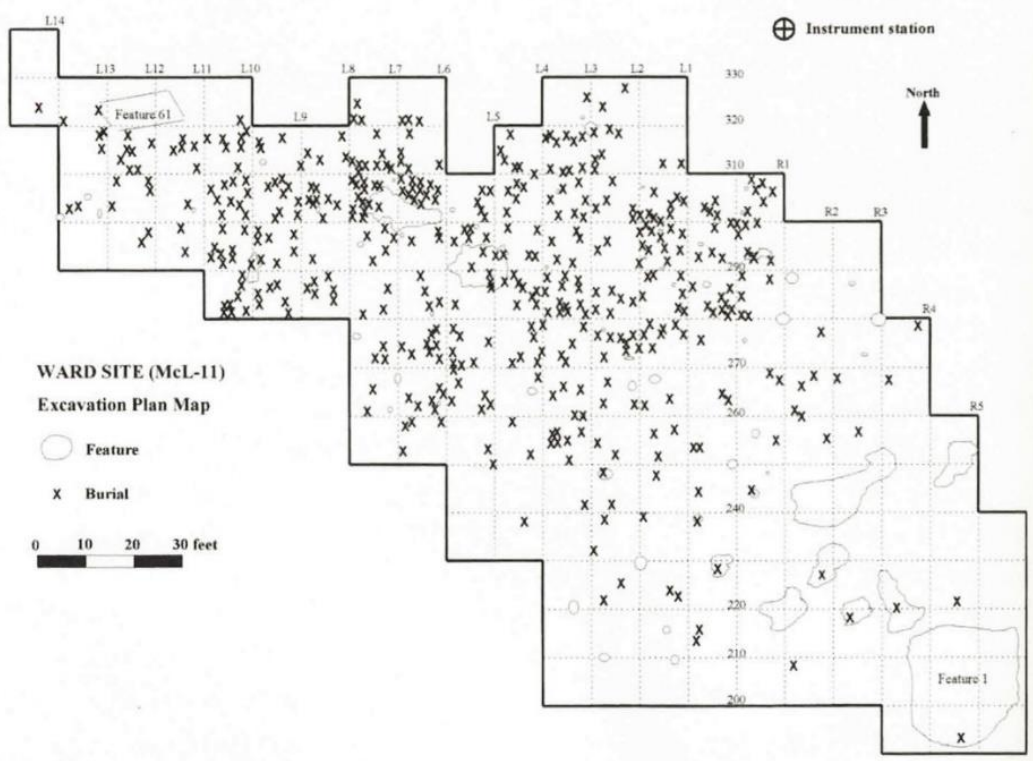

Figure 7 Ward Site Excavation Plan Map: plan view of the excavated portion of the site showing burial locations, adapted from John Elliot's field notes and reproduced here from Pedde and Prufer (2001). 


\section{Osteological Analytical Methodologies}

This study does not rely on paleopathological data collected and presented in early research for any of its analysis (for example: Snow 1948; Webb and Snow 1974), but instead reassesses skeletal remains from Ward to ensure a consistency and accuracy of data. There is significant cause for this reanalysis in the case of anemia, as it was not associated with osseous manifestations until well after the period of initial research in these collections (Angel 1966; Aufderheide and Rodriguez-Martin 1998). Demographic analysis from these earliest studies will be similarly discounted. In the case of nearby Indian Knoll (15Oh2), which was analyzed originally by Charles Snow (1948), the researcher identified eight crania of his 512 individual sample as belonging to the "'Negroid' type," and an additional two individuals as standing out due to "their 'white' traits" (Snow 1948: 420). The Ward site's demographic data was reevaluated much more recently with modern methodologies (Meindl et al. 2001), but was not utilized, as raw data pertaining to individuals was not available. Therefore the sample required all categories of relevant assessment to be performed. The author assessed sexual characteristics of the sample in adherence to Buikstra and Ubelaker (1994), analyzing non-metric characteristics of crania and innominates of all adult specimens where available. Preference was given to the pelvic characteristics over those observed in the cranium whenever disagreement between the two occurred. Sexual assessment of juveniles was not attempted.

The author also reassessed age-at-death estimations for the Ward sample. As stated previously, the demographic makeup of Ward's assemblage has been studied in the past, analyzing the auricular surface of the ilium as the singular method for estimating 
adult age-at-death (Meindl et al. 2001). This study utilizes transition analysis applied to skeletal markers in order to generate age-at-death estimations. Transition analysis utilizes a total of 19 markers on three loci in the body: iliac auricular surface (similar to Meindl et al. 2001), pubic symphysis, and cranial suture closure (DeWitte et al. 2015; Milner and Boldsen 2013). The ADBOU (Anthropological Database, Odense University) 2.1 Age Estimation software (a free-standing component of ForDisc) was used to calculate age-atdeath for all of the individuals in both samples to promote compatibility of data for statistical analysis. Transition analysis utilizing ADBOU provided point age estimates that can be utilized readily for statistical analysis (DeWitte 2014).

Subadult ages were estimated on the basis of several criteria. Fetus and Infant ages were estimated based on seriated diaphyseal lengths of long bones reported in Schaefer and colleagues (2009) publication on juvenile osteology. Measurements from the Ward assemblage were obtained by the author utilizing a mechanical sliding caliper and osteometric board. For this experiment, infants are defined as children not exhibiting evidence of limited dental eruption, estimated to be under approximately one year in age at death (Ubelaker 1979). Ages of older children were estimated on the basis of a combination of dental eruption (after Ubelaker 1979), epiphyseal appearance and fusion, and when other criteria have been exhausted, seriated long bone length (after Schaefer et al. 2009). These data provide likely age ranges for individuals. In order to obtain point estimates of age for statistical application, midpoints of these juvenile age ranges were used (after DeWitte et al. 2015). For example, UKMA 12-379, which was estimated to have an age at death between seven and 10 years, was assigned a point age estimate of 8.5. Any individual who is estimated to have an age less than or equivalent to 40 
gestational weeks will be assigned a point age of 0 in order to avoid complications with statistical analysis. The implementation of this procedure dictates that all age-related patterns presented in subsequent portions of this report are derived from these composites, and sufficient error surrounding them will be allowed for.

\section{Pathological Analysis}

The specific pathologies to be examined in this project are porotic hyperostosis, and cribra orbitalia. Both of these pathologies are regularly identified by "small holes of varying size and distribution that penetrate the outer compact bone of the skull" (StuartMacadam 1992:39). This paper will routinely refer to the manifestation of these pathologies as "porosity." Numerous arguments have been made to group both pathologies under the shared name of porotic hyperostosis, because of a presumption of shared etiology of anemia (for example, Stuart-Macadam 1989; Goodman and Martin 2002). Pursuant to a multitude of more recent studies suggesting a plethora of differential etiologies for both cribra orbitalia and porotic hyperostosis (see Walker et al. 2009; Wapler et al. 2004; Rothschild 2012) this paper will treat them as separate pathologies, if for no better justification than to maintain terminology to separate vault from orbital lesions, and further will utilize the data generated by this analysis to test that proposed relationship. 
Diagnosis of porotic hyperostosis in

the Ward assemblage was based on the macroscopic observation of porosity in the surface of the outer table of the frontal, parietals, and occipital. Evidence that was regarded as pathognomonic of hyperostosis ranged from scattered, fine porosity (after Stuart-Macadam 1985, see Figure 8) to

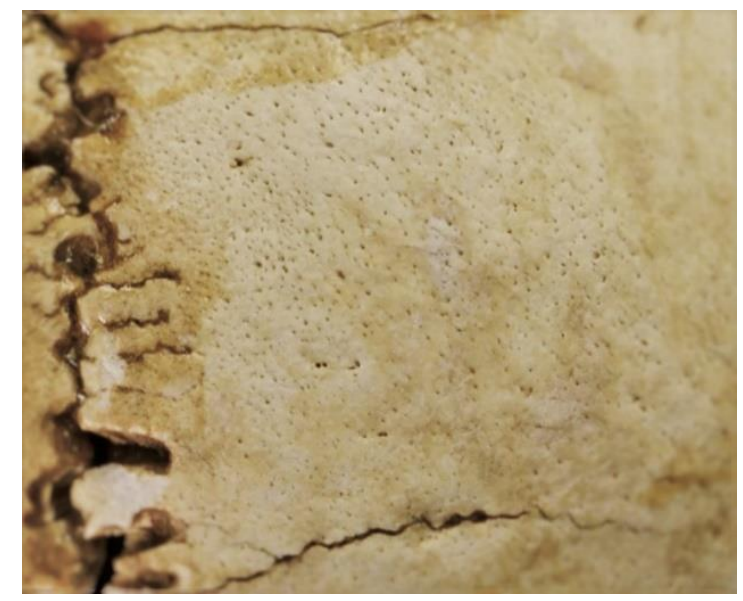

Figure 8 Scattered fine porosity on the right parietal of Ward (15Mcl11) specimen, UKMA 12-434. Photo by the author.

trabeculation of the outer table surface (Figure 9). Distribution of porosity on these four cranial elements was mapped in an effort to identify any possible relationship between porotic distribution and age at death. Diagnosis of cribra orbitalia is similar in that porosity was utilized as the primary indicator of pathology. Classification of a sample as positive for cribra was based at a minimum on the presence of porosity in the superiorlateral orbital wall (after Cook 1976). The maximum expression expected from orbital lesions would be represented by "outgrowth in trabecular structure from the normal contour of the outer bone table" (Stuart-Macadam 1985:392). In every case where either porotic hyperostosis (vault porosity) or cribra orbitalia (orbital porosity) were observed, either in isolation or combination, the distribution and observed size of porosities were 
recorded via hand drawing on a standard form created for this project from imagery reproduced from Buikstra and Ubelaker (1994, see Appendix 1).

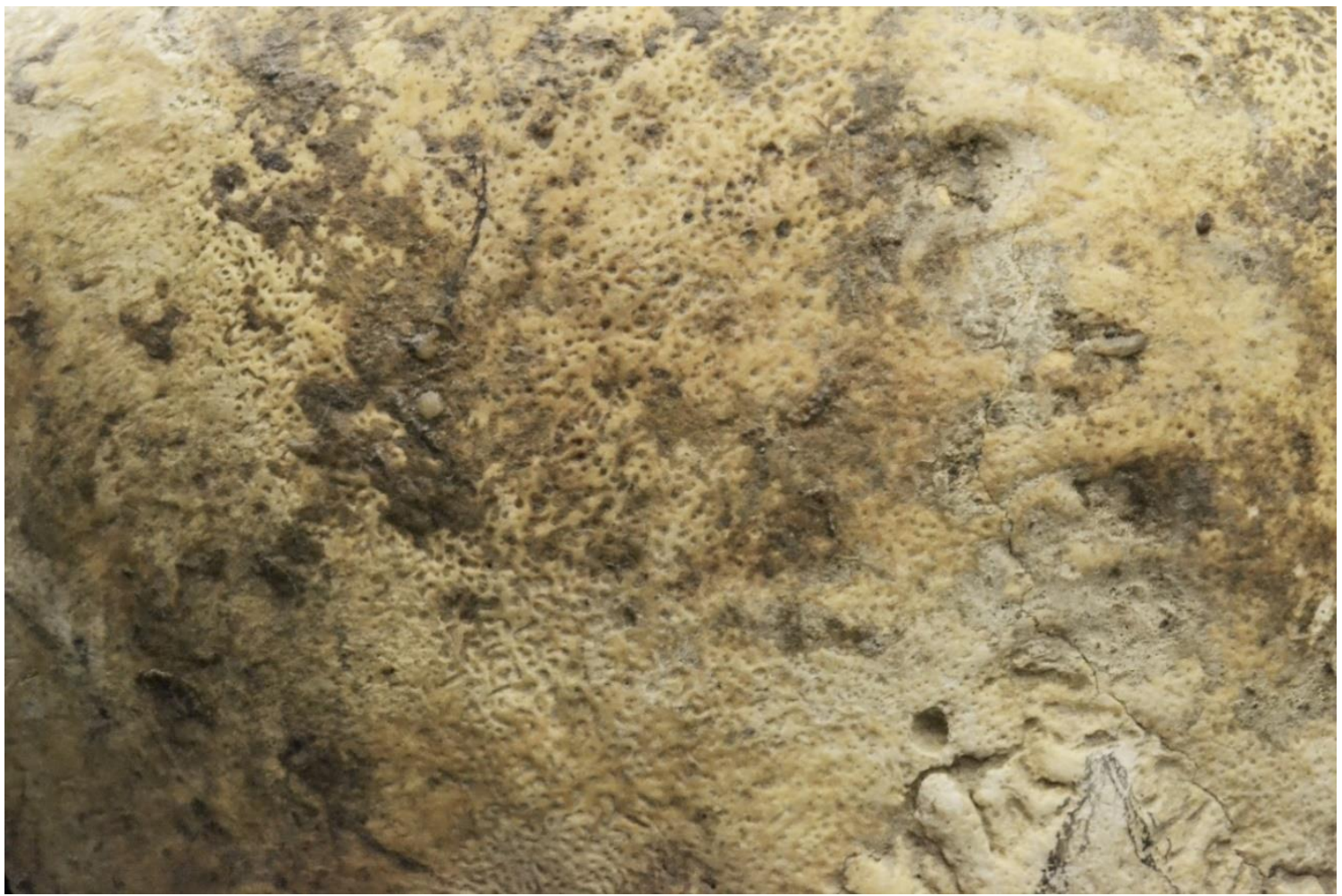

Figure 9 Hypertrophic expression of trabecular bone in an individual (UKMA 12-354) from the Ward (15Mcl11) skeletal assemblage. Photo by the author.

These features are traditionally associated with extranormal production of red blood cells (RBCs) in the flat bones of the skull in hypoxic conditions. There are numerous proposed and debated stimuli associated with augmented RBC production, as well as alternative explanations for the pathologies regularly identified as porotic hyperostosis; these will be discussed in depth later in this paper. Stimulating heavy production of red blood cells in cranial flat bones results in the expansion of the trabecular bone (middle table, or diploe), which in turn undermines and expands through the outer table of bone in a process known as marrow hypertophy (Stuart-Macadam 1989). The result is an exposure of trabecular bone and a characteristic "porous" appearance (Aufderheide and Rodriguez-Martin 1998,; Stuart-Macadam 1985, 1987, 
1989). The skull is not the only locus of red blood cell production: the medullary cavities of long bones are typically more responsible. However, the identification of irondeficiency anemia within the proposed test populations will be limited to cranial evidence because it does not require the destruction of archaeological materials or cost-prohibitive radiographic imagery to test for its presence as in the case of long bone manifestations of marrow hypertrophy. Because the assessment of pathology in this project is based on exposure of the trabecular surface of bone in individuals from an over 6000 year old assemblage, great care was exercised in identifying postmortem erosion of the outer table of bone to obviate misdiagnoses of porosity as a consequence.

\section{Statistical Analysis}

The impact of the presence and distribution of porous cranial lesions on survivorship in the Ward assemblage was tested using Kaplan-Meier survival analysis in several different configurations (after DeWitte 2014), performed using IBM SPSS version 22 . The survival curves produced by this analysis were assessed using a log-rank test (Mantel-Cox $X^{2}$ ). Impacts of multiple variables on survivorship in the Ward sample were measured using this method, including relative survival of individuals with various observed patterns of vault lesions, individuals with porotic hyperostosis, cribra orbitalia, or both in combination. 


\section{CHAPTER 5: RESULTS}

\section{Sample Demographic Makeup}

A total of 110 individuals were analyzed pursuant to the sampling strategy

discussed in Chapter 4. The number of observed individuals estimated to be under the age of five is equal to $33(30 \%)$, which very nearly approximates the $30.8 \%$ estimate identified by Meindl and colleagues (2001). Of that group, a large portion $(n=12,10.9 \%$ of the total sample) was composed of near-term fetuses and infants whose estimated ages centered around 40 gestational weeks. Meindl and colleagues suggested that $20.6 \%$ of the total assemblage were infants. Adults (individuals with an ADBOU estimated age of over 15 years) accounted for $51.8 \%(n=57)$ of the population, with the remaining $18.2 \%$ $(n=20)$ being comprised of children from ages 5 to 15 . A full distribution of ages in the assemblage can be seen in Table 2, and is illustrated in Figure $\mathbf{1 0 .}$

TABLE 2: Age and Sex Distribution in the Ward Assemblage

\begin{tabular}{r|cccc}
\multicolumn{1}{r}{ Point Age } & Male $(\%)$ & Female $(\%)$ & Sex Indeterminate $(\%)$ & Total $(\%)$ \\
\hline 0 & & & $12(10.9)$ & $12(10.9)$ \\
$>0-5$ & & & $21(19.1)$ & $21(19.1)$ \\
$6-10$ & & & $5(4.5)$ & $5(4.5)$ \\
$11-15$ & & & $10(9.0)$ & $10(9.0)$ \\
$16-20$ & $7(6.4)$ & $2(1.8)$ & $5(4.5)$ & $14(12.7)$ \\
$21-25$ & $9(8.2)$ & $3(2.7)$ & & $12(10.9)$ \\
$26-30$ & $6(5.5)$ & $3(2.7)$ & $1(0.9)$ & $9(8.2)$ \\
$31-40$ & $4(3.6)$ & $1(0.9)$ & & $6(5.5)$ \\
$41-50$ & $1(0.9)$ & $1(0.9)$ & & $2(1.8)$ \\
$51-60$ & $2(1.8)$ & $1(0.9)$ & & $3(2.7)$ \\
$61-70$ & & $4(3.6)$ & & $4(3.6)$ \\
$71+$ & $4(3.6)$ & $8(7.3)$ & & $12(10.9)$ \\
& & & & $110(100)$
\end{tabular}


Males outnumber females in the Ward sample 30.0 to $20.9 \%$, respectively. Sex was not able to be estimated in only one of the adult individuals (UKMA 12-58) as a consequence of poor preservation. All other members of the unidentified sex category were assessed as juveniles, and no attempt at sex estimation was made. Age composition of sex categories can be seen in Table 2 .

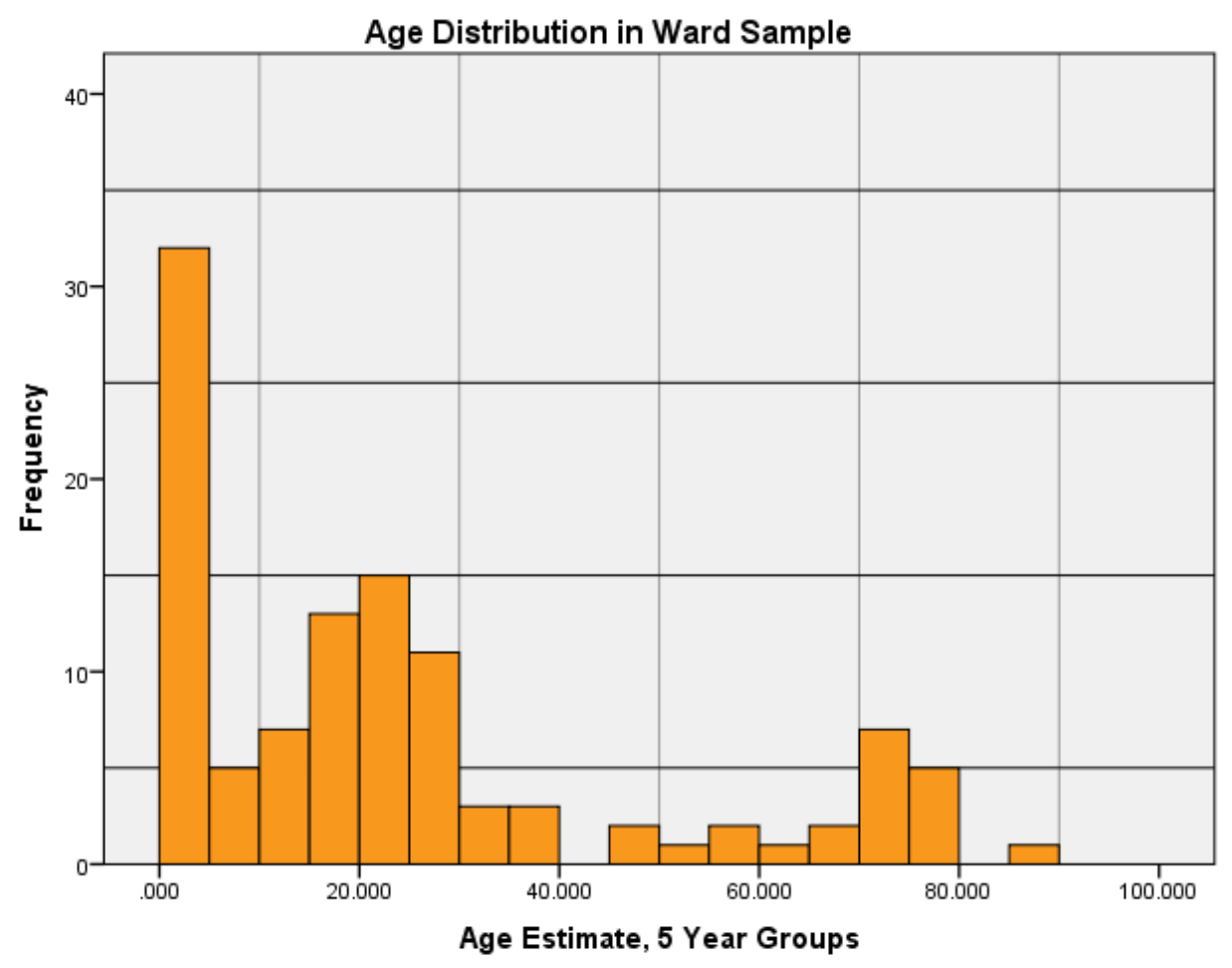

Figure 10 Representation of Ward Sample age distribution

\section{Porotic Expression}

Porotic Hyperostosis was the single most common pathological feature in the Ward sample crania. Of the 103 individuals from where valid cranial vault data could be retrieved, $90(87.4 \%)$ were observed to have some degree of porotic expression on the frontal, parietals, and/or occipital either as the only pathological condition $(\mathrm{n}=51)$, or in combination with cribra orbitalia $(n=39$, Table 3 ). The mean age associated with the 
former category was 27.1 years, while the mean age for individuals with both orbital and vault lesions was 29.1 years. The ranges for each of these categories are very broad, from 0 (near-term fetus/newborn infant) to 86.1 years and 1.25 to 78.8 years, respectively. In the case of the near-term fetus/newborn (UKMA 12-392) grouped into the porotic hyperostosis category, hypertrophic porosity was evident on the right frontal and was clearly distinguishable from the normal woven bone texture associated with children younger than one year (Ortner et al. 1999). Hypertrophic porosity is not typically identified with children under six months (Stuart-Macadam 1989). One additional individual (UKMA 12-50) under this six month age cap was observed to have vault porosity on both parietals. All individuals identified to have vault lesions exhibited porosity on both of the parietals (with the exception of UKMA 12-392, mentioned above). Porosity on the occipital and frontal were also typical. Severity of porosity varied from scattered, fine porosity (Stuart-Macadam 1985), typically associated with the frontal, to trabeculation of the outer table surface, seen most often on the posterior parietals.

TABLE 3: Porotic Expression Frequencies at Ward 
Orbital vault preservation was sufficient to test for cribra orbitalia (the roof of at least one orbital vault was observable) in $89.1 \%(n=98)$ of the sample. Of this portion, 43.9\% ( $n=43)$ exhibited porous lesions, vascularity, or both in at least one orbital roof. The co-occurrence of cribra orbitalia with porotic hyperostosis in the observable portion of the sample $(n=39,39.8 \%)$ was significantly higher than the occurrence of cribra orbitalia alone $(n=4,4.1 \%)$. All four of the individuals that displayed cribra orbitalia exclusively were juveniles, with a mean age of 3.5 years (max 4.75 years). By contrast, the mean age at death for the group of individuals with both orbital and vault porosity was significantly higher, at 31.8 years (in the scoreable subsample of 98 individuals), occurring in an age range of 1.75 to 78.8 years of age. None of the orbital lesions exhibited "outgrowth in trabecular structure from the normal contour of the outer bone table" (Stuart-Macadam 1985:392). Subjectively, the most extensive orbital porous activity observed in the sample was seen in UKMA 12-93 (Figure 11), a male estimated to be approximately 17 years old. This sample of orbital lesion activity illustrated extensive distribution of hypertrophic porosity, but still did not exhibit new bone growth. The condition of preservation of the left orbit (right side of image, Figure 11) is representative of the typical preservation observed in the rest of the sample.

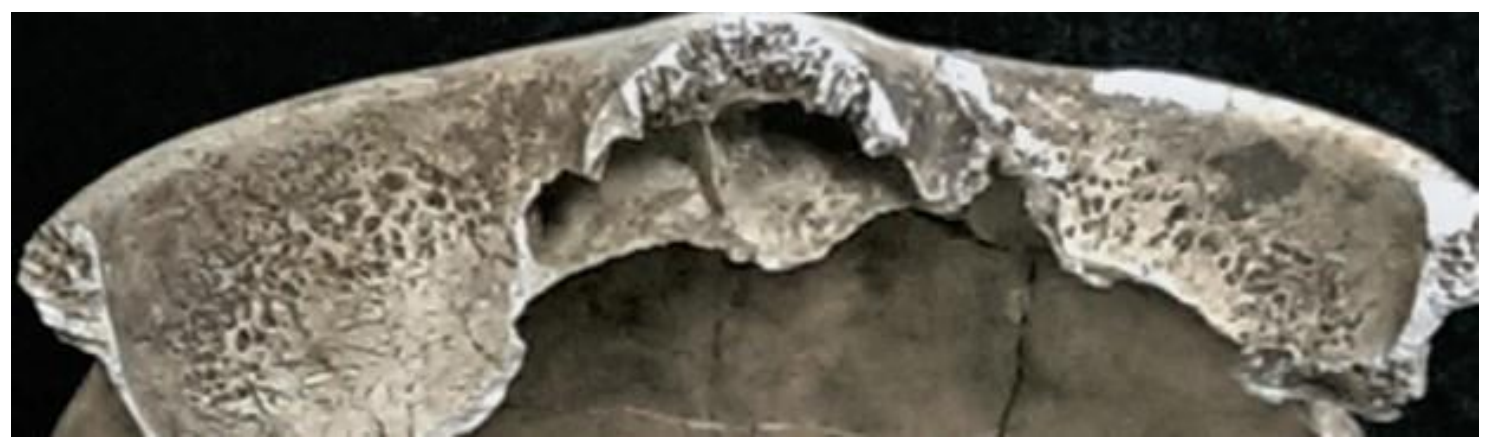

Figure 11 Bilateral orbital porosity in UKMA 12-93. Photo by the author.. 


\section{Porotic Distribution}

Four visibly distinct patterns of vault porosity were observed and recorded from the Ward sample. The distribution of porosity on the frontal, parietals, and occipital was recorded for each individual on the cranial map recording form (Appendix 1). These maps were created for all 110 individuals from the Ward sample. Of these 110, 20 (18.2\%) were not able to be scored, due principally to condition of preservation. Visual approximations of four of the observed patterns can be seen in Figures 12-15. A fifth category acts a catch-all for cases that did not exhibit any characteristic pattern (labeled "unpatterned," henceforth). There were six (6.7\% of the 90 measurable cases, Table 4) individuals assigned to this category. The oldest individual in this category was 18.30 years at death, though the other five were under the age of 6.00 (youngest at 0.12 years). In all categories, porosity did not extend laterally past the temporal lines (as visible from either the frontal or parietals), or posteriorly beneath the nuchal ridge. Anteriorly, porotic distribution was buffered by a non-uniform margin superior to the supraorbital tori.

The first of the identified patterns of cranial porosity from the Ward sample, referred to here as isolated orbital porosity (Figure 12), was identified as the presence of cribra orbitalia and no or very restricted (limited in both quantity and superficial in depth) porosity on the cranial vault. This pattern was identified in four cases $(4.4 \%$ of the 90 measurable cases, Table 4). The oldest individual in this category was estimated to be 4.75 years of age at death, with the youngest being 0.75 years. The mean age-at death for individuals in this category was 3.50 years. 


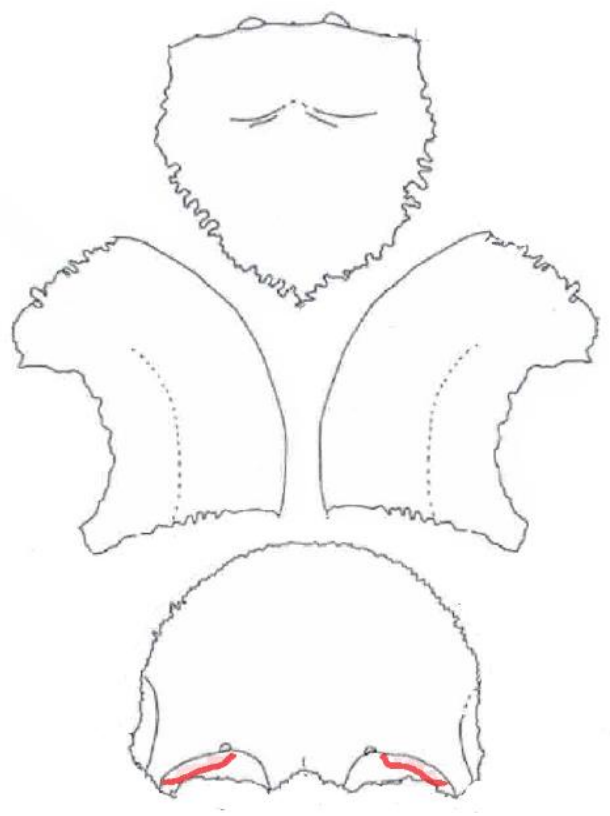

Figure 12 Representation of observed pattern of porotic lesions: isolated orbital porosity. Red areas represent observed distribution of porosity (element images adapted from Buikstra and Ubelaker (1994)).

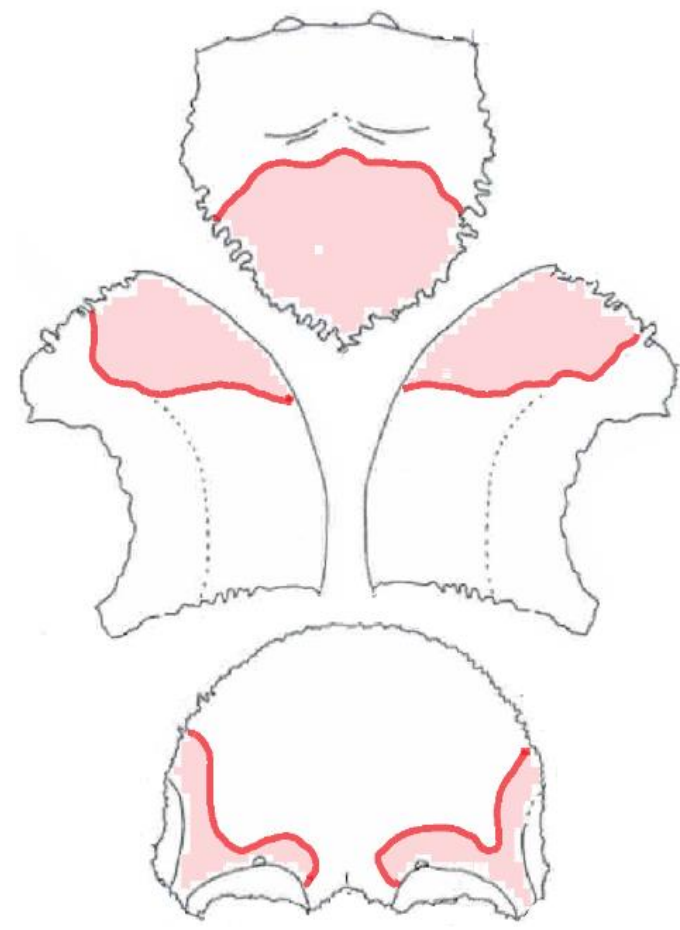

Figure 14 Representation of observed pattern of porotic lesions: lambdoidal concentration. Red areas represent observed distribution of porosity (element images adapted from Buikstra and Ubelaker (1994)).

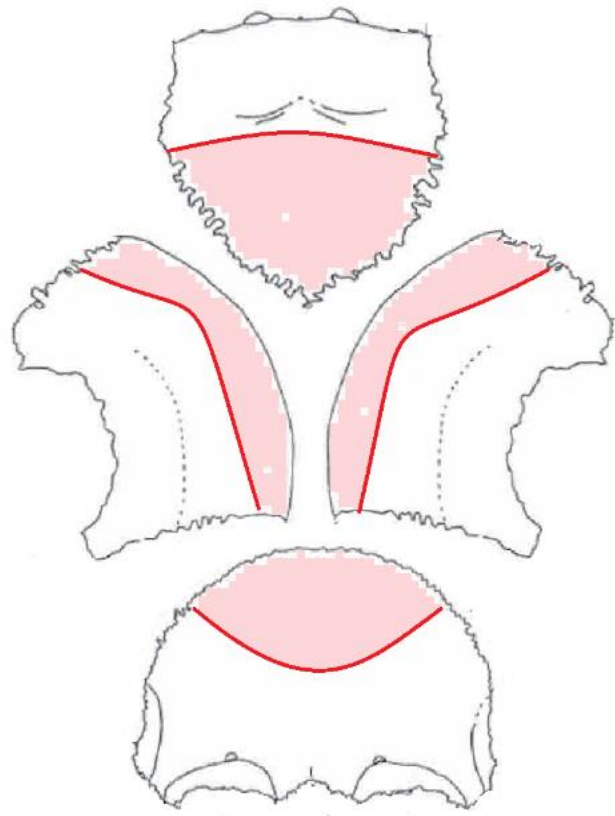

Figure 13 Representation of observed pattern of porotic lesions: sagittal concentration. Red areas represent observed distribution of porosity (element images adapted from Buikstra and Ubelaker (1994)).

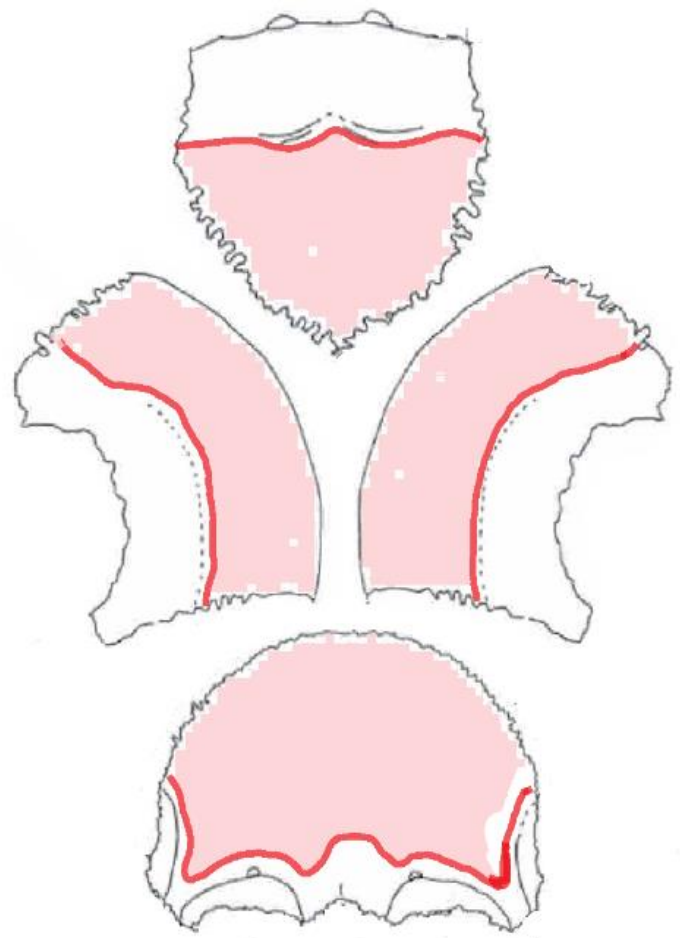

Figure 15 Representation of observed pattern of porotic lesions: full expression. Red areas represent observed distribution of porosity (element images adapted from Buikstra and Ubelaker (1994)). 
A second pattern identified in the Ward sample, referred to herein as sagittal concentration (Figure 13), was identified as the presence of hypertrophic porosity on both parietals, where its distribution concentrated along the sagittal suture, but did not extend laterally to the temporal lines. In all of the cases classified in this category, porosity was identified on both the frontal and occipital, though density and intensity of porosity for these elements was highly variable. Sagittal concentration was identified in 36 cases $(40.0 \%$ of the 90 measurable cases, Table 4$)$, and was the most common pattern observed in the sample. The range of point estimated age-at-death for this category was 3.00 to 79.80 years, with a mean age-at-death of 26.04 years.

Individuals that exhibited porotic distribution radiating from lambda, but discontinuing posterior to or near obelica, were identified as expressing a lambdoidal concentration of porotic lesion activity (Figure 14). Similar to sagittal concentration cases, all of these cases were observed to exhibit porosity on the frontal. However, the concentration (both in density and size) of porosity was observed on the outer table of the occipital, superior to the nuchal ridge, and bilaterally on the medial-posterior portions of the parietals. Lateral distribution of parietal porosity was limited in the most intensive cases by the temporal lines. Lambdoidal concentration was observed in 18 of the 90 observable cases (20.0\%, Table 4). Point estimates for age-at-death of individuals in this category ranged from 1.25 to 86.10 years, with a mean of 37.96 years.

The fourth pattern identified in Ward sample, referred to herein as full expression, was defined by continuous porotic distribution on both parietals, the frontal, and occipital (Figure 15). This pattern is primarily distinguished from lambdoidal and sagittal 
TABLE 4: Distribution Pattern Frequencies at Ward

\begin{tabular}{lcccc}
\hline & Male $(\%)$ & Female $(\%)$ & Juvenile $(\%)$ & Total (\%) \\
Sagittal & $15(46.9)$ & $7(30.4)$ & $13(38.2)$ & $36(40.0)^{*}$ \\
Full Expression & $16(50.0)$ & $6(26.1)$ & $4(11.8)$ & $26(28.9)$ \\
Lambdoidal & $1(3.1)$ & $10(43.5)$ & $7(20.6)$ & $18(20.0)$ \\
Cribra Orbitalia & $0(0)$ & $0(0)$ & $4(11.8)$ & $4(4.4)$ \\
Unpatterned & $0(0)$ & $0(0)$ & $6(17.6)$ & $6(6.7)$ \\
Total & $32(35.5)$ & $23(25.5)$ & $34(37.8)$ & $90(100)$
\end{tabular}

*Adult individual UKMA 12-58, whose sex was not estimated, accounts for the extra individual in this category

concentrations by the complete coverage of the outer surface of both parietals between the sagittal suture, medially, and the temporal lines, laterally. In all of these cases, complete coverage of the frontal and occipital were observed within the boundaries described above. Full expression was observed in 26 of the 90 observable cases $(28.9 \%$, Table 4), with ages ranging from 8.50 to 75.70 years. The mean age at death for full expression cases was 36.35 years.

\section{Kaplan-Meier Survival Curves}

The Kaplan-Meier survivorship curve for the entire Ward sample is illustrated in Figure 16. The expected likelihood of mortality is represented by the negative slope of the line. A steep slope approaching vertical represents an age of high mortality pressure, while slopes approximating a value of 0 represent low selective pressure on the population. Figure 16 illustrates very high selective pressure on infants in the population, 


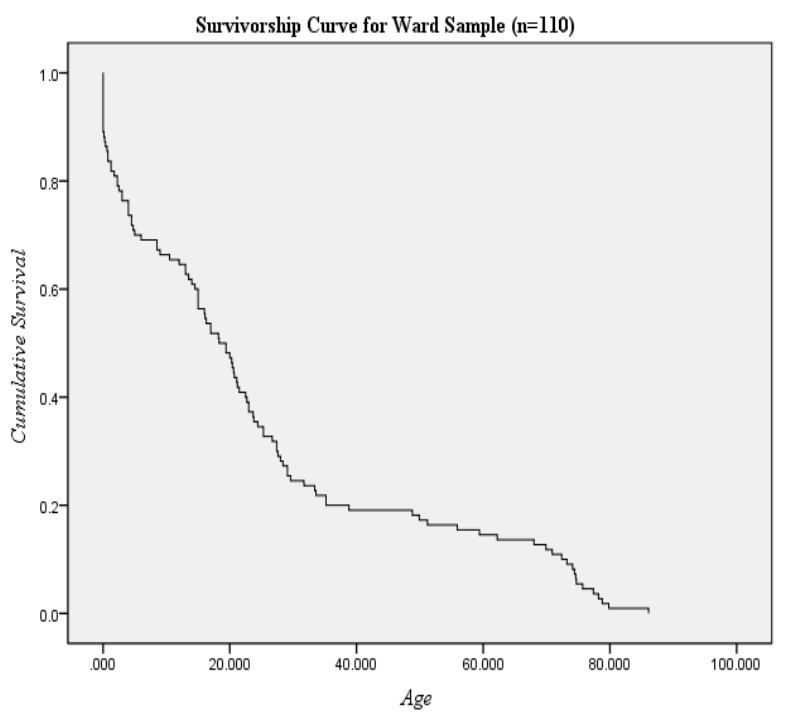

Figure 16 Kaplan-Meier survival curve for entire Ward Sample. The y-axis represents the likelihood of an individual surviving to the age represented by the $\mathrm{x}$-axis.

as evidenced by the vertical line at age .000 . Periods of diminished mortality appear to occur in early adolescence and not again until middle age through advanced age (approximately 30 to 70 years).

The results of analyses of survivorship by pattern of porotic distribution is illustrated in Figures 17-22. Figure 17 shows survivorship as impacted by each of the five distribution patterns defined above, utilizing the 90 measurable cases. Vault patterns are right clustered, while isolated cribra and unpatterned remains are confined to the left portion of the graph. This configuration implies that cribra orbitalia and unpatterned vault porosities are associated with greater selective pressure than the vault patterns observed in this study. Figure 18 presents the results of a re-analysis of the same data presented in Figure 17 based on broader criteria of lesion location. Individuals that presented any evidence of orbital lesions were counted in the orbital porosity category. Vault porosity was ascribed only to those individuals who exhibited porotic vault lesions in complete absence of orbital porosity. This grouping suggests that the presence of orbital lesions imposes greater selective pressure than vault lesions. 


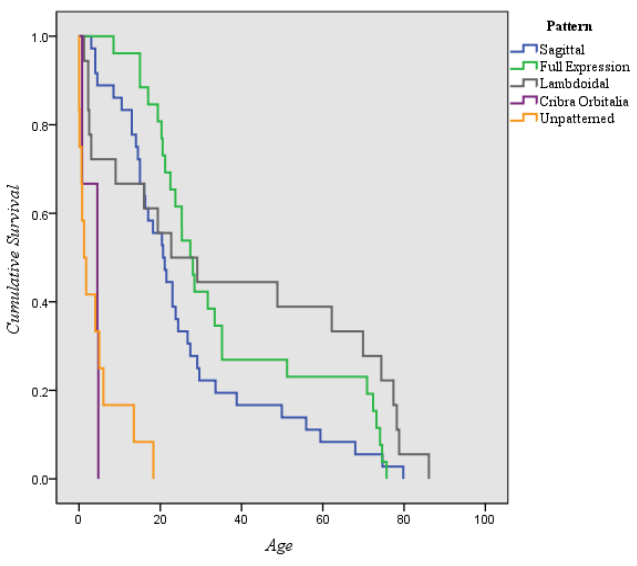

Figure 17 Kaplan-Meier survival curves pertaining to the five observed patterns of cranial porosity $(n=90)$.

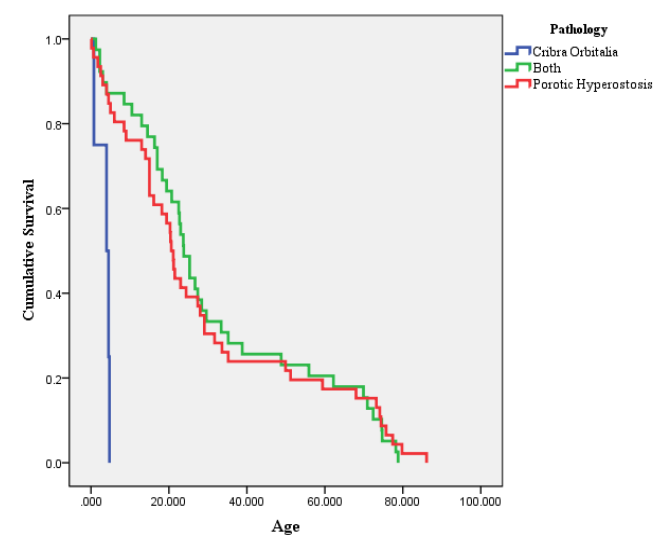

Figure 19 Kaplan-Meier survival curves testing the comparability of combined pathologies to either porotic hyperostosis or cribra orbitalia $(n=90)$.

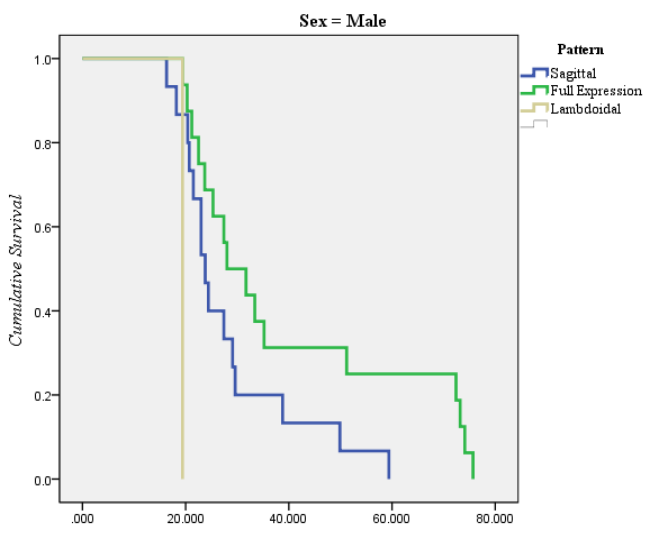

Figure 21 Kaplan-Meier survival curves based on observed patterns of porotic distribution from males in the Ward sample $(n=32)$.

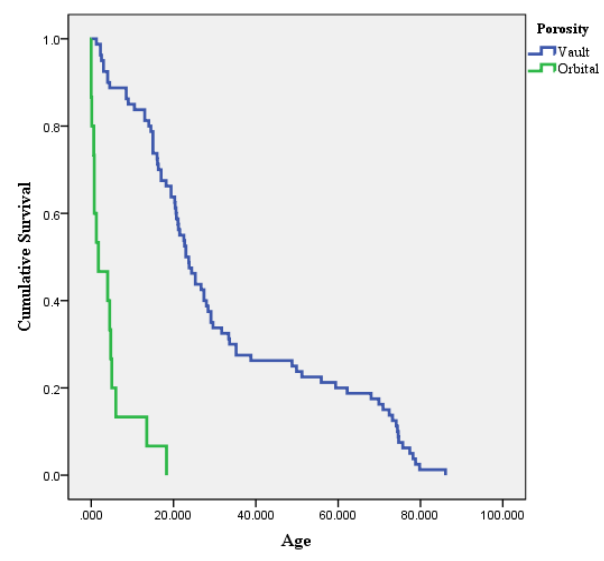

Figure 18 Kaplan-Meier survival curves simplifying observed patterns of cranial porosity into vault or orbital lesions $(n=90)$.

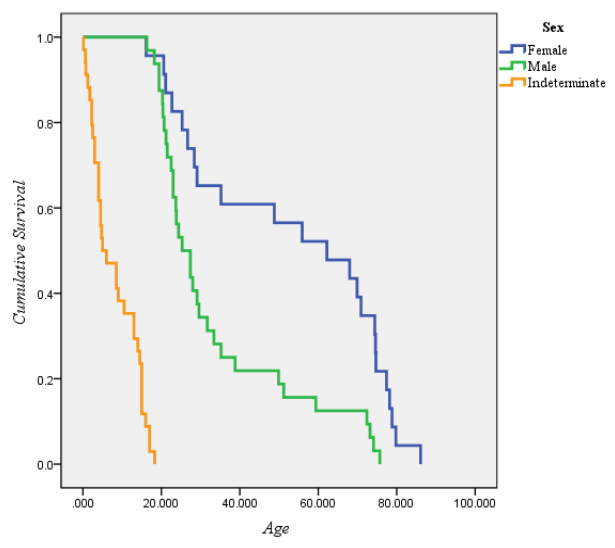

Figure 20 Kaplan-Meier survival curves based on estimated sex, with the indeterminate category representing juveniles $(\mathrm{n}=89)$.

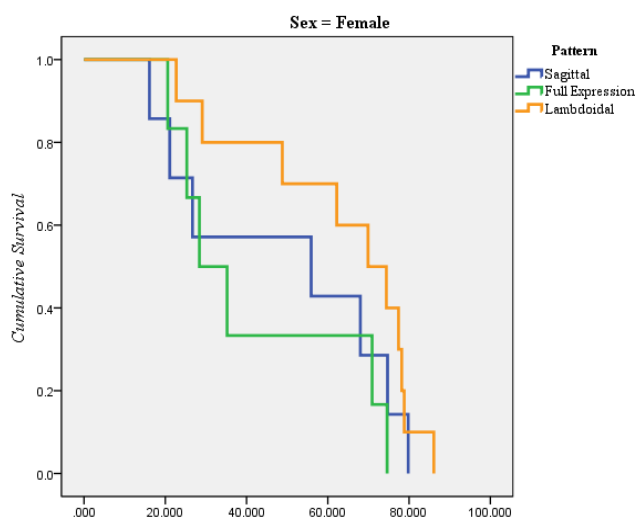

Figure 22 Kaplan-Meier survival curves based on observed patterns of porotic distribution from females in the sample $(n=23)$. 
However, when the combination of these two pathologies is treated as a separate variable from either vault or orbital porosity (Figure 19), it demonstrates a significantly stronger correlation to the survival curve associated with vault porosity.

Differential mortality as influenced by sex is depicted in Figure 20, where it was observed that females in the Ward sample were subject to generally less selective pressure than males. Males appear to face steep mortality until the approximate age of 40 , whereas females experience reduced selective pressure from near 30 until they approach the 70 year age mark. There are also observable differences in the patterns of porotic distribution possessed by either sex (Figure 21-22). Ward males were almost completely unimpacted by the lambdoidal concentration pattern, whereas the females exhibiting this pattern saw the least selective pressure of the assemblage. 


\section{CHAPTER 6: DISCUSSION}

There are significant reasons that the Green River assemblages housed at the Webb Museum have not been utilized more extensively for paleodemographic and paleopathological research. Principally, there is still a great deal of debate surrounding the nature of these sites and their use. This debate generates concern surrounding the representativeness of the skeletal samples acquired from these sites; namely, the representative fit of skeletal samples excised from the greater SMA population. Speculation as to how mobile the fisher-hunter-gatherers from these sites were in the past could create concerns for seasonal bias affecting the samples. The concern would be that a seasonal bias would deliver a different snapshot of frailty in the population than might be represented by a complete and unbiased assemblage.

This seasonal bias could take many forms. If the shell middens sites were one part of a long distance, annual migration cycle, like birds migrating South in the winter, then it would seem unlikely that the Archaic period site inhabitants would make a long distance return trip for the sole purpose of burying their dead at the shell midden sites. In such a case, the recovered skeletal assemblage would only represent mortality coinciding with the duration of occupation of that particular site. Some authors have suggested that the Green River Archaic populations were not stationary (Hensley 1991), and others have argued against the idea that Ward, and other sites in the area, served any habitational purpose at all (Claassen 2010). 
Hensley (1991) has argued that the more significant Archaic burial sites in the Green River drainage served as aggregation sites to which cultural activities would return from dispersed settlements and resource acquisition locales. As part of this system, she argues that, "the burial populations at these sites should include both primary and secondary burials of those individuals important to the group, e.g., adults who were economically and reproductively active" (ibid. 1991:91). Outlying sites, therefore, would be the final resting place for the remainder of the population. This theory is a sort of interpretation of Winters' (1969) description of the "Riverton Culture" of the nearby Wabash River valley, a tributary system of the Ohio running through south central Indiana North of the Green River drainage. The Riverton settlement pattern outlined a system of numerous occupation strategies aimed at exploiting optimal resources for every season. These occupations ranged from winter settlements with permanent architecture to transient hunting camps with little observable cultural residue (ibid. 1969:137).

Winters' (1969), Hensley’s (1991), and Claassen’s (2010) models all suggest seasonal mobility in the fisher-hunter-gatherer populations of the Green River Shell Midden Archaic populations. These models, however, do not imply mobility of significant range, but rather tolerate or suggest relatively modest intraregional migration. In this manner, the burial sites like Ward and others are still accessible throughout the year. More than the implication of accessibility, the demographic patterns elucidated by the present analysis corroborate the notion that the skeletal assemblage is free of seasonal bias, and that it is indeed a natural and representative sample. This analysis supports Meindl and colleagues' (2001) assessment of the Ward assemblage as being representative of a complete population. What this analysis stops short of, in contrast to 
Meindl and colleagues (ibid.), is asserting that the lack of demographic bias is evidence of permanent occupation, and instead allows room for both models of settlement pattern.

While there is room to suggest that the "aggregated mobility" pattern championed by Hensley (1991) might be applicable to the Ward assemblage, her other arguments suggesting status differentiation was a factor in burial practices were not borne out. In that argument, Hensley suggested that "family or subsistence group camps would be burial sites for individuals important to the family (subadults or elderly adults), but not important to the aggregated group" (1991:91). She directly stated that Ward is "probably another aggregation site" (Hensley 1991:91), and therefore the skeletal assemblage should only be representative of the higher status individuals important to the aggregate. However, this analysis demonstrated no lack of subadults or elderly adults (43.5\% under the age of $15,17.2 \%$ over the age of 50) in the Ward sample. Instead, the present study supports the long-offered ascription of egalitarianism to the Shell Midden Archaic supported by numerous authors but most definitively upheld in the publication of the SMAP monograph (Marquardt and Watson 2005).

The present paleodemographic analysis indicates no bias from either seasonal mobility or status differentiation within the Ward skeletal sample. One possible way to make a definitive declaration on the absence of seasonal bias at the Shell Midden Archaic sites would be to directly assess seasonality of death using cementochronology. This destructive analytical method, unfortunately, would need to be conducted on the human remains themselves, as much of the faunal assemblage was discarded from the museum in the past for the purpose of freeing up curatorial space. Being that the methodology is 
necessarily destructive, it is an unlikely candidate for future analysis on the museum's precious osteological resources.

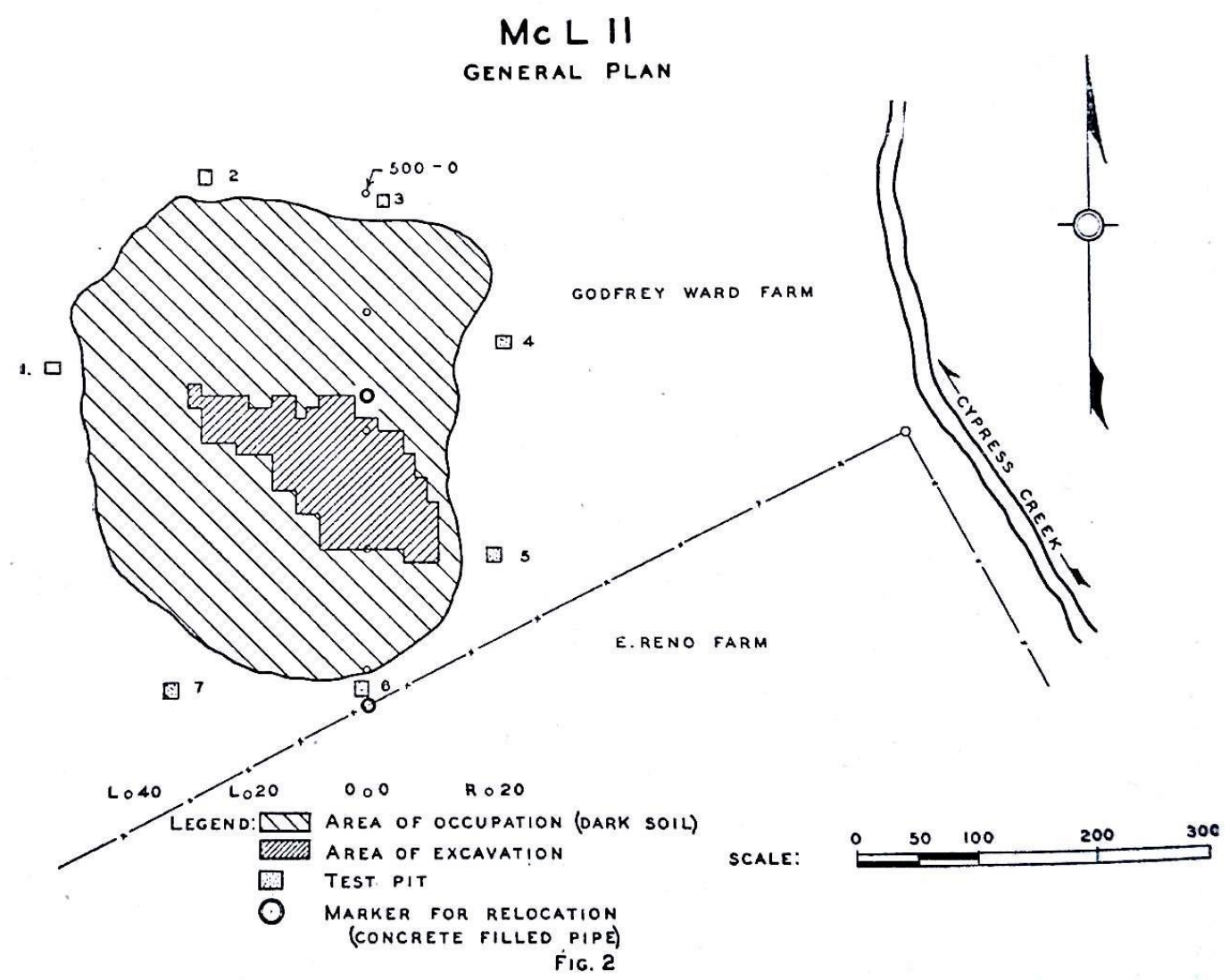

Figure 23 Original published plan view map of the Ward site's (15Mcl11) WPA excavation depicted within total estimated area of occupation (Webb and Haag 1940:70).

This analysis took steps to select a sample representative of the population of the Ward site in its entirety. Among these was to ensure that the sample of 110 individuals analyzed were distributed throughout the interment field, which was meant to assuage the likelihood of a temporal bias coloring the interpretation of the remains. This strategy was successful in preventing over-representation of any particular area within the WPA excavation block. Unfortunately, the WPA excavation block only accounted for an approximate $20 \%$ portion of the total estimated original site area (Figure 23, Webb and Haag 1940). This entails that any ascription of representation of the present studied 
skeletal sample rests on the assumption that the excavation block itself was fully representative of the Ward population. This potential source of error could only be remedied if the whole of the site were to be excavated, or if similar analyses were conducted at sites with burial components that are thought to be fully excavated (Indian Knoll, for example).

\section{Concerns and Conclusions about Diet and Porotic Hyperostosis}

This analysis allows for the practice of seasonal mobility by Ward's inhabitants, which complicates interpretation of dietary impacts on health. Accurate reconstructions of subsistence strategies employed at the Ward site are largely hampered by excavation techniques utilized in the course of the original WPA excavation, theoretical and analytical emphases at the time of original publication, and the unfortunate destruction and disposal of the majority of faunal remains during the museum's past. Instead, conclusions drawn on the Ward population's subsistence strategy must be largely based on data recovered from analogous sites in the region. There, of course, lies a considerable opportunity for error in this assumption. After all, Ward is considered to be among the earliest of the shell midden sites (Claassen 2010; Herrmann 2002), and as such there is a possibility that subsistence strategies shared by later sites, like Carlston Annis and Indian Knoll, may have been in development or exploration during the original occupation of the Ward site.

It is a possibility that health outcomes also differentiate Ward from other SMA sites in the region. The analyses of health at the nearby SMA type site, Indian Knoll, conducted by Cassidy (1973) and Kelley (1980) delivered a starkly different picture of 
porotic skull changes in these Archaic populations. These dissertations highlight the difficulty of identifying porotic cranial bone changes within the SMA specifically, but also in skeletal remains more generally. Cassidy (1973) and Kelley (1980) were both hesitant to diagnose anemia from the porosity they were both observing from the Indian Knoll skeletal assemblage. Cassidy (1973) reported porotic skull changes in $31.7 \%$ of her sample of the Indian Knoll assemblage, but chose not to diagnose those porotic lesions as anemia. Kelley (1980) diagnosed anemia in the form of porotic hyperostosis and cribra orbitalia in $3.8 \%$ of his sample. The hesitancy to diagnose anemia is not so readily shared in diagnostic methodologies utilized in studies like Steckel and Rose (2002), who in turn took inspiration from Stuart-Macadam $(1985,1989)$. This later, less hesitant pathological methodology is more similar to that utilized for the present study. Error, in this case, is likely to arise in the form of over-diagnosing pathology, resulting in an inflation of the presumed frequency of anemia in past populations.

Comparing the high rate of anemia observed in the present study with similar rates reported by Steckel and colleagues (2002b) as part of the Backbone of History project, the current results do not seem too extreme. Their study reported that on average $90.5 \%$ of individuals from every studied site were classified as anemic (Steckel et al. 2002b:78). The vast disparity between estimates of anemic bone changes reported there and in past studies of health at other SMA sites is more likely to reflect differential diagnostic methodologies than it is to reflect differential health outcomes. The present data illustrating limited impact of anemic bone changes on mortality suggests that overdiagnosis is a distinct possibility. Future studies utilizing similar methodologies should take this result into consideration when designing research strategies. 
The possibility that Ward might represent divergent strategies from the later Shell Midden Archaic sites is bolstered by the nature of the distribution of bivalve remains within these sites. Indian Knoll and Carlston Annis, for example, two later and similarly large sites in comparison to Ward, both exhibited a relatively even distribution across the site and on top of human interments (Webb 1946). Ward, on the other hand, was at one point purported to be a shell free site (Hensley 1991; Herrmann 2002), but later test excavations suggested that shell debris was concentrated at the base of the bluff, away from of the primary concentration of burials (Jefferies et al. 2007; Webb and Haag 1940). In either case, shell was identified at the site. However, it is a possibility that the shell mound at the bottom of the bluff could represent a separate later occupation episode of the same group or even a different cultural group altogether.

One resource that the SMA sites definitely had in common was white tailed deer (O. virginianus), which served as an excellent source of protein as well as dietary iron. Fresh-water mollusks have been demonstrated similarly to provide protein, though to a significantly diminished degree to that provided by deer (Parmalee and Klippel 1974). There is no known evidence for direct consumption of unionids (i.e. inclusion in paleofesces), but the conclusion that Marquardt and Watson draw is a firm one: "mollusks- more than 36 species of unionids and 5 species of aquatic gastropods- were consumed at several riverine sites" (2005:633). Shellfish and deer are part of a much larger fisher-hunter-gatherer subsistence strategy that included numerous species of fish, aquatic and terrestrial turtles, raccoon, turkey, squirrel, rabbit, and seasonally available wild plants (Marquardt and Watson 2005; Crothers 2005). All of the animal resources are potent sources of protein and dietary iron. The plant resources associated with the Green 
River shell middens, most abundantly hickory and acorn nuts, are not known to be sources of iron-inhibiting phytates (Bothwell et al. 1989; El-Najjar et al. 1976).

Hickory and acorn are known sources for folate, though do not contain measureable values of vitamin B12 (King et al. 2007). This seasonally harvested resource could have provided sufficient folate to avoid deficiency and the resultant marrow hypertrophy that might have accompanied it. Seasonal availability of nuts for harvest does not prevent their consumption year round, as they are easily dried and stored. The earliest publications on these sites have suggested the importance of nut subsistence and the Archaic population's processing of it as evidenced by the abundance of ground stone pestle tools (Webb 1946).

Subsistence data from these sites, in combination with the high observed rate of porotic hyperostosis and cribra orbitalia independently and in combination (91.3\% of all individuals) in the Ward assemblage, suggest that formation of the studied pathologies does not have a connection to rates of dietary iron absorption. This finding echoes the preponderance of analyses conducted by many researchers following the later work of Stuart-Macadam (1992; Holland and O'Brien 1997; Kent 1986), that anemia is not likely to be caused by a deficiency in dietary iron intake except for in extreme cases. The alternative hypothesis that typically follows is the suggestion that iron-withholding is the true culprit responsible for iron-deficiency anemia.

In a hypothetical environment where egalitarian hunter-gatherers were purportedly free of large scale communicable diseases that were associated with crowding and augmented social complexity (Larsen 2000; Cohen 1989), the ironwithholding hypothesis would have little going for it. Tuberculosis (Mycobacterium 
tuberculosis), one of the oldest known "crowd diseases," was not known in the New World until approximately 2000 years after the terminus of the Archaic Period in the Eastern Woodlands, carried from the Old World as a zoonotic infection by migrating pinnipeds (Bos et al. 2014). Similarly, Malaria (Plasmodium species) is not thought to have been exerting selective pressure on pre-contact New World inhabitants that might have promoted genetic adaptions like sicklemia or the thalassemias (Angel 1966). Even in the absence of genetic adaptations in New World populations, malarial infection as a parasite could still contribute to the appearance of cribra orbitalia and porotic hyperostosis by initiating iron withholding. Definitive evidence for malaria in the prehispanic New World, particularly as far back as the late Archaic, is presently absent.

Malaria does not represent the sole possibility for parasitic involvement in the Shell Midden Archaic. One of the most likely alternatives would be helminth infections. Helminths have been identified in human paleofeces from Brazil as old as $3610 \mathrm{BP}$ (Trichuris trichuria, whipworm, Ferreira et al. 1980). Much closer to the Ward site, paleofeces from Salts Cave yielded giant roundworm (Ascaris lumbricoides), as well larvae interpreted as either hookworm or Strongyloides sp (Applegate 2008; Reinhard 1990). One species of hookworm (Ancylostoma duodenale), once thought to be brought by European contact, was identified in the intestines of an Incan mummy (Reinhard 1990).

Helminth species are numerous and their impact on infected human hosts varies drastically. Some, like A. duodenale and T. trischuria, are known to promote recruitment of immunoglobulin E which resists "vulnerability to infectious disease, allergy, and autoimmune disorders" (London et al. 2014:124). Another prominent consequence of 
hookworm infection is iron-deficiency anemia (Aufderheide and Rodriguez-Martin 1998). Parasites, generally, are responsible for blood loss in infected individuals, to which an increase in $\mathrm{RBC}$ production is a natural response. Some parasites are known to consume vitamin B12, such as the fish tapeworm Diphyllobothrium sp. (Rothschild 2012). In short, parasites have multiple pathways available through which to promote the erythropoietic skull changes that define porotic hyperostosis and cribra orbitalia: promoting iron-deficiency by consuming the host's iron stores, prompting ironwithholding defense from the host's immune system, inciting overproduction of RBCs in compensation for direct blood loss, and causing irregular erythropoiesis by consuming host stores of vitamin B12.

Given these characteristics of parasitic infections, in combination with subsistence data known from previous research on the shell midden sites and the high rates of porotic hyperostosis observed in the present study, parasitism was likely endemic in the living population represented by the Ward assemblage. It is also highly likely that parasitic infection was the primary cause for cranial porosity as observed in this study. However, the present data yields no direct evidence to concretely identify any specific genera of parasite that might have served as the causative agent. 


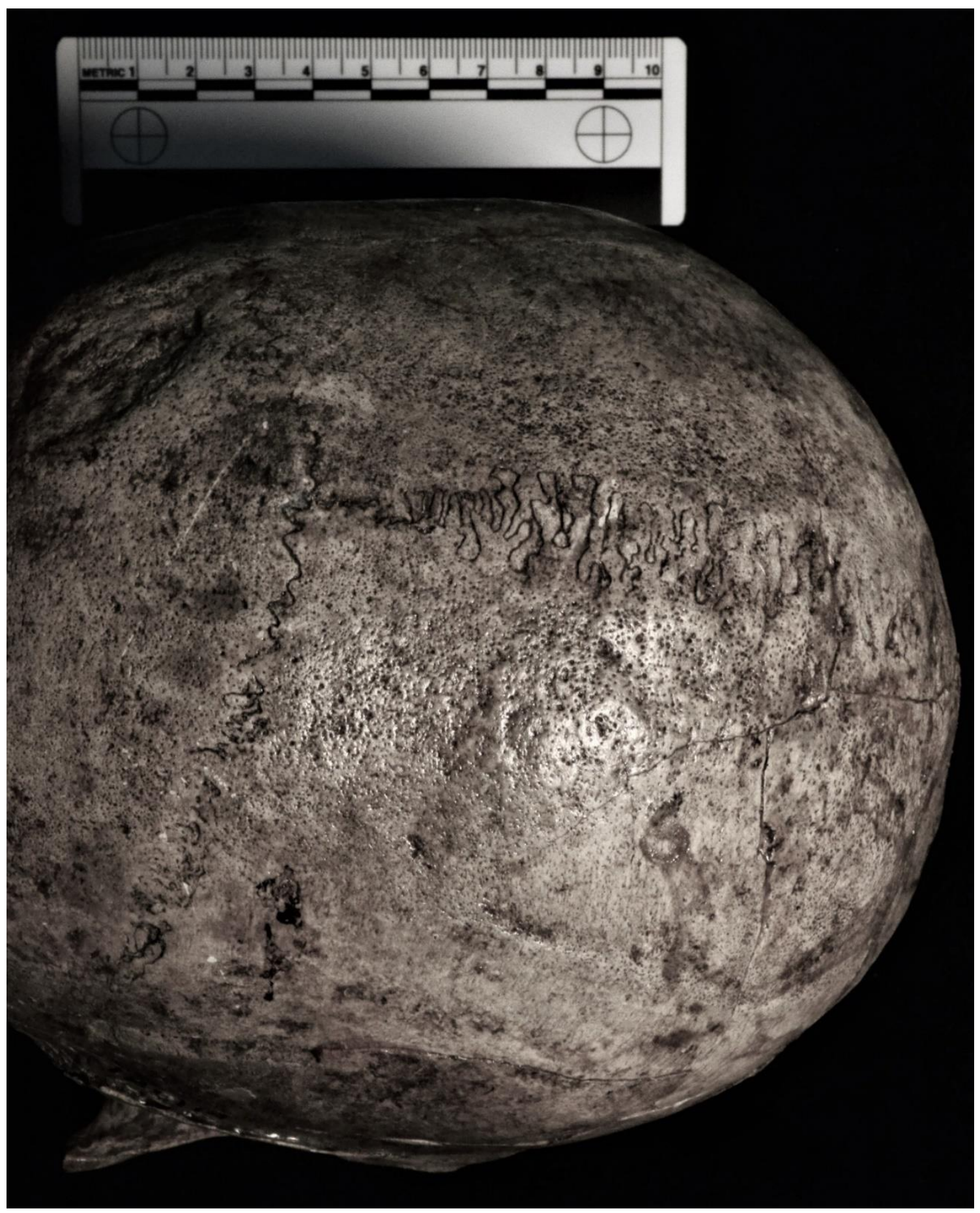

Figure 24 Cranium exhibiting lateral distribution limit at the temporal line on the left parietal, from the Ward skeletal series (UKMA 12-Unassociated, not used for analysis). Photo by the author. 


\section{Porotic Distribution Patterns and Differential Mortality}

Porotic distribution on the Ward assemblage crania showed a great degree of variation between individuals. However, distribution in all cases was firmly bounded by muscular attachments encircling the superior portion of the skull. Porosity was never observed in continuity across the temporal line on the parietals (Figure 24), which serves as the demarcation for the extent of the temporalis muscle, or the nuchal lines on the occipital. The only other study to suggest the idea of a spatial limit for porotic expression was El-Najjar and colleagues' study of Sudanese Nubian crania (1976). It is probable that the observed boundaries reflect the nature of porotic formation in itself. Cranial porosity is thought to be visibility of the trabecular bone as a consequence of cortical bone erosion. Cortical thickness is increased at the site of muscular attachment. Porosity below the temporal line or nuchal crest would mean a destruction of local muscular attachments, and therefore a loss of muscular function. The presence of muscular attachments does not necessarily guarantee that trabecular expansion did not take place. Rather, the lack of porosity in these areas is most likely a consequence of increased cortical thickness that accompanies muscular articulation. No firm conclusion can be reached on the significance of this observed pattern, but it should prove useful in future macroscopic analyses of cranial porosity.

Cribra orbitalia in isolation was a rare occurance in the Ward sample, only being identified in four individuals. With a maximum age of 4.75 years, expression of this type of pathology would seem to indicate heavy selection pressure. However, the pathology was also observed in an additional 39 individuals who enjoyed substantially more favorable health outcomes (mean age at death of 29.1 years). Though it could be 
suggested that this pattern indicates the presence of cribra orbitalia by itself has a heavy impact on mortality, the pathology's presence in combination with porotic hyperostosis in older individuals could also corroborate others' (e.g. Stuart-Macadam 1985) notion that porotic hyperostosis is a pathology for later in life. This notion, however, is not readily validated by the data derived from the present analysis.

Porotic hyperostosis was observed in young children, one of which was estimated to be a newborn (UKMA 12-392). This neonate's pathology, as mentioned in Chapter 4, did not follow the pattern of porotic distribution observed from the rest of the assemblage, suggesting that this particular atypical case may represent an alternate pathology, presenting as similar to porotic hyperostosis. Vault porosity was also identified on an individual with a 0.625 year age at death estimate, though in that case orbital preservation precluded assessment of cribra orbitalia. The youngest individual displaying only porotic hyperostosis was UKMA 12-110, a 1.75 year old who was assessed as one of the six individuals in the unpatterned category of porotic distribution. In addition to vault porosity, this individual also exhibited a lytic lesion on the left parietal and a partially healed fracture on the superior margin of the occipital. Given this evidence, it is probable that the porosity observed on UKMA 12-110 was secondary to traumatic injury and resultant infection. Porotic hyperostosis is of least concern among the variables that might have contributed to this young child's mortality.

The data derived from this study similarly does not readily suggest either pathology to represent a significant force of mortality for older individuals in the population. Of the five patterns of cranial porosity identified in the Ward sample, unpatterned porosity and cribra orbitalia were associated with the greatest selective 
pressure (Figure 17), which is to say all of the individuals who exhibited these patterns entered the skeletal assemblage by the approximate age of 18 . The survival curves generated for those three patterns which described extensive porotic distribution on the cranial vault (Sagittal concentration, lambdoidal concentration, and full expression; Figure 17), those most readily definable as porotic hyperostosis, were observed to deviate little from the overall survival curve generated for the total sample (Figure 16). This lack of deviation is in part an artifact of the proportion of the sample size (88.9\%, $\mathrm{n}=80$ ) claimed by these three patterns. In effect, they are responsible for shaping the overall survival curve. The shape of that curve, and by extension, the adherence of these three vault patterns to it, is significant in understanding the type and intensity of selection pressure that operated on individuals in the Ward assemblage.

In analyzing the Kaplan-Meier survival curve for the entire sample presented in Figure 16, it is possible to guess at numerous explanations for particular portions of the mortality curve. The near vertical portion of the line at the beginning of the graph represents the high rate of infant mortality at the site, especially that associated with mortality during the birthing process. The perils of childbirth are echoed by increased rates of female mortality experienced in the reproductive years beginning in adulthood and persisting until the mid 30s (Figure 20). Males similarly experience a steep mortality curve in adulthood, from approximately age 20 until near 40 (Figure 20). Mortality at this stage of male life for the Ward assemblage has been attributed, at least partially, to intergroup violence (Mensforth 2001). This interpretation was substantiated in the present analysis by the presence of two individuals in the sample that exhibited evidence of scalping (UKMA 12-261 and UKMA 12-421, Figure 25). The survival curves in Figure 
20 indicate that the selection pressure faced by males persists later into advanced age, which may indicate a lengthy duration for male participation in violence. Towards the end of the 30s, the survival curve levels off and the Ward site occupants face relatively low mortality until the curve approaches senescence. Mortality increases again for septagenerians, until the curve flattens out in anticipation of the sample's sole octagenerian's passing.

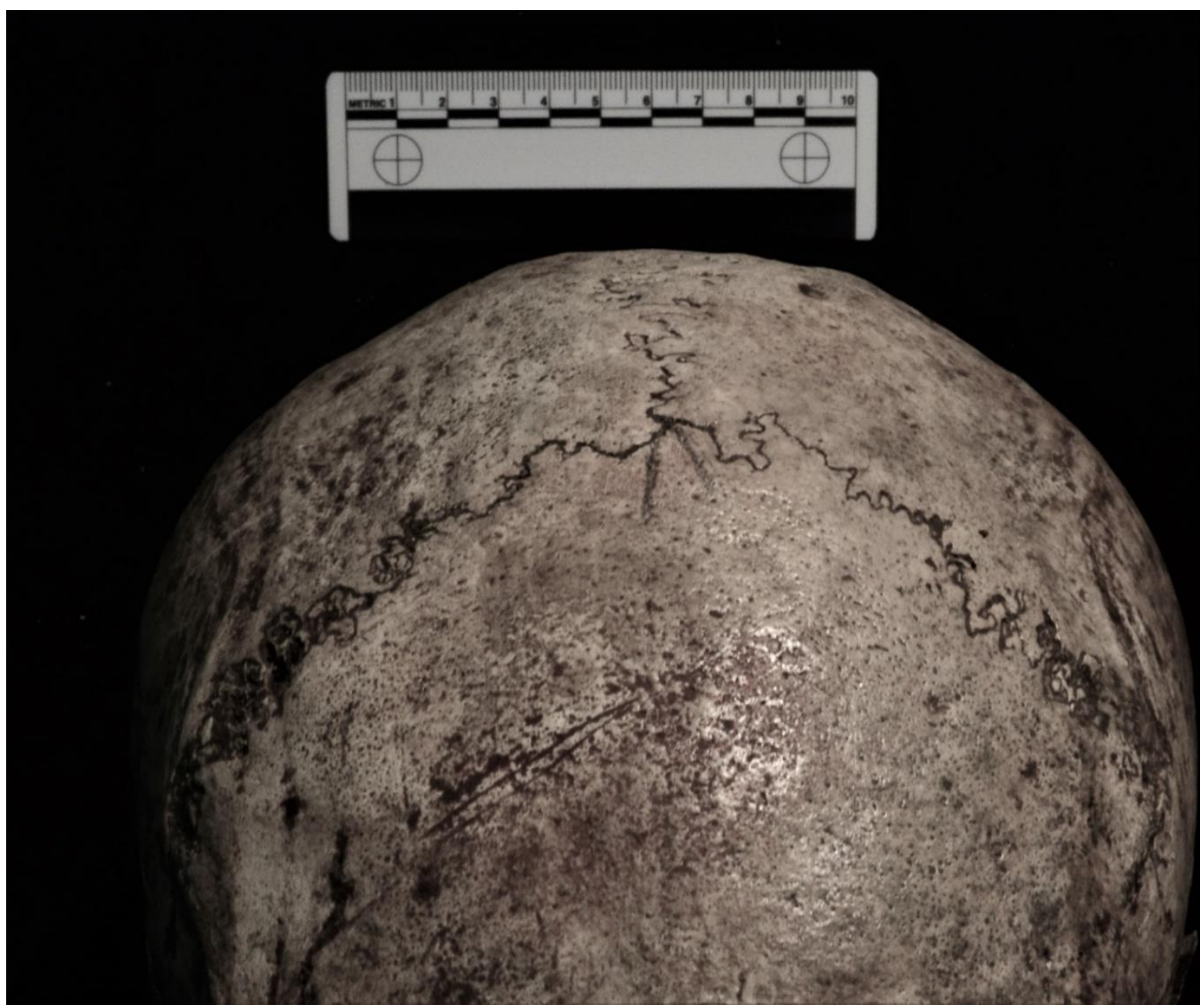

Figure 25 UKMA 12-421 showing cut marks on superior portion of frontal, interpreted as evidence of scalping by Mensforth (2001). Photo by the author..

It can be summaraized that Ward's inhabitants experienced three selection episodes: the first occurred in early childhood, from before birth to early juvenility; the second during early adulthood; and the final accompanying senescence. The blue curve in 
Figure 18, representing individuals who exhibited only vault porosity, mimics this same pattern, nearly reproducing the curve exhibited by the entire population (Figure 16). Vault porosity does not appear to be an age-related phenomenon at this level of analysis. At this broadest level, it also does not appear that porotic hyperostosis exercises any significant negative impact on mortality. In the same graph (Figure 18), the green survival curve, representing all cases in which orbital porosity was observed, depicts a very different scenario.

The presence of orbital lesions generates a steep survival curve (Figure 18) distinct from that presented by the overall sample, suggesting that cribra orbitalia has an impact on or is closely associated with mortality. For cribra orbitalia in isolation, this association makes interpretable sense; it could be suggested that individuals displaying only orbital lesions were not conducting hematopoiesis to the same extent that individuals exhibiting porotic hyperostosis were, and as a consequence succumbed to the malady that drove the augmented production to begin with. In that case, cribra orbitalia in isolation would represent frail individuals. Frailty is defined by DeWitte and colleagues as "an individual's relative risk of dying compared to other people in the same population," (DeWitte et al. 2015:7). Individuals with isolated cribra orbitalia were demonstrably associated with increased risk for early mortality in the Ward sample. However, it is not necessarily the case that the diagnosis of cribra orbitalia or even the etiological origin for its manifestation are the determinant of the individual's frailty. For example, the correlation of cribra orbitalia with frailty does not account for the persistence of the disparity depicted in the survival curves of Figure 18. If cribra orbitalia in isolation represents a minimal immune response and thus indicates frailty, then the same pathology 
in combination with porotic hyperostosis should represent a maximum immune response. In such a case, it could be anticipated that the combination of the two pathologies would achieve a greater survival outcome than porotic hyperostosis alone. Figure 19 illustrates this scenario, but the survival curves for isolated porotic hyperostosis and both pathologies combined follow very similar curves. Given the low resolution of data (diminutive sample size), firm conclusions regarding the differentiation of these two particular pathological expressions cannot be drawn.

Variation in survivorship between the identified vault patterns is similarly difficult to definitively argue for differential mortality in connection with vault porosity distribution. The largest difference suggested by the survival curves in Figure 17 is that presented by the lambdoidal curve, which suggests connection to early mortality, and subsequently levels off from adolescence into senescence. The latter part of the lambdoidal curve in Figure 17 mirrors the female survival curve presented in Figure 20, because the lambdoidal concentration of porosity was only observed in one male in the Ward sample. As a result, the impacts of said pattern and ascription of female sex on mortality cannot be disentangled. The sample size is too small for adults with the Lambdoidal concentration $(\mathrm{n}=11)$ to make any conclusions regarding sex-related distribution of vault porosity, though the current data suggests that such a relation may exist.

Sagittal and full expression porotic distribution patterns were observed in males at more than twice the frequency of those in females. Males were also more readily represented in the sample, at $35.5 \%(\mathrm{n}=32)$ in comparison to the female proportion of the included sample $(\mathrm{n}=90)$ at $25.5 \%(\mathrm{n}=23)$. It is possible that the under-representation of 
females in the sample accounts for the disparity between male and female representation of sagittal and full expression distribution. Given the proportion that each distribution pattern represents within the two groups as presented in Table 4, it is likely that these proportions will persist if these methodologies are repeated elsewhere, but firm conclusions cannot be drawn on the limited data present.

Some concern should be given to the disparity in representation of males versus females in the sample. One explanation would be that the demographic makeup is an accurate (well-estimated) representation of the sample, but the bias occurs from the sample itself. Another, more pessimistic, scenario would be that sexual estimations were not made accurately, or relied upon flawed criteria. Another probable explanation would be that females were represented more heavily in the subadult portion of the sample which was not estimated for sex for lack of secondary sexual characteristics. This pattern of female underrepresentation was also observed by Meindl and colleagues (2001) in their assessment of the Ward population, as well as in Mensforth's (2005) report on paleodemography at Carlston Annis (15Bt5).

Figures 21 and 22 suggest that individual porotic distribution patterns between the sexes do not vary much from each sex's broader survival curve (Figure 20). The exception, again, is the lambdoidal pattern in females, which appears to push the overall female survival curve deeper further into senescence (Figure 22). It is clear from Figure 20 that adult males face much higher selective pressure during adulthood than do females. Only approximately $20 \%$ of adult males survived to age 40 , in contrast to the $60 \%$ of females. The only explanatory model for this disparity presently available is that 
mentioned previously, which suggests that males face violence as a heavy and persistent source of mortality (Mensforth 2001).

Two interpretations can be made from the survival curves in Figure 18. First, a sort of ranking scenario where cribra orbitalia in isolation suggests frailty and an insufficient immune response, porotic hyperostosis in isolation represents a successful immune response, and the two in combination indicate a maximum immune response that was overwhelmed by the pressure that caused it. This ranking scenario carries the implication that orbital lesions might heal and are remodeled over time, while vault lesions are not. The second, likely scenario is that orbital and vault porosities represent different etiologies, both of which were common among the Ward population. Under this scenario, the factors that contributed to the manifestation of cribra orbitalia would have influenced mortality more than those factors responsible for porotic hyperostosis. The notion that porotic hyperostosis and cribra orbitalia may occur as manifestations of disparate etiologies is one that has been explored in recent analyses (Rivera and Mirazon Lahr 2017; Wapler et al. 2004).

The notion that cribra orbitalia and porotic hyperostosis do not always share a common etiology is not a new one (Walker et al. 2009; Wapler et al. 2004; Rothschild 2012). The operative term in that statement is always. The debate surrounding the causative agent behind vault porosities is routinely debated as being one nutritional deficiency: either iron through withholding (Stuart-Macadam 1992), vitamin B12, or Folic acid (Walker et al. 2009). Cribra orbitalia, on the other hand, is much more commonly associated with multiple etiologies, and as one paper astutely phrased it: "it is 
not a disease, but a symptom of one of many underlying problems driven by both environmental and physiological circumstances" (Steyn et al. 2016:2).

It should be stated that the orbital lesions observed in the Ward sample did not exhibit signs of substantial hypertrophic outgrowth of trabecular bone, but rather qualitatively consisted of porous intrusions through the natural relief of the cortical bone of the orbital roof. This type of manifestation might be characterized as healed or remodeled cribra orbitalia, left from a previous episode of marrow hyperplasia, but it may similarly be evidence of alterative diagnoses for the specific causative malady. For instance, some individuals exhibited unilateral cribrous lesions, as in the case of UKMA 12-44 (Figure 26). It is possible that instances of unilateral cribra orbitalia are suggestive of subperiosteal hemorrhage resulting from trauma, and is reminiscent of the colloquial manifestation of a "black eye." Profusion of blood at the site of hemorrhage is credited with the generation of porosity in contiguous skeletal tissues, which is similarly the pathogenesis responsible for osseous evidence of scorbutic activity (Ortner 2003; Ortner et al. 1997). Not all cases of cribra orbitalia in the Ward sample were observed to be

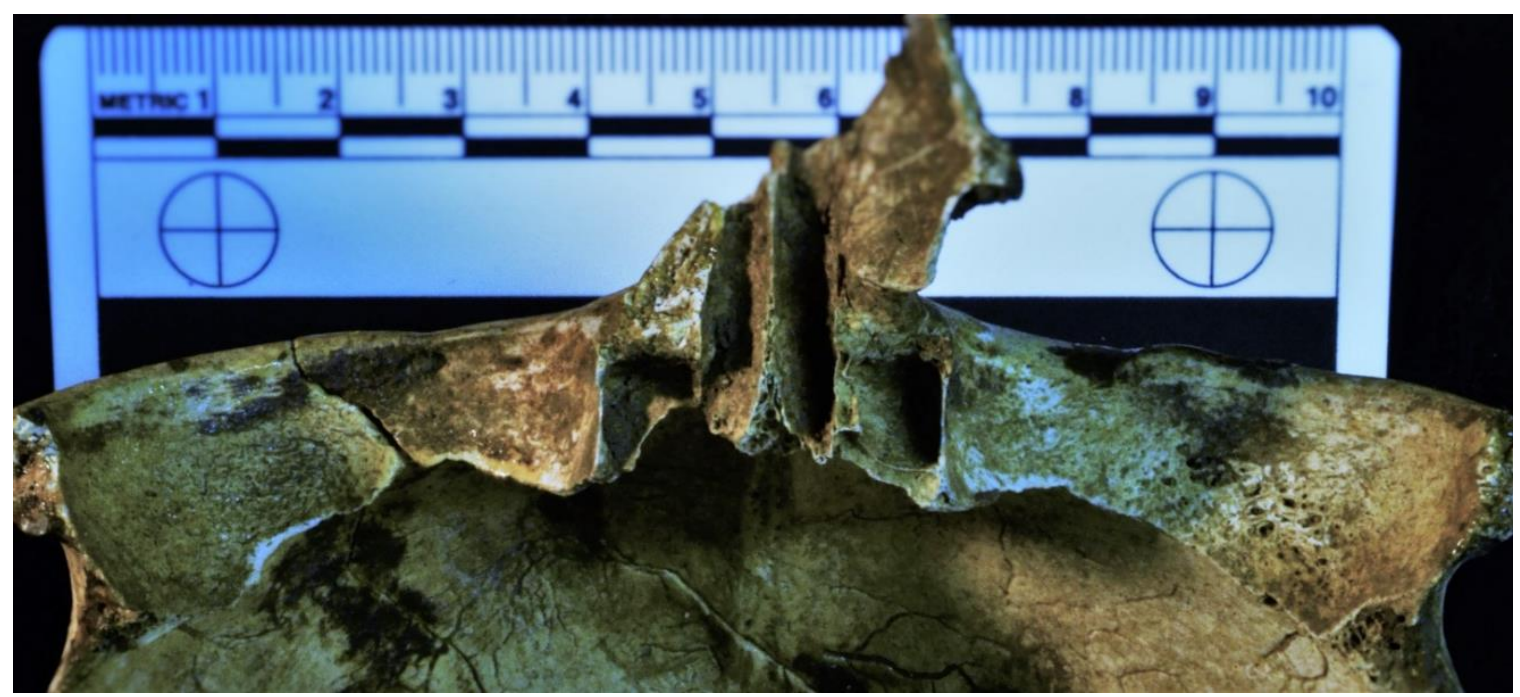

Figure 26 UKMA 12-44 exhibiting unilateral cribra orbitalia in the left orbit (right of picture). Photo by the author 
unilateral, and it is easily possible that traumatic injury is not the only culprit behind cribrous lesions at the site. This simple possibility reflects two larger conclusions concerning the methodology of orbital pathology employed in this research.

The first conclusion concerns a methodological oversite that resulted in a weakness in this analysis. UKMA 12-392 was assessed as free of cribra orbitalia based on examination of its left orbital roof, made necessary by the absence of its right counterpart. Several other crania $(n=6)$ were diagnosed as having only porotic hyperostosis under the same circumstances. This was considered acceptable under the experimental design of this analysis based on the initial assumption that cribra orbitalia occurs bilaterally. UKMA 12-44 (Figure 26) illustrated that this assumption was not prudent, as in that case porous lesions were limited to the left orbit. It is possible that unilateral cribra represents a separate pathology, perhaps indicative of infection or inflammation isolated to the tissue of one eye only, as hematopoeisis should occur bilaterally. Nevertheless, the negative diagnosis of cribra orbitalia based on the presence of only one orbital vault represents a weakness in this analysis. Any future analyses utilizing any of these methodologies or criteria should bear this weakness in mind, and reserve negative diagnoses of cribra orbitalia to specimens preserving both orbits, which will significantly limit available specimens given the fragility of the location.

The second conclusion that can be drawn from this analysis' treatment of orbital lesions is similarly limiting. Attempts to diagnose the specific causative agent behind the cribra orbitalia observed within the Ward sample are, unfortunately, speculative and largely beyond the skills of the present researcher. However, the data derived from the Kaplan-Meier survivorship curves, particularly those depicted in Figure 18, demonstrate 
that cranial and orbital lesions had differential impacts on mortality, and further very strongly suggests differential etiologies for at least some of the pathologies. Where the association of vault lesions with relative longevity has been taken to indicate either megaloblastic anemia due to vitamin B12 deficiency or iron-withholding, both the probable result of parasitic infection, a specific etiology for cribra orbitalia in the Ward sample cannot be determined. Perhaps said etiology should not be assumed to be singular; this study does not generate sufficient evidence to draw a conclusion for either scenario. 


\section{CHAPTER 7: CONCLUSIONS}

As a Middle Archaic, pre-agricultural, hunter-fisher-gatherer population, the Ward site's inhabitants should not have porotic hyperostosis or cribra orbitalia to any significant degree according to the traditional model of dietary iron-deficiency anemia. This model, despite having been discounted by numerous sources, persists in archaeological literature and scholarship to the present day. The present study identified the opposite pattern: high incidence of porotic hyperostosis in an environment where iron-rich foods were abundantly present and exploited while in absence of phytate-rich agricultural products. Porotic expression on either the cranial vault or orbits was nearly ubiquitous in the Ward sample, a fact which would seem to corroborate the prevailing interpretation that dietary iron deficiency is not the causative agent behind porotic hyperostosis generally. Specifically, iron deficiency due to inadequate intake of dietary iron should be excluded from the list of etiologies that may have contributed to the high occurrence of porotic hyperostosis and cribra orbitalia in the Ward population.

There is room in the data to support iron with-holding as a contributor to augmented erythropoiesis as observed in porotic alterations to Ward crania. Similarly, megaloblastic anemia resulting in irregular erythropoiesis represents another probable contributor to the high occurrence of porous lesions at Ward. Both of these etiologies would in turn likely have been caused by parasitic infection. Heavy parasitic infection similarly does not fit within standard aggregation-disease load scenarios proposed in 
previous literature (e.g. Kent 1986) and popularized in explanatory models for health deterioration accompanying social advancement utilizing bioarchaeological evidence. If porotic hyperostosis and cribra orbitalia are assumed to be indicators of poor health, then the Ward site's population was a far cry from the idyllic healthy pre-agricultural groups envisaged by Kent's (1986) model.

The present research demonstrates that the Ward site population, if not more broadly those populations of the SMA, do not fit neatly within these models. Still the present study represents only one counterexample, it does not disqualify either theory, rather it raises questions about the assumptions on which we build our understandings of health in the past. Similarly the present study does not approach in any way the scale of evidence compiled in the monographs that originally put forth these theories (e.g., Larsen 2000; Cohen 1989; Steckel and Rose 2002; Kent 1986), and more research is always required in supporting such assertions.

As an important tool in the conception of these models, this study evaluated the relationship of porotic hyperostosis and cribra orbitalia to mortality. It was predicted at the beginning of this study that the extent of porotic distribution on the crania would correspond to the intensity of the immune response of the afflicted individual. To test this prediction, the present research identified patterns of porotic distribution and compared them to estimated age at death. The survival curves generated by the Ward site data indicates that this prediction holds in regards to limited expression being associated with early mortality. Individuals that displayed limited or no porosity (labeled unpatterned for 
the purposes of this study) were deceased prior to reaching adulthood. Cribrous lesions are also strongly associated with juvenile mortality.

It was also predicted that the extent of porotic distribution on the cranial vault could be used to reflect successful adaptive responses. As part of this prediction, it was anticipated that an extensive porotic distribution would indicate a robust but ultimately failed immune response. The data derived from porotic distribution at the Ward site did not support either of these predictions. Instead, porotic distribution on the cranial vault was shown to be most indicative of adulthood. Vault lesions do not appear to significantly impact mortality, and the survivorship curve can be explained by other factors. Namely, impacts of porotic distribution on differential mortality are confounded with or obscured by sex-related impacts on survivorship. At Ward, culture appears to be a strong force of mortality. Maternal fatality as a result of childbirth was likely also high.

That vault lesions were not definitively associated with a particular pattern of mortality stands in contrast to the survivorship patterns observed for orbital lesions. This disparity reflects the possibility of different etiologies for cribra orbitalia and porotic hyperostosis, at least among juveniles, in this assemblage and possibly beyond. It is a major assumption of this and many other bioarchaeological studies that the pathologies observed and measured are related or the same as what actually killed an individual. There are a myriad other selective forces acting on a population at any given point, and parasitic infection does not always exert the most significant pressure of those.

The present study does not provide the resolution of data necessary to specify which of these two etiologies may have been the specific causative agent, or whether they might not both have been in effect. Similarly, the methodologies employed in this 
research cannot provide any specific parasitic culprits. Further research in the Shell Midden Archaic in Kentucky would benefit from targeted investigation of parasitology. Confirmation of parasitic infection and identification of specific perpetrators would go a long way toward understanding their impact on health in the SMA sites. Unfortunately, positive identification of parasites within human remains is rare and sometimes difficult to achieve. Most evidence for parasitic infection in the Eastern Woodlands is derived from analysis of coprolites recovered from cave sites in the region. Preservation of coprolites in open sites like Ward is not expected.

While the survivorship curves presented in Chapter 5 indicate some degree of differential mortaility, Kaplan-Meier curves benefit significantly from greater resolution of data. These curves could be made substantially more precise with increased sample size. Only increased sample size would elucidate the specific impacts of the identified distribution patterns on differential mortality. Though there are some differences in the Ward survival curves between distribution patterns, it cannot be concluded from this data alone whether these specific patterns are the best to test. Mapping distribution on crania and generating new patterns, however, is prohibitively time-consumptive. Future studies attempting to measure porosity and differential mortality could benefit from utilizing the patterns observed among the Ward assemblage to further assess any differentiation that might occur in their survival curves. The Ward data suggests that there may be distinct mortality curves from each of the observed patterns of porotic distribution. These patterns seem likely to differentiate in the later stages of adulthood, so any attempt to contribute data to this question of porotic distribution will require an age-at-death assessment methodology that delivers point or tight range age estimates. Traditional age estimation 
techniques will not be able to distinguish these curves, since much of the data points will fall within the same age group.

Much has been assumed about the utility of porotic hyperostosis and cribra orbitalia in understanding health of past populations. The Ward assemblage, as a representative of the greater SMA complex, exemplifies a significant counterexample to several of the prevailing theories which relied upon cranial porosities as an indicator of anemia. Further, this study's attempt to probe the impacts of porotic distribution on differential mortality revealed that porotic hyperostosis and cribra orbitalia manifest in starkly different contexts. Cribra orbitalia is primarily related to juvenile mortality, whereas porotic hyperostosis is a broadly adult condition. So broad is this association that it is difficult to assign any relationship of porotic hyperostosis to mortality. These pathologies were long assumed to be concurrent manifestations of the same disease process, but they are distinguished from one another readily by their impacts on differential mortality. The study of anemia in the past is riddled with assumptions. It is imperative that bioarchaeology, as a field, critically evaluates and re-examines such conjectures upon which substantial research is built from time to time: the consequences of mistakes, misjudgments, and miscalculations are confounded until the preponderance of scholarship can overcome its steadfast assumptions. 


\section{REFERENCES}

Angel, J. Lawrence

1966 Porotic Hyperostosis, Anemias, Malarias, and Marshes in the Prehistoric Eastern Mediterranean. In, Science 153(3737):760-763.

Aufderheide, Arthur and Conrado Rodríguez-Martin.

1998 The Cambridge Encyclopedia of Human Paleopathology. Cambridge University Press, Cambridge.

Applegate, Darlene

2008 Woodland Period. In Past Accomplishments and Future Directions: The Kentucky State Archaeology Plan (2 ${ }^{\text {nd }}$ Edition), edited by David Pollack, pp. 339-604.

Kentucky Heritage Council, Frankfort.

Barrett, Ron and George Armelagos

2013 An Unnatural History of Emerging Infections. Oxford University Press, Oxford.

Blom, Deborah, Jane Buikstra, Linda Keng, Paula Tomczak, Eleanor Shoreman, and Debbie Stevens-Tuttle

2005 Anemia and Childhood Mortality: Latitudinal Patterning Along the Coast of PreColumbian Peru. In, American Journal of Physical Anthropology 127:152-169.

Bos, Kirsten, Kelly Harkins, Alexander Herbig, Mireia Coscolla, Nico Weber, Iñaki Comas, Stephen A. Forrest, Josephine Bryant, Simon Harris, Verena Schuenemann, Tessa Campbell, Kerttu Majander, Alicia Wilbur, Ricardo Guichon, Dawnie Wolfe Steadman, Della Collins Cook, Stefan Niemann, Marcel Behr, Martin Zumarraga, Ricardo Bastida, Daniel Huson, Kay Nieselt, Douglas Young, Julian Parkhil, Jane Buikstra, Sebastien Gagneux, Anne Stone and Johannes Krause

2014 Pre-Columbian Mycobacterial Genomes Reveal Seals as a Source of New World Human Tuberculosis. In Nature, 514:494-497.

Bothwell, Thomas, Roy Baynes, BJ MacFarlane and AP MacPhail

1989 Nutritional Iron Requirements and Food Iron Absorption. In, Journal of Internal Medicine, 226:357-65.

Buikstra, Jane, and Douglas Ubelaker 1994 Standards for Data Collection from Human Skeletal Remains. Arkansas Archaeological Survey Research Series, No. 44. Fayetville. 
Cassidy, Claire

1973 Comparison of Nutrition in Pre-Agricultural and Agricultural Pre-Colombian Skeletal Populations. Ph.D. dissertation, Department of Anthropology, University of Wisconsin, Madison.

Cavill, Ivor

2002 Erythropoiesis and Iron. In, Best Practice \& Research Clinical Hematology 15(2):399-409.

Centers for Disease Control and Prevention

2013a Parasites - Hookworm. Electronic document, https://www.cdc.gov/parasites/hookworm/index.html, accessed September 4, 2018.

2013b Parasites - Diphyllobothrium Infection. Electronic document, https://www.cdc.gov/parasites/diphyllobothrium/index.html, accessed October 30, 2019.

Claasen, Cheryl

1996 Research Problems with Shells from Green River Shell Matrix Sites. In, Of Caves and Shell Mounds, edited by Kenneth Carstens and Patty Jo Watson, pp. 132-139. University of Alabama Press, Tuscaloosa and London.

2010 Feasting with Shellfish in the Southern Ohio Valley: Archaic Sacred Sites and Rituals. University of Tennessee Press, Knoxville.

Cohen, Mark

1989 Health and the Rise of Civilization. Yale University Press, New Haven and London.

Cook, Della Collins

1976 Pathological States and Disease Processes in Illinois Woodland Populations: An Epidemiologic Approach. Ph.D. dissertation, Department of Anthropology, University of Chicago.

Crawford, Gary

2005 Plant Remains from Carlston Annis (1972, 1974), Bowles, and Peter Cave. In, Archaeology of the Middle Green River Region, Kentucky, edited by William Marquardt and Patty Jo Watson, pp. 181-212. University of Florida, Gainesville.

Crothers, George

2005 Vertebrate Fauna from the Carlston Annis Site. In, Archaeology of the Middle Green River Region, Kentucky, edited by William Marquardt and Patty Jo Watson, pp. 295-314. University of Florida, Gainesville. 
Crothers, George

2011 Theses and Dissertations Using WPA Collections at the University of Kentucky Museum of Anthropology (1960-2011). Handout to poster William S. Webb's WPA Archaeological Legacy: From Adena to Indian Knoll. Poster presented at the $76^{\text {th }}$ Annual Meeting of the Society for American Archaeology, Sacramento, California.

Delcourt, Paul, Hazel Delcourt, Cecil Ison, William Sharp, and Kristen Gremillion 1998 Prehistoric Human Use of Fire, The Eastern Agricultural Complex, and Appalachian Oak-Chestnut Forests: Paleoecology of Cliff Palace Pond, Kentucky. In American Antiquity 63(2): 263-278.

DeWitte, Sharon

2014 Differential Survival Among Individuals with Active and Healed Periosteal New Bone Formation. In, International Journal of Paleopathology 7:38-44.

DeWitte, Sharon, Gail Hughes-Morey, Jelena Bekvalac, and Jordan Karsten 2015 Wealth, Health, and Frailty in Industrial-era London. In Annals of Human Biology. Early Online, 2015: 1-14.

El-Najjar, Mahmoud, Dennis Ryan, Christy Turner, and Betsy Lozoff

1976 The Etiology of Porotic Hyperostosis Among the Prehistoric and Historic Anasazi Indians of the Southwestern United States. In, American Journal of Physical Anthropology 44:477-488.

Fiedel, Stuart

2001 What Happened in the Early Woodland? In, Archaeology of Eastern North America 29:101-142.

Ferreira, L. F., A. J. G. de Araújo, and U. E. C. Confalunieri

1980 The Finding of Eggs and Larvae of Parasitic Helminths in Archaeological Material from Unai, Minas Gerais, Brazil. In, Transactions of the Royal Society of Tropical Medicine and Hygiene 74(6):798-800.

Funkhouser, William and William Webb

1928 Ancient Life in Kentucky. Kentucky Geological Survey, Series 6, Vol. 34. University of Kentucky Press, Lexington.

Goodman, Alan and George Armelagos

1989 Infant and Child Mobidity and Mortality Risks in Archaeological Populations. In, World Archaeology 21(2):225-243.

Goodman, Alan and Debra Martin

2002 Reconstructing Helth Profiles from Skeletal Remains. In, The Backbone of History: Health and Nutrition in the Western Hemisphere. Eds. Richard Steckle and Jerome Rose. Cambridge University Press, Cambridge. 
Haskins, Valerie and Nicholas Herrmann

1996 Shell Mound Bioarchaeology. In, Of Caves and Shell Mounds, eds. Kenneth Carstens and Patty Jo Watson pp. 107-118. University of Alabama Press, Tuscaloosa.

Hensley, Christine

1991 The Middle Green River Shell Mounds: Challenging Traditional Interpretations Using Internal Site Structure Analysis. In, The Human Landscape in Kentucky's Past: Site Structure and Settlement Patterns, eds. Charles Stout and Christine Hensley. Kentucky Heritage Council, Frankfort.

Herrmann, Nicholas

2002 Biological Affinities of Archaic Period Populations From West-Central Kentucky and Tennessee. Ph.D. Dissertation, Department of Anthropology, University of Tennessee, Knoxville.

Holland, Thomas and Michael O'Brien

1997 Parasites, Porotic Hyperostosis, and the Implications of Changing Perspectives. In American Antiquity 62(2):183-193.

Hrdlička, Aleš

1914 Anthropological Work in Peru in 1913, with Notes on the Pathology of the Ancient Peruvians. Smithsonian Miscellaneous Collections 61(18):1-69.

Huss-Ashmore, Rebecca, Alan Goodman and George Armelagos

1982 Nutritional Inference from Paleopathology. In, Advances in Archaeological Method and Theory 5:395-474.

Janzen, Donald

2008 Unearthing the Past: the Archaeology of the Falls of the Ohio River Region. Butler Books, Louisville.

Jefferies, Richard

2008 Archaic Period. In Past Accomplishments and Future Directions: The Kentucky State Archaeology Plan ( $2^{\text {nd }}$ Edition), edited by David Pollack, pp. 193-338. Kentucky Heritage Council, Frankfort.

Jefferies, Richard, Victor Thompson, George Milner, Renee Bonzani, and Tanya Peres

2007 Cypress Creek Villages Revisited: Archaic Settlement and Subsistence in the Creek Watershed. In, Current Archaeological Research in Kentucky, Volume Eight, edited by Sarah Miller, David Pollack, Kenneth Carstens, Christopher Moore, pp. 37-76. Kentucky Heritage Council, Frankfort. 
Kelley, Marc

1980 Disease and Environment: A Comparative Analysis of Three Early American Indian Skeletal Collections. Ph.D. Dissertation, Department of Anthropology, Case Western Reserve University, Cleveland.

Kent, Susan

1986 The Influence of Sedentism and Aggregation on Porotic Hyperostosis and Anemia: A Case Study. In, Man 21(4):605-636.

Kidder, Tristram

2006 Climate Change and the Archaic to Woodland Transition (3000-2500 Cal B.P.) in the Mississippi River Basin. In American Antiquity 71(2): 195-231.

King, Janet, Jeffrey Blumberg, Linda Ingwersen, Mazda Jenab, and Katherine Tucker

2007 Tree Nuts and Peanuts as Components of a Healthy Diet. In Journal of Nutrition, 2007 Nuts and Health Symposium:1736S-1740S.

Lallo, John, George Armelagos, and Robert Mensforth

1977 The Role of Diet, Disease, and Physiology in the Origin of Porotic Hyperostosis. In, Human Biology 49(3):471-483.

Larsen, Clark

2000 Skeletons in Our Closet: Revealing Our Past Through Bioarchaeology. Princeton University Press, Princeton and Oxford.

2015a Bioarchaeology: Interpreting Behavior from the Human Skeleton, $2^{\text {nd }}$ ed. Cambridge University Press, Cambridge.

2015b Colonialism and Decline in the American Southeast: the Remarkable Record of La Florida. In, Beyond Germs: Native Depopulation in North America, edited by Catherine Cameron, Paul Kelton, Alan Swedlund, pp. 74-98. University of Arizona Press, Tuscon.

Larsen, Clark, Mark Griffin, Dale Hutchinson, Vivian Noble, Lynette Norr, Robert Pastor, Christopher Ruff, Katherine Russell, Margaret Schoeninger, Michael Schultz, Scott Simpson, and Mark Teaford

2001 Frontiers of Contact: Bioarchaeology of Spanish Florida. In, Journal of World Prehistory, 15(1):69-123.

London, Douglas and Daniel Hruschka

2014 Helminths and Human Ancestral Immune Ecology: What is the Evidence for High Helminth Loads Among Foragers? In, American Journal of Human Biology 26:124-129.

Lyon, Edwin

1996 A New Deal for Southeastern Archaeology. University of Alabama Press, Tuscaloosa. 
Marquardt, William and Patty Jo Watson

2005 The Green River Shell Mound Archaic: Conclusions. In, Archaeology of the Middle Green River Region, Kentucky, edited by William Marquardt and Patty Jo Watson, pp. 629-647. University of Florida, Gainesville.

McIlvaine, Britney

2015 Implications of Reappraising the Iron-Deficiency Anemia Hypothesis. In, International Journal of Osteoarchaeology 25:997-1000.

Meindl, Richard, Robert Mensforth, and Heather York

2001 Mortality, Fertility, and Growth in the Kentucky Late Archaic: The Paleodemography of the Ward Site. In Archaic Transitions in Ohio and Kentucky Prehistory, edited by Olaf Prufer, Sara Pedde, and Richard Meindl, pp. 59-86. Kent State University Press, Kent and London.

Mensforth, Robert

2001 Warfare and Trophy Taking in the Archaic Period. In, Archaic Transitions in Ohio and Kentucky Prehistory, edited by Olaf Prufer, Sara Pedde, and Richard Miendl, pp. 110-140.

2005 Paleodemography of the Skeletal Population from Carlston Annis (15Bt5). In, Archaeology of the Middle Green River Region, Kentucky, edited by William Marquardt and Patty Jo Watson, pp. 453-487. University of Florida, Gainesville.

Milner, George and Jesper Boldsen

2013 Transition Analysis Age Estimation: Skeletal Scoring Manual. Pennsylvania State University Park, Pennsylvania.

Morey, Darcy and George Crothers

1998 Clearing up Clouded Waters: Paleoenvironmental Analysis of Freshwater Mussel Assemblages from the Green River Shell Middens, Western Kentucky. In, Journal of Archaeological Science 25:907-926.

Morey, Darcy, George Crothers, Julie Stein, James Fenton, and Nicholas Herrmann 2002 The Fluvial and Geomorphic Context of Indian Knoll, an Archaic Shell Midden in West-Central Kentucky. In, Geoarchaeology : An International Journal, 17(6):521-553.

Mushrif, Veena

2000 Porotic Hyperostosis: a Bio-Cultural Perspective on Iron Deficiency Anemia. In, Bulletin of the Deccan College Research Institute 60/61:367-372.

Neumann, Thomas, Robert Sanford, and Karen Harry

2010 Cultural Resources Archaeology: an Introoduction, $2^{\text {nd }}$ ed. Altamira Press, Lanham. 
Ortner, Donald

2003 Identification of Pathological Conditions in Human Skeletal Remains, $2^{\text {nd }}$ ed. Academic Press, San Diego and London.

Ortner, Donald and Mary Ericksen

1997 Bone Changes in the Human Skull Probably Resulting from Scurvy in Infancy and Childhood. In, International Journal of Osteoarchaeology 5:212-220.

Ortner, Donald, Erin Kimmerle and Melanie Diez

1999 Probable Evidence of Scurvy in Subadults From Archaeological Sites in Peru. In, American Journal of Physical Anthropology 108:321-331.

Ortner, Donald J., Whitney Butler, Jessica Cafarella, and Lauren Milligan

2001 Evidence of Probable Scurvy in Subadults From Archaeological Sites in North America. In, American Journal of Physical Anthropology 114:343-351.

Oxenham, Marc and Ivor Cavill

2010 Porotic Hyperostosis and Cribra Orbitalia: the Erythropoietic Response to IronDeficiency Anemia. In, Anthropological Science 118(3):199-200.

Palkovich, Ann

1987 Endemic Disease Patterns in Paleopathology: Porotic Hyperostosis. In, American Journal of Physical Anthropology 74:527-537.

Parmalee, Paul and Walter Klippel

1974 Freshwater Mussels as a Prehistoric Food Resource. In, American Antiquity 39(3):421-434.

Peckmann, Tanya

2003 Possible Relationship Between Porotic Hyperostosis and Smallpox Infections in Nineteenth-Century Populations in the Northern Frontier, South Africa. In, World Archaeology 35(2):289-305.

Pedde, Sara and Olaf Prufer

2001 The Kentucky Green River Archaic as Seen From the Ward Site. In Archaic Transitions in Ohio and Kentucky Prehistory, edited by Olaf Prufer, Sara Pedde, and Richard Meindl, pp. 59-86. Kent State University Press, Kent and London.

Ponec, Donald and Donald Resnick

1984 On the Etiology and Pathogenesis of Porotic Hyperostosis of the Skull. In, Investigative Radiology 19(4):313-317.

Powell, Mary Lucas

1996 Health and Disease in the Green River Archaic. In, Of Caves and Shell Mounds, eds. Kenneth Carstens and Patty Jo Watson, pp. 119-131. University of Alabama Press, Tuscaloosa. 
Rivera, Frances and Marta Mirazon Lahr

2017 New Evidence Suggesting a Dissociated Etiology for Cribra Orbitalia and Porotic Hyperostosis. In, American Journal of Physical Anthropology 164:76-96.

Reinhard, Karl

1990 Archaeoparasitology in North America. In, American Journal of Physical Anthropology 82:145-163.

Rothschild, Bruce

2000 Porotic Hyperostosis as a Manifestation of Iron Deficiency? In, Chungara:

Revista de Antropologia Chilena 32(1):85-87.

Rothschild, Bruce

2012 Extirpolation of the Mythology That Porotic Hyperostosis Is Caused by Iron Deficiency Secondary to Dietary Shift to Maize. In, Advances in Anthropology 2(3):157-160.

Schaefer, Maureen, Sue Black, and Louise Scheuer

2009 Juvenile Osteology: A Laboratory and Field Manual. Academic Press, Oxford.

Schmidt, Christopher

2001 Dental Microwear Evidence for a Dietary Shift Between Two Nonmaize-Reliant Prehistoric Populations from Indiana. In American Journal of Physical Anthropology 114:139-145.

Schultz, Michael

2001 Paleohistopathology of Bone: A New Approach to the Study of Ancient Diseases. In, Yearbook of Physical Anthropology 44:106-147.

Snow, Charles

1948 Indian Knoll Skeletons of Site Oh 2: Ohio County, Kentucky. Reports in Anthropology, Volume 4(3), Part 2. University of Kentucky, Lexington.

Steckel, Richard and Jerome Rose

2002 The Backbone of History: Health and Nutrition in the Western Hemisphere. Cambridge University Press, Cambridge.

Steckel, Richard, Jerome Rose, Clark Larsen, and Phillip Walker

2002a Skeletal Health in the Western Hemisphere from 4000 B.C. to the Present. In, Evolutionary Anthropology 11(4):142-155.

Steckel, Richard, Paul Sciulli, and Jerome Rose

2002b A Health Index from Skeletal Remains. In, The Backbone of History: Health and Nutrition in the Western Hemisphere. Eds. Richard Steckel and Jerome Rose, pp 61-93. Cambridge University Press, Cambridge. 
Steyn, Maryna, Sarah Voeller, Deona Botha, and Ann Ross

2016 Cribra Orbitalia: Prevalence in Contemporary Populations. In Clinical Anatomy 29:823-830.

Stuart-Macadam, Patty

1985 Porotic Hyperostosis: Representative of a Childhood Condition. In, American Journal of Physical Anthropology 66:391-398.

1987 A Radiographic Study of Porotic Hyperostosis. In, American Journal of Physical Anthropology 74:511-520.

1989 Porotic Hyperostosis: Relationship Between Orbital and Vault Lesions. In, American Journal of Physical Anthropology 80:187-193.

1992 Porotic Hyperostosis: A New Perspective. In, American Journal of Physical Anthropology 87:39-47.

2006 Integrative Anthropology: A Focus on Iron-Deficiency Anemia. In Archaeological Papers of the American Anthropological Association 16:129-137.

Sullivan, Amy

2005 Prevalence and Etiology of Acquired Anemia in Medieval York, England. In, American Journal of Physical Anthropology 128:252-272.

Ubelaker, Douglas

1979 Human Skeletal Remains: Excavation, Analysis, and Interpretation. Smithsonian Institute Press, Washington, DC.

United States Geological Survey

2017 USGS 03321210 Cypress Creek Near Calhoun, KY, https://nwis.waterdata.usgs.gov/ky/nwis/peak?site_no=03321210\&agency_cd=US GS\&format=html, accessed March 21, 2017.

Walker, Phillip, Rhonda Bathurst, Rebecca Richman, Thor Gjerdum, and Valerie Andrushko

2009 The Causes of Porotic Hyperostosis and Cribra Orbitalia: A Reappraisal of the Iron-Deficiency-Anemia Hypothesis. In, American Journal of Physical Anthropology 139:109-125.

Wapler, Ulrike, Eric Crubezy, and Michael Schultz

2004 Is Cribra Orbitalia Synonymous With Anemia? Analysis and Interpretation of Cranial Pathology in Sudan. In, American Journal of Physical Anthropology 123:333-339.

Watson, Patty Jo and Richards Yarnell

1969 The Prehistory of Salts Cave, Kentucky. Reports of Investigations, 16. Illinois State Museum, Springfield. 
Watson, Patty Jo and William Marquardt

2005 The Shell Mound Archaeological Project: Chronology of Fieldwork. In Archaeology of the Middle Green River Region, Kentucky, edited by William Marquardt and Patty Jo Watson, pp. 13-18. University of Florida, Gainesville.

Webb, William

1946 Indian Knoll Site Oh 2, Ohio County, Kentucky. Reports in Anthropology and Archaeology 4(3) Part 1. University of Kentucky, Lexington.

Webb, William and William Haag

1940 Cypress Creek Villages, Sites 11 and 12, McLean County, Kentucky. Reports in Anthropology and Archaeology 4. University of Kentucky, Lexington.

Webb, William and Charles Snow

1974 The Adena People. University of Tennessee Press, Knoxville.

Welcker, Hermann

1885 Die Abstammung der Bevölkerung von Socotra. In, Verhandlunger des Fünften Deutschen Geographentages zu Hamburg, edited by H. Michow, pp. 92-94. Dietrich Reimer, Berlin.

Winters, Howard

1969 The Riverton Culture: A Second Millenium Occupation in the Central Wabash Valley. Monograph No. 1, Illinois Archaeological Survey. Illinois State Museum.

Wolverton, Steve

2008 Harvest Pressure and Environmental Carrying Capacity: An Ordinal-Scale Model of Effects on Ungulate Prey. In American Antiquity 73(2):179-199

Wood, James

1992 The Osteological Paradox: Problems of Inferring Prehistoric Health from Skeletal Samples. In, Current Anthropology 33(4):343-370.

Zuckerman, Molly K., Evan M. Garofalo, Bruno Frolich, and Donald J. Ortner

2014 Anemia or Scurvy: A Pilot Study on Differential Diagnosis of Porous and Hyperostotic Lesions using Differential Cranial Vault Thickness in Subadult Humans. In, International Journal of Paleopathology 5:27-33. 


\section{APPENDIX 1: Porosity Patter Recording Form}

Catalog \#
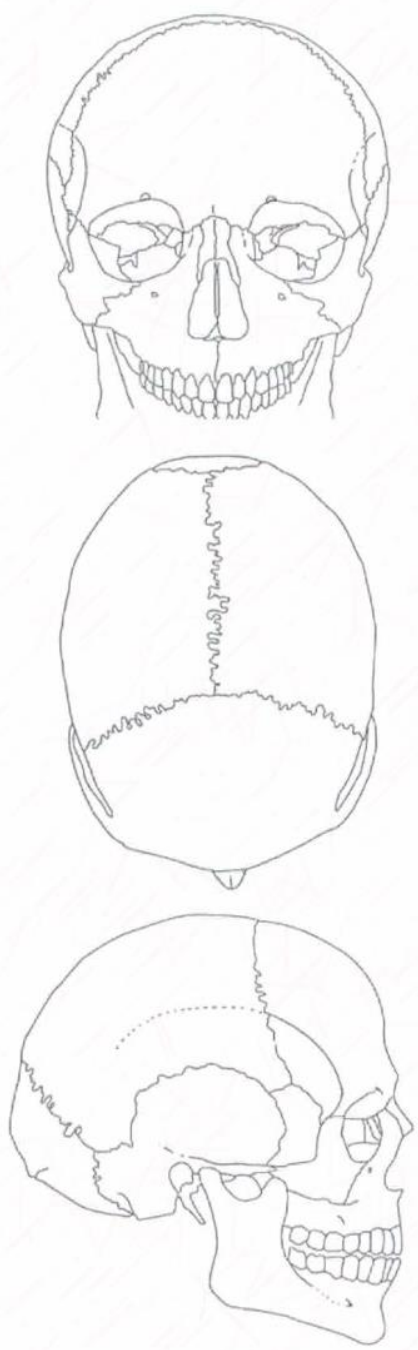

Pathology
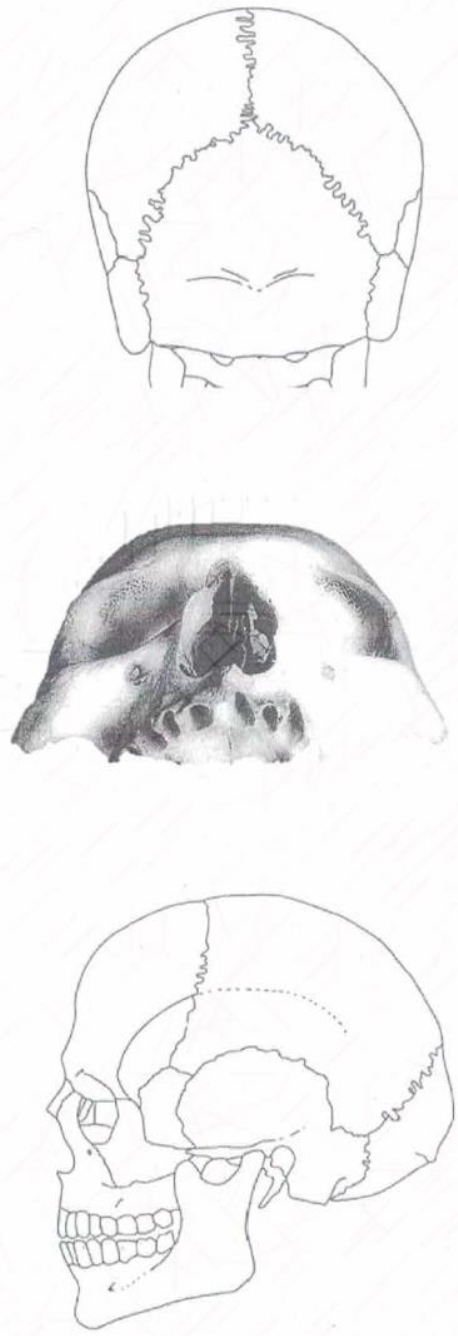

Appendix 1 Porosity mapping form. Images compiled from Buikstra and Ubelaker (1994) 


\title{
CURRICULUM VITAE
}

\author{
Austin L. Warren \\ 2903 Cambridge Rd. \\ Louisville, KY 40220 \\ (502) 718-4500 \\ alwarr04@cardmail.louisville.edu
}

\section{EDUCATION}

\section{University of Louisville \\ 2014-2018}

Western Kentucky University
2009-2012

RECENT EMPLOYMENT

Graduate Research Assistant

Aug 2014-2016

\section{Restoration Manager Oct 2013-present}

\section{Maintenance Supervisor Aug 2012-Mar 2013}

Master of Arts anticipated December 2019

Major: Anthropology (archaeology concentration)

GPA: $4.00 / 4.00$

Bachelor of Arts May 2012

Majors: Anthropology (archaeology concentration), Spanish

GPA: 3.94/4.00, Summa cum Laude

Honors Program Graduate

Archaeological Laboratory, University of Louisville Supervisors: Phil DiBlasi, Dr. Jonathan Haws

1820 Arthur St., Louisville, KY 40208

Duties: process, analyze, and catalogue human and faunal skeletal remains, lithic assemblages, and historic artifacts, manage archaeological collections, conduct research on Archaic collections, prepare and modify student laboratory activities, interact with and instruct forensic anthropology and lithics students, create and manage research and historic databases, and conduct archival research

\section{Gist Piano Company}

Supervisors: Hannah Gist, Amanda Gist

1714 Lincoln Ave., Louisville, KY 40213

Duties: perform and direct all procedures associated with the entire piano rebuild process, diagnose and resolve problems with new and used instruments, reconstruct and redesign soundboards, bridges, pinblocks, and string scales, perform, teach, and manage others in all aspects of refinishing and action regulation and restoration, manage and bid restoration and retail sales, run a shop internship program, install and repair multiple brands of player systems, and manage customer relationships in store and in their homes

Country Inn \& Suites, Red Roof Inn, and News Inn

Supervisors: Paul Patel, Becky Kohlhaas

535 Wall St., Bowling Green, KY 42104

Duties: identified and undertook maintenance projects, supervised other maintenance employees, coordinated with property managers, and communicated with sales representatives, service professionals, and guests 


\section{Archaeological Field \\ Technician \\ Jan 2012-Jun 2012}

\section{EXPERIENCE}

Volunteer, Mammoth Cave

National Park

Apr 2013-Sep2013

\author{
Volunteer, Living \\ Archaeology Weekend \\ Sep 2011, 2012, 2013
}

Lab Assistant, Forensic
Anthropology Lab
Jan 2012-May 2012

Researcher, Prehistoric

Earthworks in Kentucky

Jan 2012-May 2012

\author{
Student, Field Course in \\ Archaeology \\ Jul 2011
}

\section{Student, Study Abroad Program in Ecuador Jun 2011}

Researcher, Islamic Center of Bowling Green

Jan 2011-May 2011

Volunteer, McChesney Field Campus

Mar 2010, Nov 2011
Upper Green River Biological Preserve; Western Kentucky University Supervisor: Dr. Darlene Applegate

1906 College Heights Blvd. \#61029, Bowling Green, KY 42101

Duties: located and recorded landscape features, collected surface artifacts, excavated shovel tests, screened soil, and prepared field sample bags

Green River Ferry

Supervisors: Dr. Darlene Applegate, Bobby Carson (NPS)

Duties: monitored heavy equipment excavation, screened soil, collected artifacts, analyzed recovered artifacts, and ensured compliance with NHPA Section 106, NPS, and Army Corps of Engineers regulations

Gladie Center, Daniel Boone National Forest

Supervisors: Dr. Darlene Applegate, Dr. Gwynn Henderson, Wayna Adams Activities: demonstrated prehistoric and historic Appalachian technologies and cultural practices to elementary students, with the purpose of cultivating an appreciation of cultural diversity and promoting preservation

Department of Folk Studies and Anthropology, Western Kentucky University

Faculty Mentor: Dr. Darlene Applegate

Activities: identified and analyzed human and faunal skeletal elements, interacted with and instructed students

Department of Folk Studies and Anthropology, Western Kentucky University

Faculty Mentor: Dr. Darlene Applegate

Activities: conducted literature reviews, performed deed searches, conducted pedestrian surveys, interviewed local informants, prepared written report, prepared and delivered oral presentations

Omo Temple Site, Moquegua, Perú

Principal Investigator: Dr. Paul Goldstein (UCSD)

Skills: hand excavation, dry screening, stratigraphic profiles, plan view maps, field notes, photography, artifact sorting, and artifact cataloguing

Kentucky Institute for International Studies, Western Kentucky University Instructors: Dr. Sonia Lenk, Dr. Gonzalo Bonilla

Courses: Hispanic Literacy and Cultural Studies, Social Development in Ecuador

Department of Folk Studies and Anthropology, WKU

Faculty Mentor: Dr. Kate Hudepohl

Activities: conducted interviews with members of the multinational and multicultural congregation, utilized participant observation, complied with Human Subjects Review Board review procedures, created informed consent document, and presented findings

Department of Folk Studies and Anthropology, WKU

Faculty Mentor: Dr. Darlene Applegate

Skills: pedestrian survey, hand excavation, historic artifact identification and cataloguing 


\section{WORKSHOPS}

Paleodemography Workshop Nov 13-14, 2015

PLAN Professional Development

Apr 9, 2015

Mar 25, 2015

\section{PRESENTATIONS}

Mar 24, 2012 and

Mar 17, 2012

Nov 17, 2011
University of North Carolina, Chapel Hill, Department of Anthropology and Research Labs of Archaeology

Presented by Dr. Sharon DeWitte

University of Louisville, School of Interdisciplinary and Graduate Studies Technology for Effective Teaching

More Than a Discussion Board: Best Practices and Effective Applications for Teaching Online

Prehistoric Hilltop Enclosures in Kentucky, coauthored by Dr. Darlene Applegate. Paper presented at the 42nd annual Western Kentucky University Student Research Conference, and at the $29^{\text {th }}$ annual Kentucky Heritage Council Archaeology Conference, Mammoth Cave National Park

What is Service Learning?, presented by Dr. Sonia Lenk (WKU), Nick Bratcher, Autumn Ward, and Austin Warren at the Kentucky Engagement Conference, Murray State University 